\title{
EVALUATION OF STRATEGIC SOFTWARE INVESTMENTS \\ FOR THE CANADIAN CABINET INDUSTRY
}

\author{
by \\ Richard Hewitt \\ B.Sc. in Wood Products Processing \\ University of British Columbia, 2009
}
A THESIS SUBMITTED IN PARTIAL FULFILLMENT OF
THE REQUIREMENTS FOR THE DEGREE OF
MASTER OF SCIENCE
in

THE FACULTY OF GRADUATE STUDIES

(Forestry)

THE UNIVERSITY OF BRITISH COLUMBIA

(Vancouver)

December 2011

(C) Richard Hewitt, 2011 


\section{Abstract}

Manufacturing is the single largest sector of the Canadian economy, accounting for 12.7\% of the nation's GDP in 2009 (Statistics Canada 2011). Over the past decade, this sector has faced numerous challenges such as a stronger Canadian dollar, increased foreign competition, and the recent decline of the US economy. One of the ways Canadian manufacturers have responded to these challenges is through increased information technology (IT) investments (Baldwin \& Sabourin 2004). Wood products industries, though, generally invest much less in IT than the sector as a whole (Atrostic \& Gates 2001). When wood manufacturers do invest in IT, it is often at a very basic level (Hewitt et al. 2011). Consequently, more intensive and sophisticated use of IT presents an opportunity for the cabinet industry to improve their competitive position.

The first research objective was to determine the types of software products currently available to the cabinet industry and their associated functionalities. This was done using simple proportions, cluster analysis, and association rule learning. Next, a strategic analysis of which types of software applications are most important for the industry's future competitiveness was done using the analytic network process. Lastly, any large gaps between what is currently represented in the industry and what is important for future competitiveness were identified.

Operations \& Engineering functionalities were found in $65.7 \%$ of all observed functionalities, whereas Content, Collaborative, and CRM functionalities were found in less than $10 \%$ each. Operations \& Engineering and ERM software were determined to be the most important for future competitiveness because of their contribution to the Quality strategy. While Operations \& Engineering software is important for the industry, they may be overrepresented because the current market is highly saturated with these functionalities. ERM, Collaborative, and CRM software are underrepresented as their future priority is higher than their current presence. The sensitivity analysis shows that the final priorities of software applications are most sensitive to the weighting of the Customer Service strategy. If an individual firm places a high emphasis on customer service and marketing, then CRM and Collaborative software become most critical for success. 


\section{Preface}

This research was undertaken by the author, Richard Hewitt, with advising support given by the research supervisor, Dr. Taraneh Sowlati. The author's work includes an extensive literature review, research design, decision model development, expert recruitment, survey design, survey deployment, and data analysis. Also, all written work derived from this research was created by Richard Hewitt with comments from Dr. Taraneh Sowlati.

This research has thus far yielded two journal articles:

1. Hewitt, R., Sowlati, T., \& Paradi, J.C., 2011. Information technology adoption in US and Canadian forest products industries. Forest Products Journal, 61(2), pp.161-169.

This article has been published and a modified version of it is included in Chapters 1 and 2 .

2. Hewitt, R., Sowlati, T., \& Paradi, J.C. Analysis of available software products in the North American cabinet industry.

This article has been submitted for publication and is under review as of November 2011. A modified version of it is included in Chapters 3 and 4.

The author intends to also write a third article for publishing in a peer-reviewed journal. This article will be based on the findings of the analytic network process model, mentioned throughout Chapters 3 - 5 .

Since this research utilized surveys, the required Human Ethics Board approval was obtained on March 11, 2011 under the UBC BREB number H11-00512. The surveys were deployed and collected according to all the requirements of the UBC Human Ethics Board. Survey results were kept anonymous in all published material to protect the respondents' privacy. 


\section{Table of Contents}

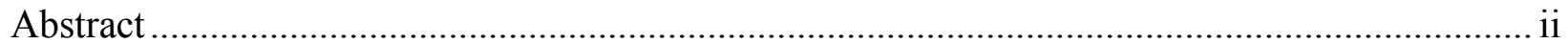

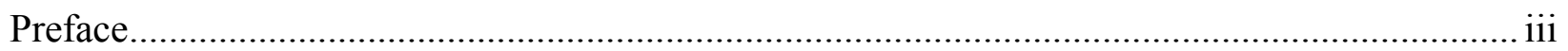

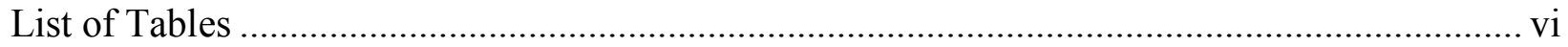

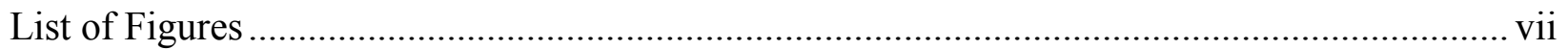

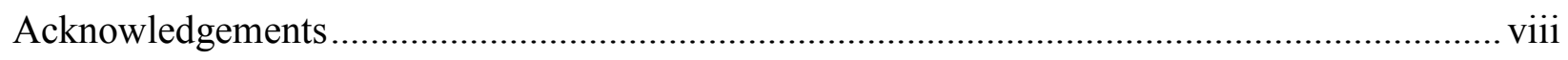

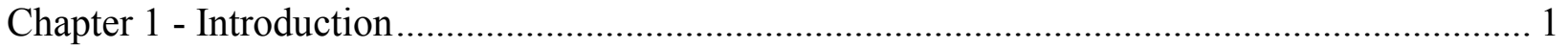

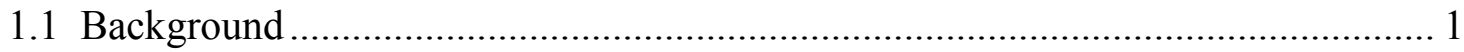

1.1.1 The Canadian Manufacturing Sector and Cabinet Industry.......................... 1

1.1.2 Rising Importance of IT in Manufacturing Competitiveness ........................ 3

1.1.3 IT Adoption in North American Forest Products Industries .......................... 6

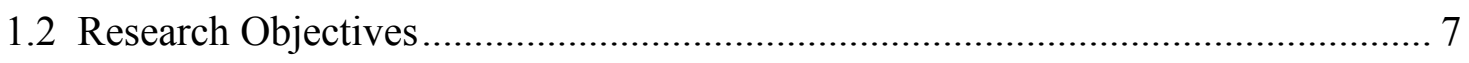

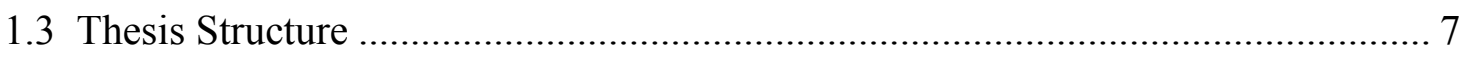

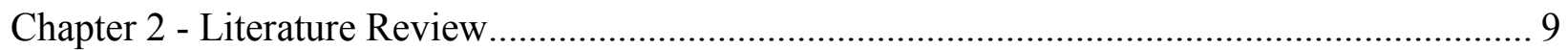

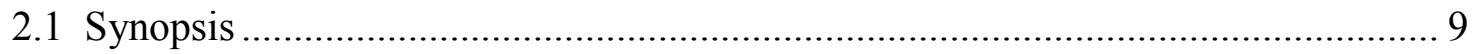

2.2 Previous Research on IT Adoption in N. American Forest Products Industries ..... 9

2.3 Discussion of Previous Studies ................................................................... 16

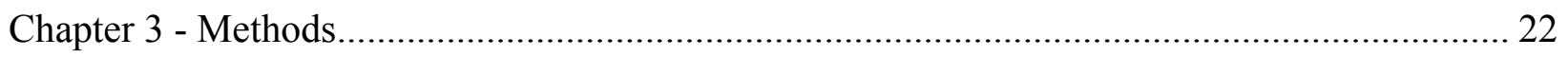

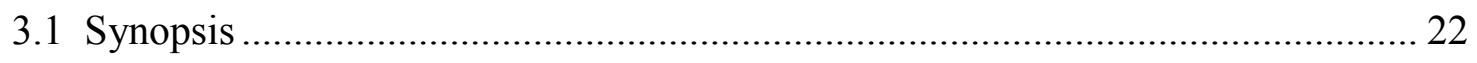

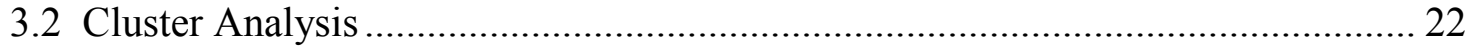

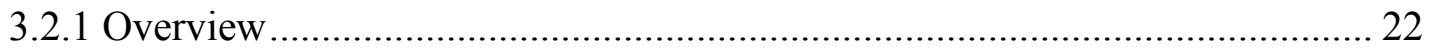

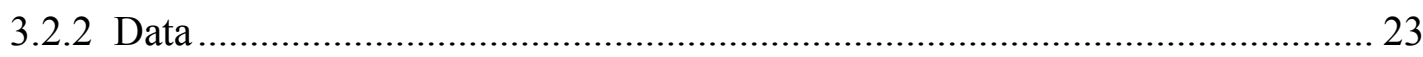

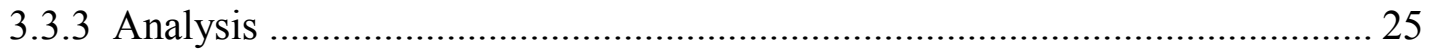

3.3 Association Rule Learning............................................................................. 28

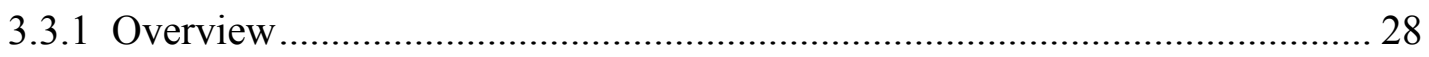

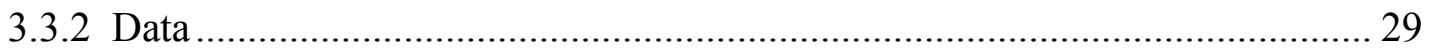

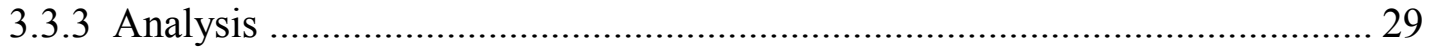

3.4 Analytic Hierarchy / Network Process ............................................................ 33

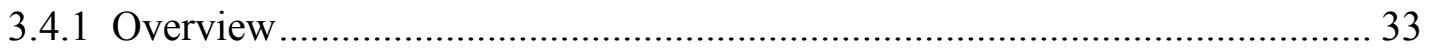

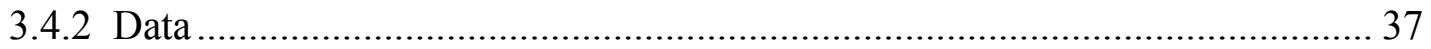




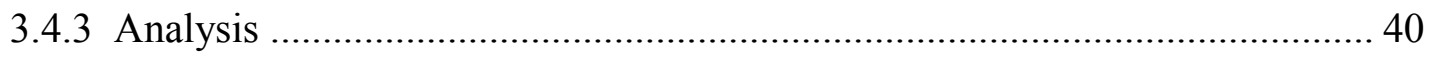

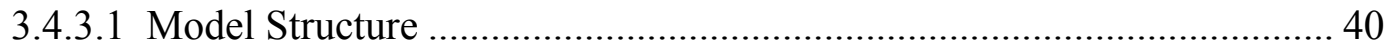

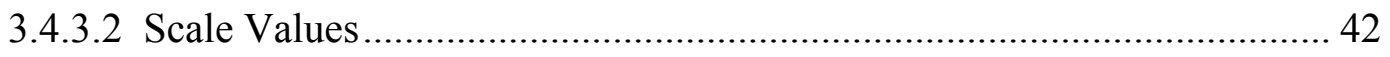

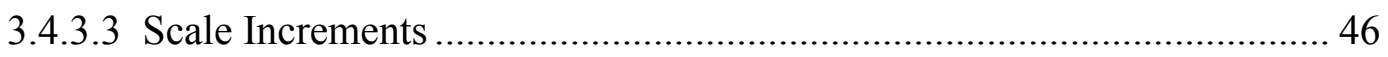

3.4.3.4 Preference Elicitation...................................................................... 46

3.4.3.5 Reduction in Pairwise Comparisons ..................................................... 47

3.4.3.6 Aggregation of Individual Responses ..................................................... 49

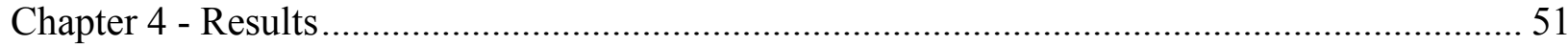

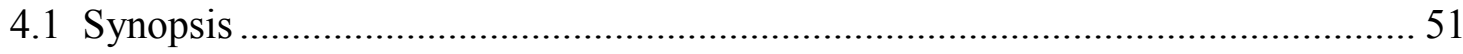

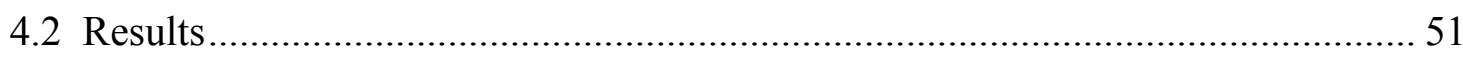

4.2.1 Current State of Software............................................................................ 51

4.2.1.1 Representation of Applications and Functionalities ................................ 51

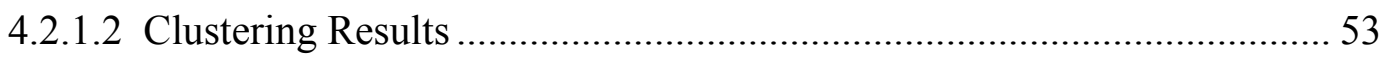

4.2.1.3 Association Rules.......................................................................... 57

4.2.2 Future State of Software ............................................................................ 58

4.2.2.1 Consistency and Consensus Measures ...................................................... 58

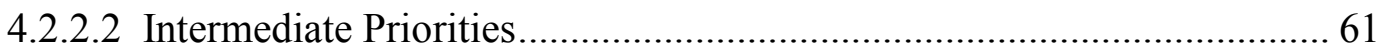

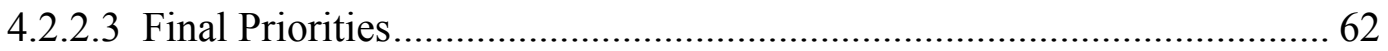

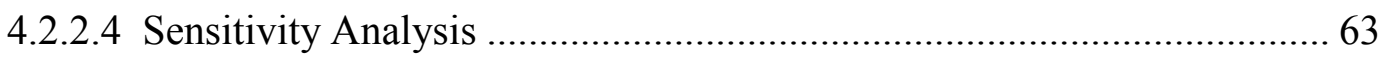

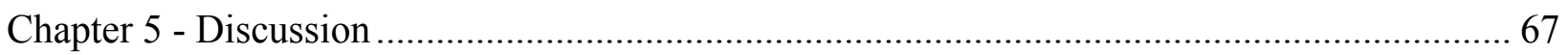

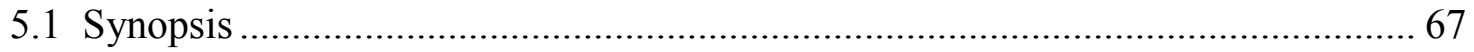

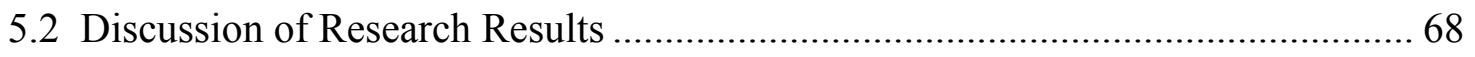

5.3 Discussion of Research Contribution............................................................ 73

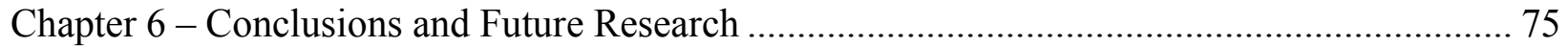

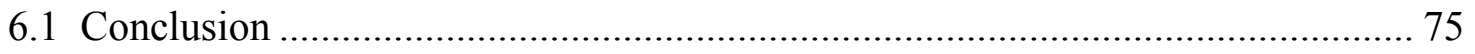

6.2 Limitations and Future Research …………………........................................ 77

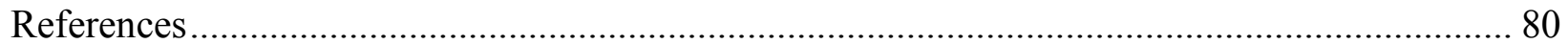

Appendix 1: Overview of Common Findings of Forest Products IT Research............................ 90

Appendix 2: Software Taxonomy and Defs. of Software Applications and Functionalities........ 91

Appendix 3: Glossary of Competitive Capabilities .......................................................................... 94 


\section{List of Tables}

Table 1: Summary of clustering methodology................................................................... 28

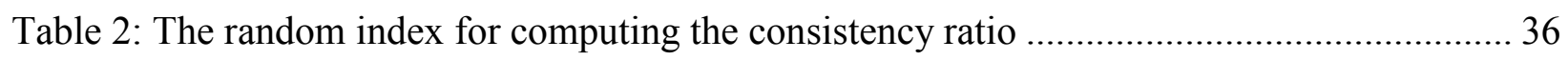

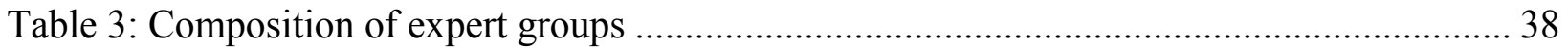

Table 4: Relationships between competitive capabilities. ................................................ 41

Table 5: Four possible AHP scales with values shown up to 9 increments............................. 43

Table 6: Representation of software application types in the cabinet industry software market. 52

Table 7: Proportion of products having specified functionality. ............................................ 53

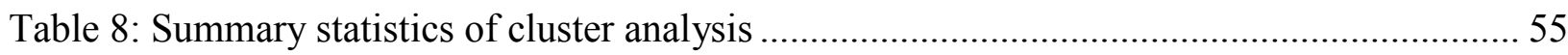

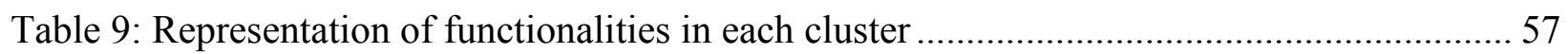

Table 10: Association rules with minimum support of 0.1 and minimum confidence of $0.6 \ldots . . .58$

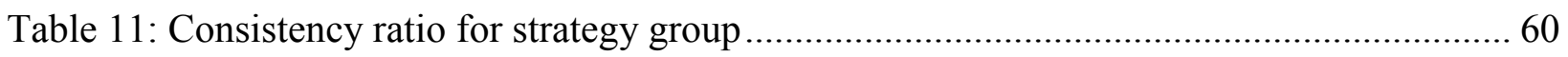

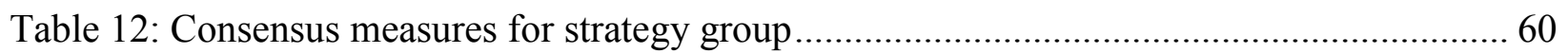

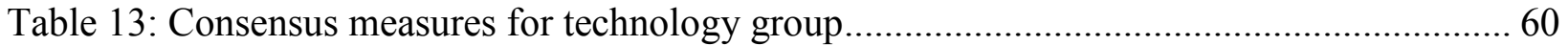

Table 14: Difference between current market representation and future priorities of software

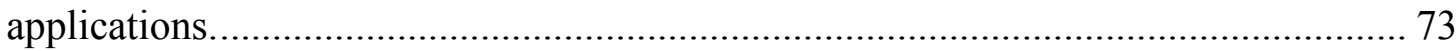




\section{List of Figures}

Figure 1: Domestic vs. imported product in the apparent domestic market for cabinets in Canada, $2000-2009$

Figure 2: Total value of manufacturing shipments by Canadian cabinet manufacturers, $2000-2009$. 2

Figure 3: Percentage change in exports to US and no. of US housing starts from previous year.. 3

Figure 4: Percentage of all capital investments going towards IT in the Canadian manufacturing sector 4

Figure 5: Percentage of all ICT investment dollars going towards communications infrastructure, computer hardware, and software. ………………………................................... 5

Figure 6: Example of a binary matrix such as the one used in this analysis.................................. 25

Figure 7: Possible outcomes of a binary variable with two observations ........................................ 26

Figure 8: A flowchart briefly explaining the steps of the apriori algortihm ............................... 32

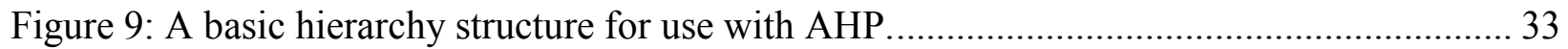

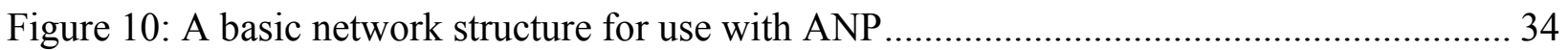

Figure 11: The ANP model used in the study as seen in the SuperDecisions ${ }^{\circledR}$ software ............. 42

Figure 12: Calinski-Harabasz vs. Number of Clusters for select asymmetric binary measures ... 54

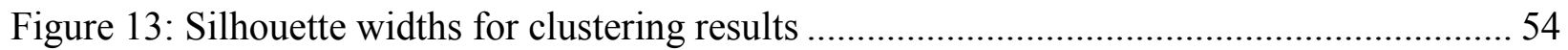

Figure 14: Intermediate priorities for general competitive strategies ........................................... 61

Figure 15: Intermediate priorities of software applications contributions towards performance

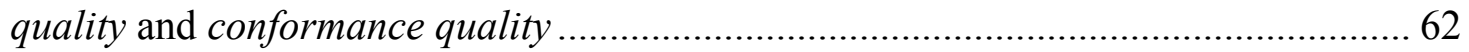

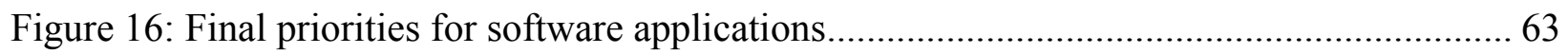

Figure 17: Sensitivity of final priority vector to Cost strategy ……………………………......... 64

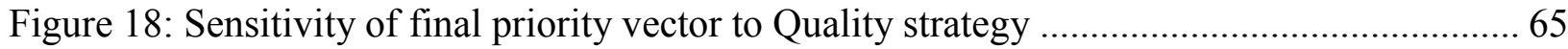

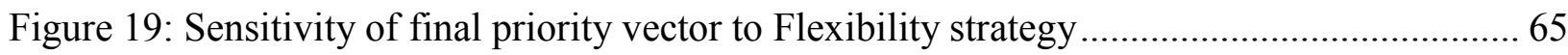

Figure 20: Sensitivity of final priority vector to Delivery strategy ........................................... 66

Figure 21: Sensitivity of final priority vector to Customer Service strategy ................................. 66 


\section{Acknowledgements}

I would like to thank my supervisor, Dr. Taraneh Sowlati, for her time and effort in advising me on the research design and her comments on my written materials. She was especially patient during the early stages of the research when I was still figuring out the details of the methodology. Above all, I am grateful for the opportunity she gave me to join her research group. Doing a Masters in Science has significantly improved my future prospects and, more importantly, greatly expanded my understanding of science and math.

I would also like to acknowledge the time and effort of my internal committee members, Dr. David Cohen and Dr. Robert Kozak. Much of their previous research was the basis for my work, so it was especially valuable to have them on the committee. Dr. Younes Alila was very kind in giving his time to be my external reviewer. Dr. Valerie LeMay, with her expert knowledge in statistics, was very gracious in helping me form parts of the research design. Additionally, numerous experts from industry and academia took time away from their busy schedules to fill out the research survey. This work would not be complete without their survey responses for the model's input data.

A very special thanks goes to Dr. Joseph Paradi and the Centre for Management of Technology \& Entrepreneurship (CMTE) at the University of Toronto. The CMTE made this work possible by generously providing funding. I am honoured to have the opportunity to add to the high quality of research coming from this organization.

Finally, I wouldn't have made it to this milestone without my parents. Their insistence on the value of education became instilled in me at a young age and has carried me through the many years. My academic achievements are as much theirs as they are mine. 


\section{Chapter 1 - Introduction}

\subsection{Background}

\subsubsection{The Canadian Manufacturing Sector and Cabinet Industry}

Manufacturing is a significant component of the Canadian economy. The sector provided 1.5 million direct jobs (Industry Canada 2011) and contributed \$151.1 billion (in 2002 dollars), or 12.7\%, to Canada's total GDP in 2009 (Statistics Canada 2011).

The Canadian manufacturing sector has experienced significant changes during the past two decades, occurring both internally and externally. Some of these changes include the North American Free Trade Agreement (NAFTA), the appreciation of the Canadian dollar against the US dollar, increased foreign competition from Asia, and the Great Recession of the late 2000s (Baldwin et al. 2009). Although some of the changes have presented opportunities to the sector, most of them have presented significant challenges.

As a member of the manufacturing sector, the cabinet industry (NAICS 33711) is relatively small. However, it is still a considerable contributor to the domestic economy, adding $\$ 1.3$ billion in value-added and providing nearly 20,000 full-time equivalent jobs in 2009 (Industry Canada 2011). The apparent domestic market for cabinets remains strong in Canada, with 7.4\% average annual growth from 2000 to 2009 (Figure 1). However, the total value of shipments from Canadian cabinet manufacturers has been decreasing since 2006 (Figure 2).

In many Canadian manufacturing industries, decreasing shipments have been attributed to increased pressure from foreign competitors due to globalization. In the cabinet industry, this is not the entire story. While the proportion of imported products in the domestic market has been increasing at a steadily modest pace, it has not exceeded $10.3 \%$ over the past ten years (Figure 1). Rather, exports have been decreasing since 2002, largely due to events in the US. The US is the single most important market for Canadian cabinet exports, consuming between 95.4\% and 99.1\% of the export volume from 2000 - 2009 (Industry Canada 2011). Beginning in 2001/2002, Canadian exports to the US began contracting, being negatively influenced by the declining \$USD to \$CAD exchange rate. In 2005, the US housing bubble began to deflate and exports to the US began declining even more rapidly (Figure 3). 


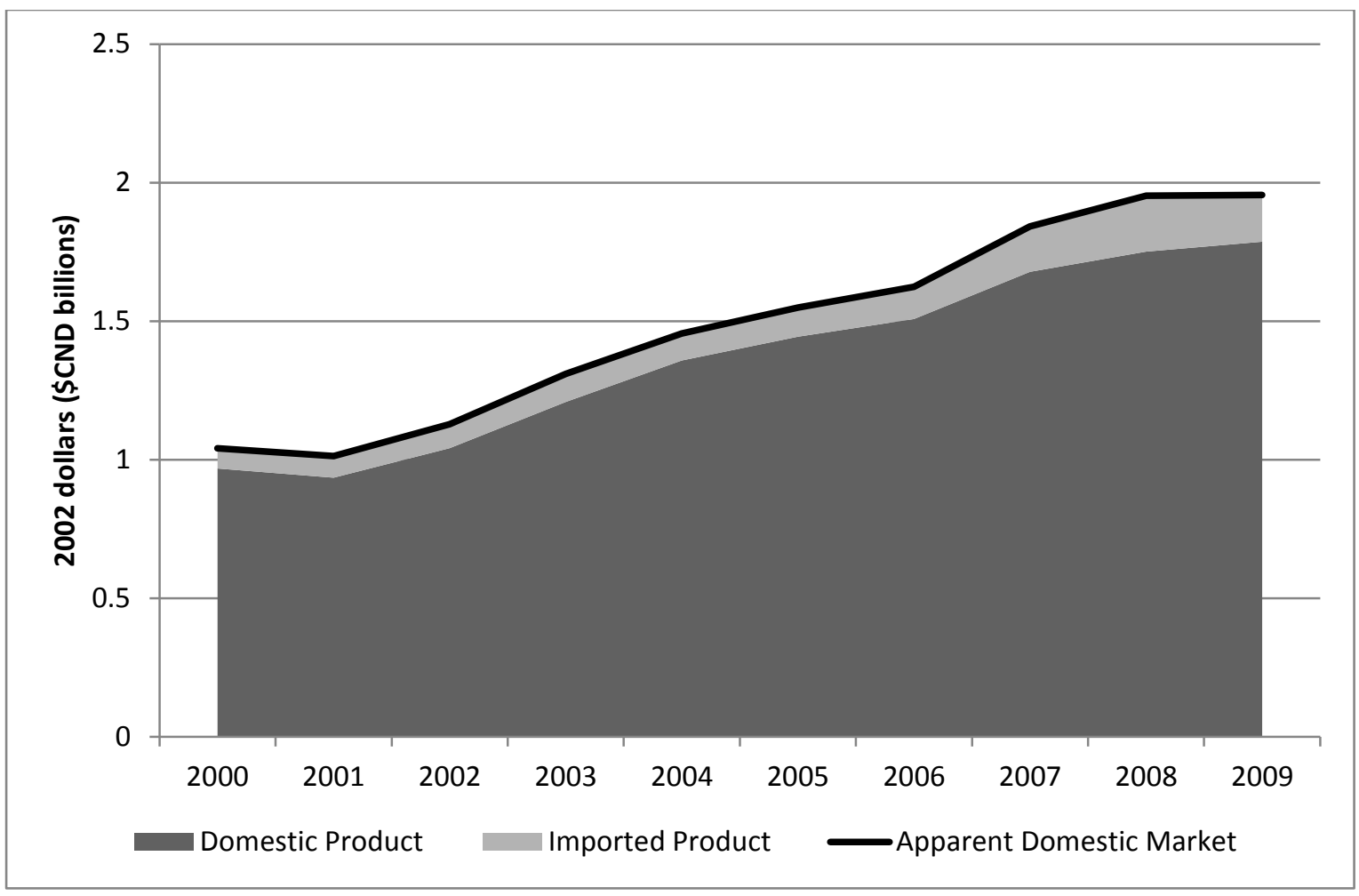

Figure 1: Domestic vs. imported product in the apparent domestic market for cabinets in Canada, where "Domestic Product" represents cabinets produced by Canadian manufacturers for the Canadian market 2000 - 2009.

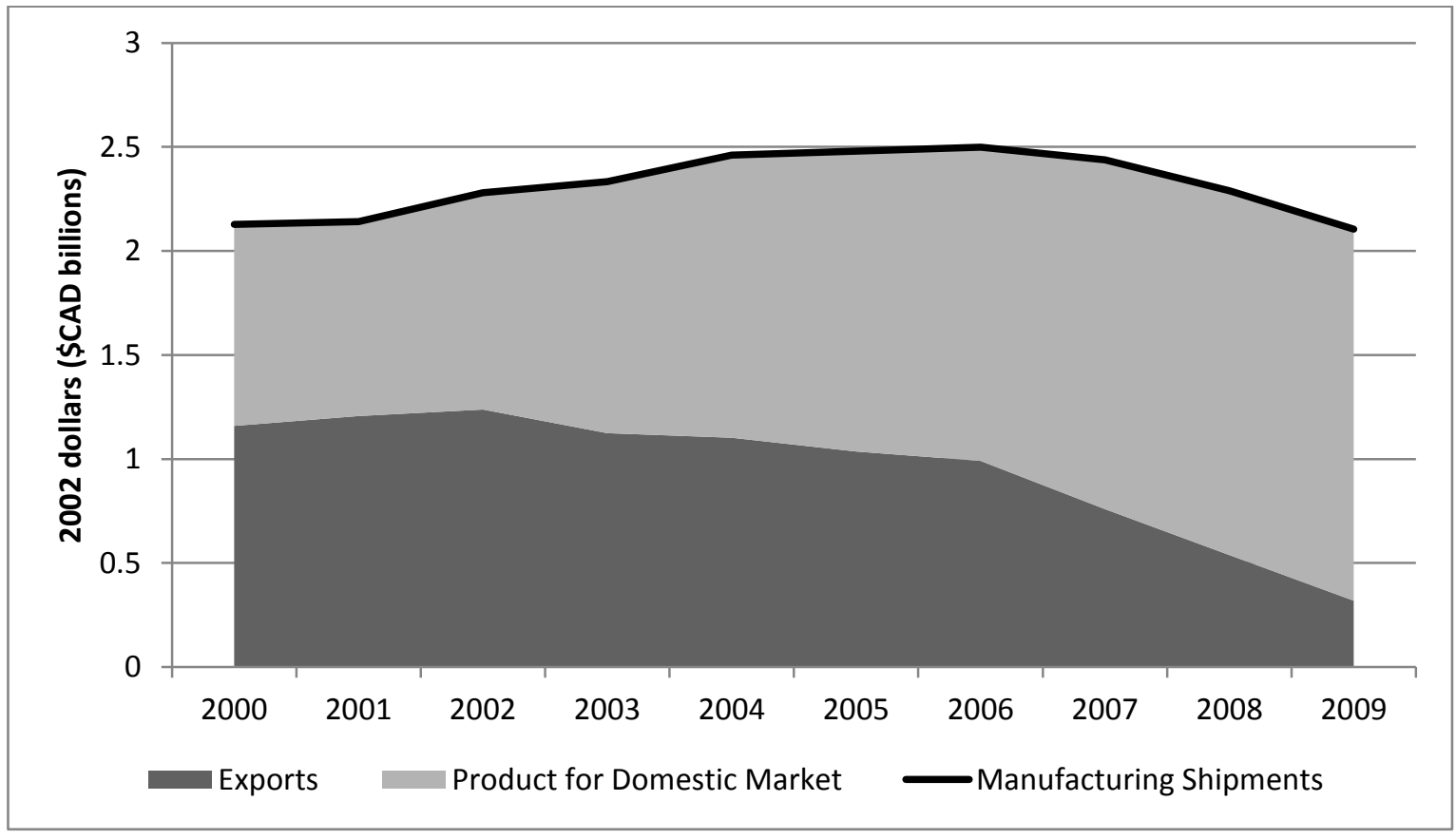

Figure 2: Total value of manufacturing shipments by Canadian cabinet manufacturers, $2000-2009$. 


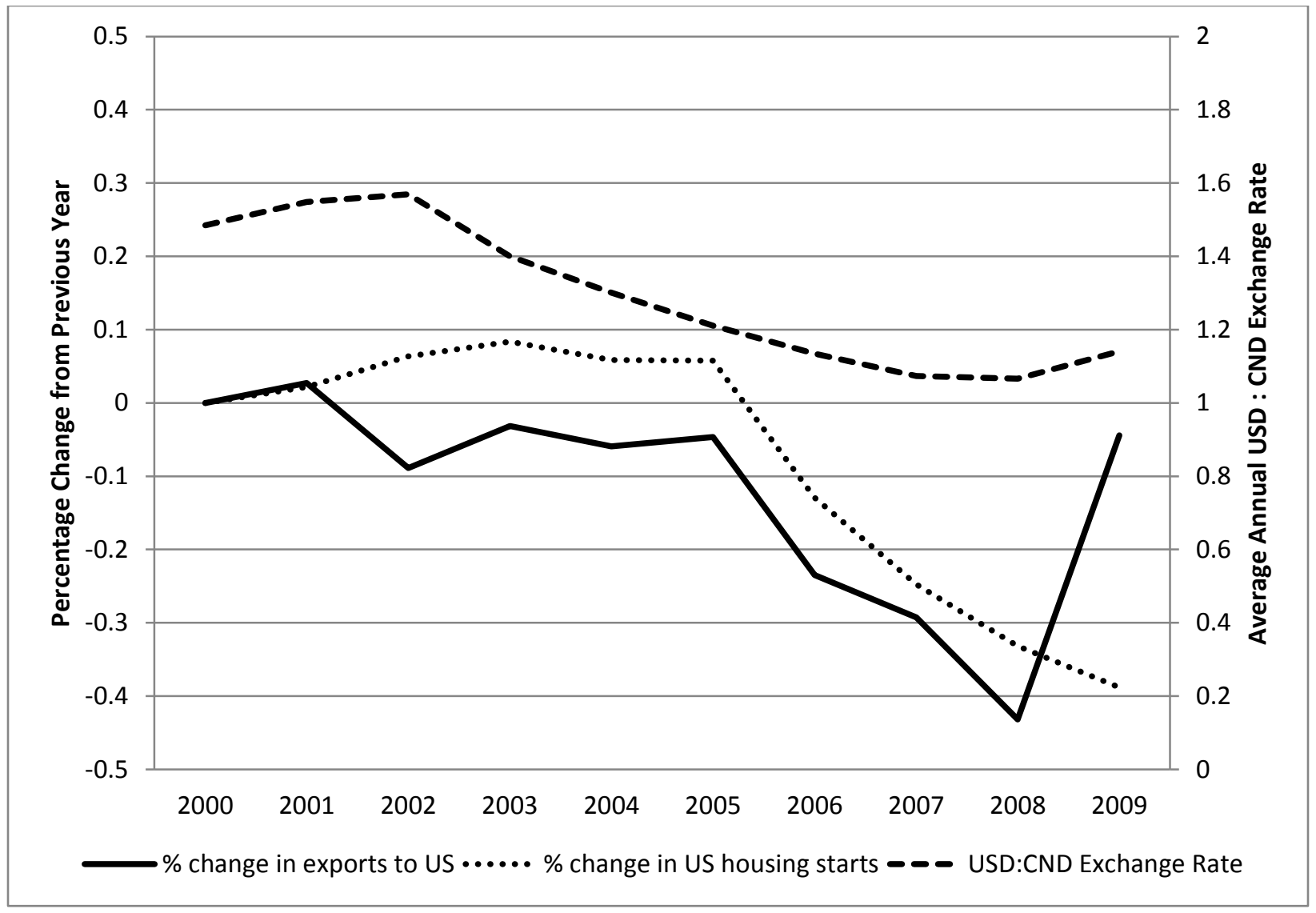

Figure 3: Percentage change in exports to US and no. of US housing starts from previous year. \$USD : \$CAD exchange rates (Source: Industry Canada 2011; U.S. Census Bureau 2011).

\subsubsection{Rising Importance of IT in Manufacturing Competitiveness}

Over the past two decades, the integration of information technology (IT) with manufacturing processes, in both production and non-production activities, allowed some manufacturers to overcome new challenges and remain competitive (Goldman \& Nagel 1993). The rising importance of IT in manufacturing is illustrated by the fact that Canadian manufacturing firms invested $\$ 2.6$ billion in IT in 2010, representing a 524\% increase in these types of investments since 1981. The percentage of all capital investments going towards IT has risen from $3.7 \%$ in 1981 to $17.0 \%$ in 2010 (Figure 4).

IT is commonly defined as being comprised of software, hardware, and network communications components (Merriam-Webster 2011). The presence of software, hardware, and network communications is positively correlated with labour productivity and market share in Canadian manufacturing firms. The strongest correlations were found in firms that 
implemented all three types of IT simultaneously (J. R. Baldwin \& Sabourin 2001). This study focuses on the software component of IT. This is because it is apparent that during the past decade the software component of information technologies has received the most investment capital (Figure 5). Additionally, it should be noted that this research considers only commercialoff-the-shelf (COTS) software products. There are two reasons for this. First, it is assumed that the large majority of Canadian cabinet manufacturers do not develop their own custom software because most firms are small in size and do not have technically savvy personnel (Hetemäki \& Nilsson 2005; Grushecky et al. 2006). Second, it is much more straightforward to study discrete, commercial products than customized, internally-developed software.

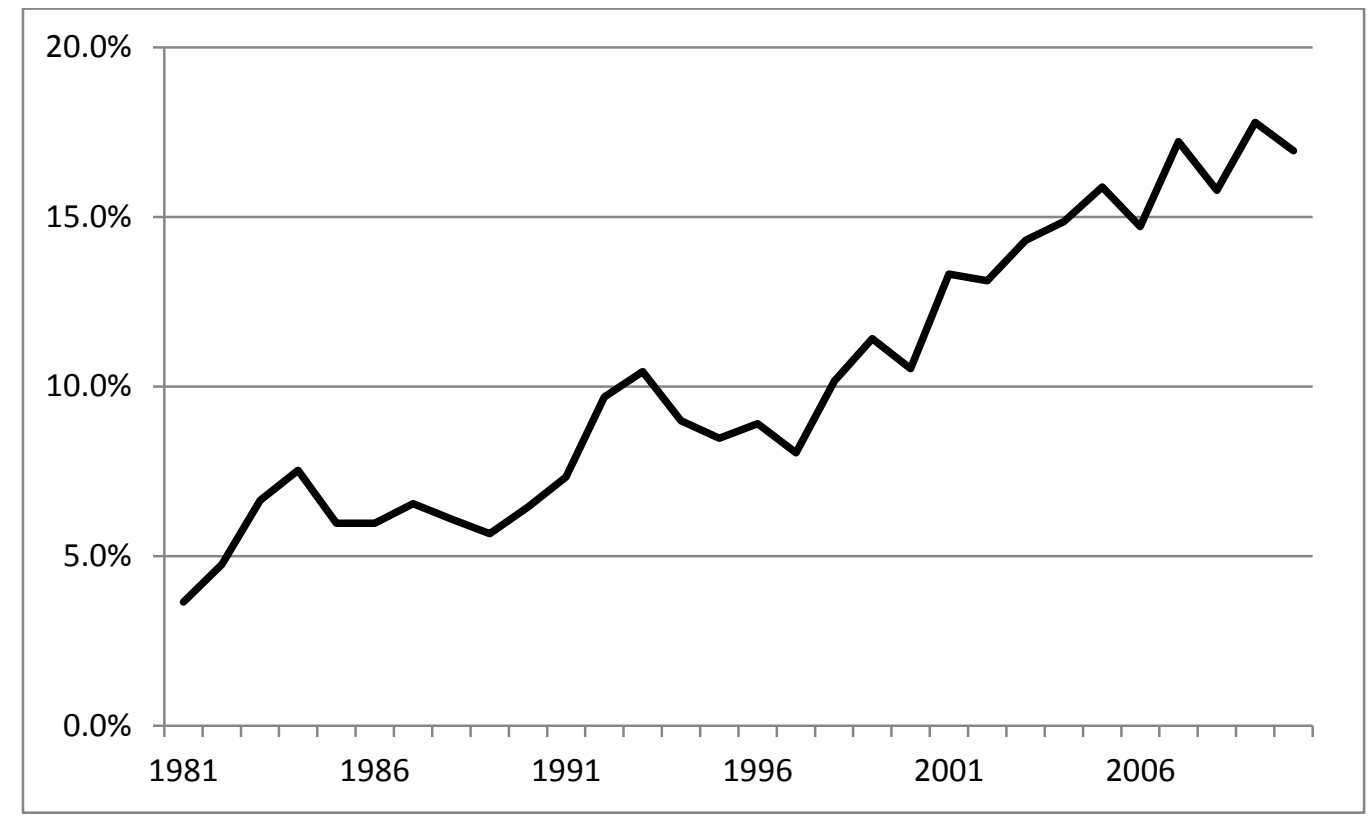

Figure 4: Percentage of all capital investments going towards IT in the Canadian manufacturing sector. (Source: CSLS 2011) 


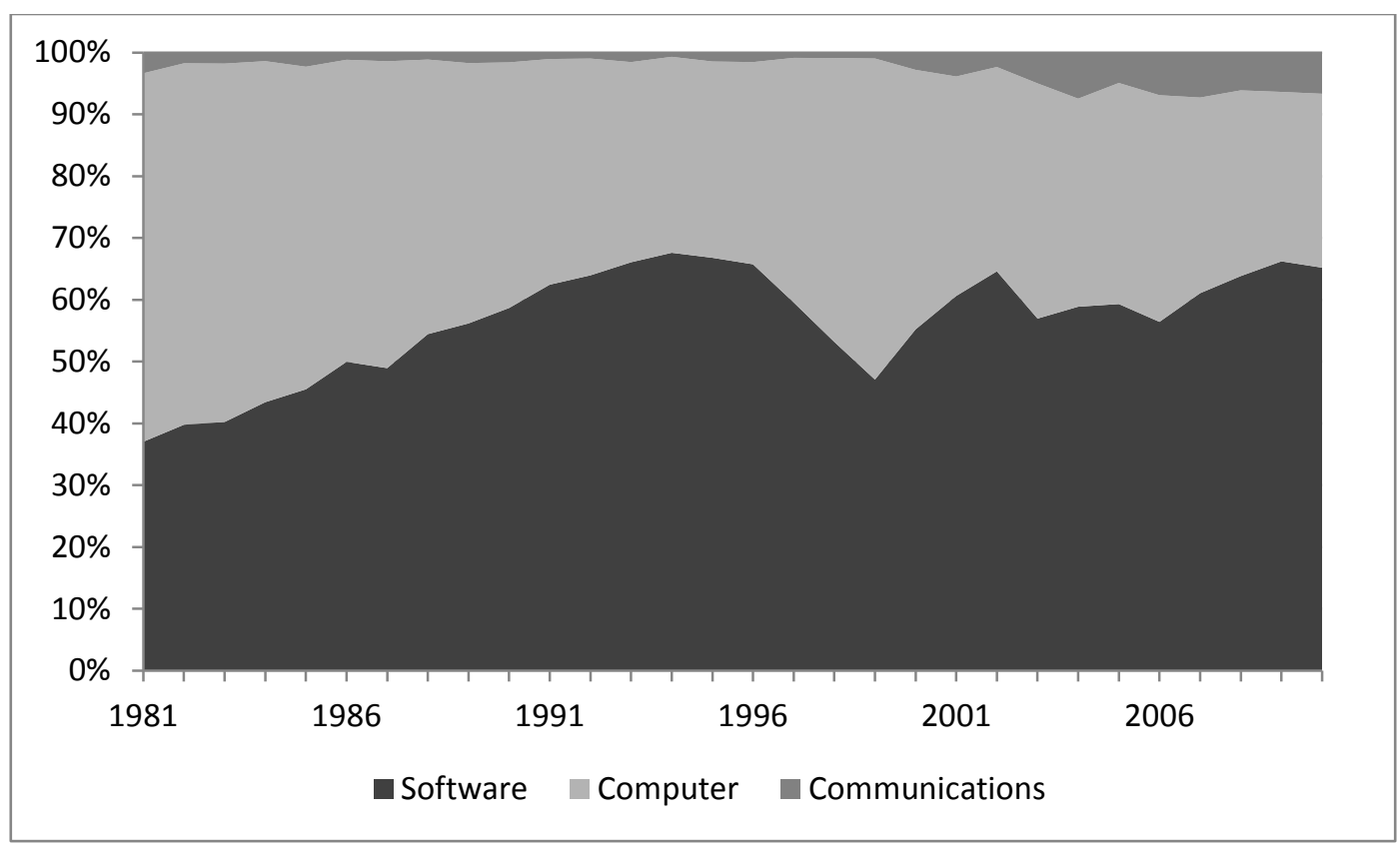

Figure 5: Percentage of all ICT investment dollars going towards communications infrastructure, computer hardware, and software. (Source: CSLS 2011)

One of the first empirical studies to investigate the value of information technology (IT) investments found no consistent evidence of a positive relationship between IT investment and firm performance (Weill 1992). Brynjolfsson (1993) argued that although computing power had been growing rapidly during the past few decades, productivity had been stagnating in several sectors. He thus coined the phrase "the productivity paradox of information technology". After scores of conflicting studies, researchers began to realize the importance of intangible costs and benefits in assessing the value of IT investments (Irani 2002). Brynjolfsson and Hitt (1998) explained that intangible benefits form the majority of value from IT investments. Since then, it has been recognized that although information technology alone cannot provide competitive advantage, it is an enabler of it, especially through business process redesign (Mooney et al. 1996).

Information technology can provide benefits in three general ways. First, it can improve firm performance through process automation; thus increasing labour productivity and lowering labour costs. Second, information technologies allow companies to redesign their business processes to make them more efficient and more closely aligned with corporate strategy. Third, they assist in the formation of collaborative and inter-organizational relationships that can open new markets and encourage innovation (Hetemäki \& Nilsson 2005). 


\subsubsection{IT Adoption in North American Forest Products Industries}

With the possible exception of the pulp and paper industry, IT adoption in forest products firms has been below the manufacturing sector average. For example, in the period 1999-2000, half of all U.S. manufacturing firms (NAICS 31 - 33) had at least one computer network in place, while $43.5 \%$ and $35.3 \%$ of wood products (NAICS 321) and furniture (NAICS 337) plants reported having a computer network, respectively. Similarly, $2.9 \%$ of wood products and $3.3 \%$ of furniture plants used Enterprise Resource Planning (ERP) information systems, compared to $8.2 \%$ of all manufacturing plants (Atrostic \& Gates 2001).

This low adoption rate is troubling for the Canadian cabinet industry because it is facing a challenging environment due to sharply lower US exports and slowly increasing foreign competition. The effective use of IT is becoming increasingly critical to remain competitive in manufacturing and deal with these types of challenges. Previous research has found that IT is even more critical for wood products exporters (Appendix 1). Thus, stronger IT investments can play an important role in regaining lost ground in exports. For these reasons, it is important to research how IT can be better leveraged to increase the competitiveness of the Canadian cabinet industry.

This research takes a strategic perspective on IT investments in the industry and attempts to prioritize different types of software applications according to their ability to contribute to the future competitiveness of the industry. This approach differs from previous research in this area, because those studies have generally investigated current IT adoption, whereas this study is forward-looking in nature. Assadi and Sowlati (2009) have previously used similar methods and applications as this research. However, this research differs in several ways, including scope and time frame. 


\subsection{Research Objectives}

The objectives of this research are as follows:

1. To assess the composition and representation of functionalities in the software products currently available to the cabinet industry.

Cabinet industry software products are evaluated according to their functionalities. Cluster analysis and association rule learning are used to gain a better understanding of what types of software applications are currently available to the industry and how functionalities are grouped together to achieve integrated business functions.

2. To determine the desired future state of software products in the cabinet industry. The analytic network process (ANP) is used to model the strategic question: "Which types of software applications are most important for future competitiveness?" Expert responses to structured surveys are used as the inputs to the model.

3. To identify any gaps between the current and desired future states to determine where the industry may better leverage software to be more competitive. Any large differences between the types of applications currently represented and applications with high future priorities will be highlighted and discussed.

\subsection{Thesis Structure}

The chapters of this thesis are organized as follows:

A review of the pertinent literature is provided in Chapter 2. The scope of the review is limited to studies done in North America, beginning in 1996 and ending in 2008. The review begins by describing the key findings from each study. Many of the studies have similar findings and these communalities are discussed.

Chapter 3 introduces background information on the different methods used in this research: cluster analysis, association rule learning, and ANP. Cluster analysis groups software products by their functionality, while association rule learning gives insight into how these 
functionalities are used together to achieve integrated business functions. ANP is used to determine the strategic priorities of the different software applications considered.

Chapter 4 discusses the source of the datasets used in analysis. Data for cluster analysis and association rule learning are gathered from software vendor websites. Data for ANP are gathered from surveys of industry and IT experts. Additionally, much of Chapter 4 is devoted to describing the specific details of each method. In particular, there are many issues in implementing AHP/ANP and the author took much care to choose the most appropriate methods.

Results and a discussion of results are given in Chapter 5. Software products are clustered by functionalities and functionalities are assigned association rules to give a portrait of the current state of software in the industry. Priorities of software application types are also given. Then, an informal gap identification is done to identify any applications that are over or under represented.

Chapter 6 completes the thesis with conclusions and suggestions for future research. 


\section{Chapter 2 - Literature Review}

\subsection{Synopsis}

This chapter begins with a comprehensive literature review on previous research on IT in the wood products industries. The reviewed studies begin in 1996 and cover the work done up to 2008. Most of the research was exploratory in nature, with surveys sent out to firms in the industry. These studies were generally trying to determine which types of IT were currently being used in wood products industries. The reviewed work includes both primary and secondary (or value-added) industries. One study focused on the pulp and paper industry.

Section 2.3 is a discussion of common findings between these studies. Numerous studies reported that most wood products manufacturers invest less than $\$ 10,000$ in IT. When they do make IT investments, it is usually in technologies with low sophistication (e.g. static websites). Additionally, it was found that firm size and export intensity are positively correlated with IT investment levels.

The chapter concludes with some possible explanations for the low IT investment observed. Possible reasons include low information processing requirements, production vs. marketing orientation, and a workforce that is not technically savvy.

\subsection{Previous Research on IT Adoption in North American Forest Products Industries}

Vlosky and Gazo (1996) were one of the first researchers to study IT adoption in forest products industries. At this time, the Internet was just starting to gain popular acceptance and its variety of uses were beginning to be explored. The goal of this study was to discern which Internet-enabled services were of highest interest to Forest Products Society members. Access to industry information and forest products databases was seen as the most valued service.

Industry-wide surveys began with Vlosky and Fontenot (1997). They surveyed 364 primary and secondary wood products firms across the U.S. to examine their current and future use of the Internet for business purposes. Although most respondents (52\%) had Internet access, less than one third of them (28\%) had a company website. While secondary manufacturers had a greater web presence than primary manufacturers, a greater percentage of primary manufacturers 
were planning on developing a website in the near future ( $80 \%$ vs. $20 \%$ ). Most firms were using or planned to use email and company websites for customer communication and product promotion, but fewer than $10 \%$ were using or intended to use the Internet to facilitate purchases and sales. The greatest perceived benefit of the Internet was greater exposure to customers, while the lowest perceived benefit was lower prices to customers.

In a similar survey, Vlosky (1999) expanded the sample to include Canadian firms and the pulp and paper industry. Results from this survey indicated that IT adoption in the forest products sector was slow. Most respondents (60\%) reported not using the Internet for any business activities and approximately one third of them (34\%) did not plan on utilizing such technologies in the future. A positive correlation was found between firm size and Internet adoption rate. Investment in Internet technologies was found to be minimal, with $44 \%$ of adopting firms investing less than $\$ 10,000$ cumulatively. The highest ranked perceived benefit was increased access to industry information, while the lowest ranked benefit was lower prices to customers. The biggest concern regarding Internet technologies was the security of sensitive information. Most adopting firms were not satisfied with their IT implementation in terms of completion time and benefits received. This coincided with half of the firms not conducting or planning to conduct an audit of their IT projects. The lack of formal review could have been a major contributor to the firms' disappointment.

Pitis and Vlosky (2000a, 2000b) surveyed 104 U.S. primary wood products exporters in 1999 to examine their use of Internet technologies in business activities. In this study, $82 \%$ of respondents reported using the Internet for business purposes, much higher than previous studies. Companies with higher revenues were statistically more likely to use the Internet, similar to the findings in (Vlosky 1999). Email was the most commonly used Internet technology (94\%), followed by web navigation (81\%). Nearly half of the firms (49\%) reported spending less than $\$ 10,000$ in total on Internet technologies. The highest ranked perceived benefits of using the Internet were increased access to industry information, greater access to one's company, and an enhanced image of one's organization. None of the impediments to implementation (technical issues, internal factors, acceptance of technology) were perceived to be very strong. Although three-fourths of respondents were at least somewhat willing to sell their products online, onefourth strongly opposed it. In summary, U.S. primary wood products exporters were early 
adopters of Internet technology compared to other wood products sectors. There was widespread use of basic Internet technologies such as email, but a cautious attitude still existed towards using the Internet for financial transactions in 1999.

A survey of 372 primary wood producers and pulp and paper mills was done by Dupuy and Vlosky (2000) to learn more about their adoption of Electronic Data Interchange (EDI). EDI is used to electronically transmit business documents; reducing operating costs and increasing responsiveness. In 1999, only $16 \%$ of the surveyed companies were using EDI, although $28 \%$ that were not using the technology planned to do so by 2002. Survey results showed that EDI use was highly correlated with firm size. The impetus to adopt EDI came primarily from their customers (e.g. home center retailers such as Home Depot and Lowe) rather than internally. The lowest rated motivation to change was the potential cost savings. The critical success factors highlighted by those firms that had implemented EDI were the need to commit the necessary resources and willingness to change.

Few studies have focused solely on Canadian forest products firms and their IT adoption. Kozak (2002) represents one of the first such studies, where he examined the usage of and attitudes towards IT by 126 Canadian secondary manufacturers. By then, the Internet had been widely adopted in North America, reflected by $88 \%$ of survey respondents having Internet access. Internet use increased with firm size and tripled for firms with more than 100 employees. The most common Internet activities were online research, exchanging documents with partners, and emailing customers. Fewer than $10 \%$ of respondents used the Internet for purchasing products or emailing employees. Half of the firms had an active website in 1999. Websites were primarily being used to provide information to customers and increase exposure to potential customers. None of the company websites facilitated financial transactions. Survey responses were separated into early and late adopters based on whether the firm had an active website or not. In general, firms producing higher-value products (cabinetry; moldings, millwork, and floors; homes; engineered wood products; doors and windows) were more likely to be in the early adopter group, with the exception of furniture manufacturers. The lower value-added pallet, box, shake, and shingle manufacturers were exclusively in the late adopter group. Overall, the B.C. value-added wood products industry was receptive to using the Internet in business operations and confident that its use would increase in the future. However, the industry had yet 
to fully invest in information technology and take advantage of the significant benefits (e.g. lowering supply chain costs) that more advanced technologies could provide.

Vlosky and Westbrook (2002) surveyed 70 top-level home center managers to examine the role of Internet technologies between home center retailers and forest products companies. Most respondents (78\%) had a website, while one fourth of them used the Internet for forest product purchases. No correlation was found between firm size and Internet purchases, signalling uniform adoption. The highest ranked perceived benefits of the Internet were increased access to industry information and greater exposure to potential suppliers. The biggest impediment to adoption of Internet-facilitated procurement was the fear of losing relationships with suppliers since wood procurement was still generally done through traditional communication. Moreover, many home centers did not intend to invest in these technologies since the perception was that few forest product companies were interested in forming such a partnership.

An in-depth analysis of the underlying demographic factors associated with IT adoption in secondary wood products firms was carried out by Shook et al. (2002). The study surveyed 780 secondary manufacturers in Montana, Idaho, and Washington in 1999. The effect of gross sales, sales from wood-based products, capacity utilization, number of full time employees, and the ratio of wood to non-wood material costs on the Internet use of companies was assessed. A higher percentage of large companies compared to small companies had websites. Those firms with a website operated at significantly lower capacity $(76 \%$ vs. $82 \%)$ and had higher employment (32\% vs. 20\%) than those without a website. Most respondents (53\%) used email in their business activities. Plant size and email usage were found to be positively correlated, with email usage in large plants being $70 \%$ higher than in small plants. Companies using email in their business activities had twice the gross sales and $175 \%$ more employees than those not using email. Overall, 21\% of firms reported selling online and 22\% purchasing online. Small firms were less likely to sell and purchase online than large firms. Firms that sold online derived a significantly higher percentage of their gross revenues from non-wood products and services and also had significantly lower overall plant utilization rates. Those that purchased business supplies over the Internet had significantly higher gross revenues and full-time employment. 
Overall, only $8 \%$ of manufacturers utilized Internet banking services. Firms that used the web to conduct online research had higher gross sales and employment.

The Internet adoption of 55 primary wood products producers in western U.S. was studied by Vlosky et al. (2002). Mail and fax were found to be vastly preferred over email and EDI for business document exchange. Similar to previous studies, greater exposure to potential customers and increased access to industry information were indicated to be the greatest benefits of the Internet. Offering lower prices to customers was perceived to be the lowest benefit.

Vlosky and Smith (2003) surveyed 195 U.S. hardwood lumber firms to gauge their adoption of Internet technologies. A high percentage of respondents (90\%) had used the Internet for business purposes. Slightly more than half of respondents (55\%) reported having a company website, of which $48 \%$ used them for promotion and advertising, 12\% for customer service, $9 \%$ for financial transactions, and $7 \%$ for internal operations. Mail and fax were found to be the most common methods for transmitting business documents, while the use of email for this purpose was low and EDI nearly non-existent. Hardwood lumber firms used the Internet primarily for applications such as email communications and static website development. Half of the respondents invested less than \$5,000 in Internet technologies and 19\% invested between $\$ 5,000$ and $\$ 10,000$. Surprisingly, the majority of firms reported no serious impediments to implementation. The highest rated impediment was lack of IT staff. The highest ranked perceived benefits of using Internet technologies was greater exposure to potential customers, greater access to existing customers, and increased access to industry information.

Several Internet-based business-to-business forest products exchanges (eMarketplaces) failed after the dot.com crash of 2001. A survey by Shook et al. (2004) of 11 former and current executives of forest products eMarketplaces revealed many possible reasons for their decline. First, the aftermath of the 2001 dot.com crash put an overall damper on user adoption. Second, many executives cited an overall slower technology adoption rate in the forest products sector. They also stated that a hasty over-promotion of the technology had intimidated potential customers. The eMarketplaces' underestimation of the importance of the human factor in the forest products sector was a critical factor in their decline. It was oftentimes easier to pick up the phone and discuss the minute details of a transaction with a person, rather than interacting with software. High switching costs and change management issues also inhibited adoption. Overall, 
eMarketplace providers oftentimes failed to show how their service added value to a business. eMarketplaces may have been more successful if they implemented their technology incrementally, instead of an "all-or-nothing" approach. Forest product companies are typically slower to adopt and may need more time to be eased into new technologies.

Janssen (2004) surveyed U.S. and Canadian pulp and paper mills on their use of information technologies. The primary reason to justify the use of an Information Management System (IMS) was the need to store information more efficiently. All respondents agreed that the most important benefits of an IMS were the improved process data flow and the increased capabilities for problem solving resulting from process-related data. Time and financing constraints were the main barriers for IT adoption in these mills. Personnel's resistance to change was also perceived to be a significant barrier (60\%). Overall, survey results showed that while the paper mills were relatively high users of IT, they had yet to fully exploit the potential of information systems, especially with regards to supply chain management.

A study by Holmes et al. (2004) investigated the Internet use of small wood products manufacturers in New York and Louisiana. Non-response bias was detected, thus the study is considered exploratory in nature. Overall, the usage of eCommerce technologies was found to be low, although New York had higher usage levels than Louisiana. Although only 44\% and $36 \%$ of New York and Louisiana firms had a website respectively, respondents from either state did not indicate any serious impediments to website development.

Stennes et al. (2006) used logit regression on survey results from British Columbian secondary manufacturers to determine factors that influence eCommerce usage. The effects of variables, such as wood volume, proportion of domestic market sales, and firm type (remanufacturers, engineered wood products, millwork, and furniture / cabinets) on having a website, web procurement, and sales over the Internet were assessed. Wood volume and firm type was found to have a significant $(\alpha=0.10)$ positive relationship on having a company website. There was a significant $(\alpha=0.10)$ negative relationship between remanufacturers and sales over the Internet. Also, furniture and cabinet firms were most likely to engage in Internet procurement. All three regressions indicated that exporting firms were more likely to engage in these three eCommerce activities. 
The IT adoption of 312 forest product firms in Quebec was studied by Karuranga et al. (2006). Overall, 64\% of respondents had a company website. Paper and carton mills (90\%) were more likely to have a website compared to building material plants (59\%) and sawmill $(56 \%)$. Annual revenue was also found to be a significant distinguishing variable, with higher revenue companies being more likely to have a website. Corporate websites and accounting software were the most ubiquitous applications of IT. Conversely, usage rates for IT in operational planning, supply planning, inventory management, process control, and buying/selling were very low (less than 5\% for all technology groups). Once again, industry type emerged as a distinguishing factor in IT use. Furniture manufacturers were much less likely to engage in online financial transactions, while paper and carton mills were more likely to use IT in different internal operations. Greater access to industry information was the primary perceived benefit of using IT. Similar to other studies, $82 \%$ of respondents stated that information security was a very important barrier to adoption, while $70 \%$ identified the lack of trained IT personnel as an important barrier.

Arano (2008) surveyed West Virginian hardwood manufacturers on their IT adoption and reported several findings similar to previous studies. Most respondents (46\%) reported investing less than $\$ 10,000$ on e-commerce. A significant positive correlation was found between firm size and e-commerce adoption. A similar relationship was observed between gross sales revenue and e-commerce adoption. Exporting firms were more likely to use e-commerce. The greatest perceived benefits of e-commerce were improved service to customers and greater exposure to potential customers, while lower prices to customers was shown to be the lowest perceived benefit. Security of sensitive information was the biggest concern among firms in adopting e-commerce into their business operations. In contrast to earlier studies, though, over $75 \%$ of adopters reported using Internet technologies for email, supply purchasing, company website, and taking customer orders over the Internet.

Melville and Ramirez (2008) propose a new paradigm to explain why IT adoption differs across industries and uses the wood products and beverage industries as contrasting examples. Their conceptual model explains that an industry's information processing capabilities are determined by its information processing requirements. The requirements are driven by the industry's production process complexity, rate of new product turnover (clock speed), and supply 
chain complexity. In turn, the information processing capabilities are defined as IT-based production control and supply chain management. Their qualitative comparison of the wood and beverages industries concludes that the low information processing capability found in the wood industry is due to their relatively low information processing requirements. More specifically, their production process complexity, clock speed, and supply chain complexity are lower than the beverage industry. Hence, their IT adoption rate is lower.

Assadi and Sowlati (2009) was the precursor to this research. Their study applied the analytic hierarchy process (AHP) to software selection for a Canadian cabinet firm. Their AHP model included 36 criteria relevant to a software purchase and four design and production software packages (Assadi \& Sowlati 2009). The motivation behind this study was the lack of any prior research that applied a systematic evaluation method to IT investments in the forest products sector (Hetemäki \& Nilsson 2005). Later, interdependencies between criteria were accounted for in an ANP model applied to the same decision (Assadi et al. 2009).

This research is similar to Assadi and Sowlati (2009), but differs in a few ways. First, it investigates at the industry-level, whereas those studies were done at the firm-level. Second, their research focused specifically on design and engineering software, whereas this study is more broad and investigated all types of business software. Third, this research also incorporates cluster analysis and association rule analysis to characterize the current software market. Fourth, this study is strategic in nature. It attempts to determine which types of software applications are most important for the industry's future competitiveness.

\subsection{Discussion of Previous Studies}

A review of these studies revealed many common findings between them (Appendix 1). First, nearly all studies noted a lack of using advanced Internet technologies in wood products companies. Examples of advanced Internet technologies include e-commerce for online financial transactions and Electronic Data Interchange (EDI) for transmission of digital business documents. Most of the surveyed firms reported using the Internet primarily for email, static websites, and research on the web.

Information technologies with increasing complexity are those for competitive assessment activities, value-chain linkages, and business processes (Pitis and Vlosky 2000a, 
2000b). Vlosky and Smith (2003) describe the differentiation between information technologies as lower-order versus high-order technologies, with the latter group requiring networking and connectedness to business systems both internally and externally. This observation mirrors the ICDT model of Internet business strategy evolution where companies begin in the "Information" space and then progress through the "Communication", "Distribution", and "Transaction" space. Information space refers to new channels for displaying product, service, and company information. Communication space consists of new channels for relationship-building activities. Distribution space refers to new channels for distributing products and services. Transaction spaces are new avenues for executing electronic sales and purchases (Angehrn 1997). Research thus far has shown that the majority of forest products firms are in the Information and Communication space (e.g. static websites and email) and relatively few have entered the Distribution and Transaction space (e.g. online transactions and supply chain management technologies).

Another major trend in the studies was the observation of a significantly positive correlation between firm size and IT usage. For example, Shook et al. (2002) found that respondents using email had mean gross sales of $\$ 4.81$ million versus $\$ 1.99$ million for nonusers (significantly different at $\alpha=0.05$ ). Companies that used the web to do business research also reported mean gross sales of $\$ 4.25$ million versus $\$ 2.18$ million for companies that did not (significantly different at $\alpha=0.05$ ). Those firms engaging in the previously stated Internet activities also reported significantly higher employment. This correlation was also noticed in higher-order technologies. A 1999 survey of U.S. and Canadian primary wood products and pulp and paper producers found that firm size was highly correlated with EDI use (Dupuy and Vlosky (2000). Stennes et al. (2006) found a significant positive correlation $(\alpha=0.05)$ with firm size and presence of a website, but not Internet sales and purchases. These findings agree with a large body of previous research showing that firm size has a large impact on IT adoption, in both manufacturing and non-manufacturing industries (Cohen 1995; Hollenstein 2004; Lal 1999; Sabourin \& Beckstead 1999).

In addition to firm size, percentage of sales from exports also had a positive influence on IT adoption (Appendix 1). Pitis \& Vlosky (2000b) were early to notice this trend, but firm statistical evidence was unavailable at the time. The relationship was statistically validated by 
Stennes et al. (2006) when they observed that that the proportion of domestic market sales was negatively related to website presence and Internet sales/ purchases. These findings are not particularly surprising because the Internet is particularly well-suited to benefit exporters through lower documentation, communication, promotion, and transaction costs (Hetemäki \& Nilsson 2005)

In 2008, the mean IT investment per employee in the manufacturing sector was $\$ 3,489$ in the US and \$1,480 in Canada (CSLS 2011). While the reviewed studies did not report per employee figures, their findings that the majority of surveyed companies invested less than $\$ 10,000$ in total is indicative of below average IT investment levels. While this amount may be sufficient for developing lower-order technologies (Information and Communication space in the ICDT model), it is not adequate for high-order technologies (Distribution and Transaction space in the ICDT model) (Kozak 2002).

There was a general consensus among primary and secondary manufacturers that greater access to industry information was one of the greatest benefits of IT (Appendix 1). Janssen et al. (2004) reported that $90 \%$ of surveyed executives in the pulp and paper industry realized the ability to store information more efficiently was the top benefit. This indicates that pulp and paper firms expected more from their IT investments than primary and secondary wood products firms. This is likely a direct result of the paper industry's more sophisticated use of information technology. It is noteworthy that all of the studies were survey-type and therefore reported perceived benefits. There were no empirical studies of firm performance before and after IT implementation to quantify actual benefits.

The ability of IT investments to lower costs is arguably one of its more important benefits. However, lowering prices for customers and lowering operational costs were often perceived as less important benefits of using IT for wood products firms, while greater access to industry information was the highest perceived benefit. This perception was first observed in 1996 and has continued throughout the last decade with a more recent study in 2008. Additionally, Brynjolfsson and Hitt (2000) suggest that the most significant long-term benefits are the improvements in business processes and organizational structure that can arise from successful IT investments. None of the reviewed studies indicated that forest product companies 
perceived these as important benefits. These survey responses support the conclusion that most wood products manufacturers are not realizing the full potential of IT investments.

With the exception of pulp and paper companies, U.S. and Canadian forest products companies have been slow in integrating information technology into their business. IT adoption has been primarily in lower-order technologies such as email and static websites. There is likely a confluence of factors that contribute to this. The significant influence of firm size on level of adoption is an important finding because the secondary wood products industry is highly fragmented in both the U.S. and Canada (Hetemäki \& Nilsson 2005). This does not, however, explain slow IT adoption by primary wood product industries that tend to be larger and more capital intensive. The cause here may be explained by the information processing requirements paradigm proposed by Melville \& Ramirez (2008). That is, the relatively low production process complexity, rate of new product turnover, and supply chain complexity of primary wood products industries explain their low IT adoption.

U.S. primary wood producers have historically been production-oriented, where the focus is on the product and improving the production process. A marketing-orientation is becoming increasingly important in the modern economy. A firm with this orientation focuses on the needs and wants of the customer, adjusting their offerings accordingly. In a study of U.S. primary producers, Poku (2003) found that firms with a high level of market-orientation had higher levels of IT adoption than firms with low market-orientation. It should be noted that many larger sawmills utilize networks of programmable logic controllers linked with high-speed Ethernet to control their machinery. While this is certainly a form of IT, it was not within the scope of the studies reviewed and hence is not included in this literature review.

Slow IT adoption could also be due to a workforce that is not technologically savvy. A relatively low-skilled workforce is common in many forest product industries (Hetemäki \& Nilsson 2005). A recent study on the decline of the U.S. furniture industry asked respondents to gauge the effect of labour force issues on their business. They indicated that an inability in finding a sufficiently skilled workforce was making it difficult to make investments in new technologies. Firms also stated that they had to pay more than they wanted for technologically savvy workers (Grushecky et al. 2006). Another study reports that the greatest determinant of IT adoption success in U.S. forest products firms was the quality of IT staff (Poku 2003). 
Finally, the degree of value-added in a product may influence IT adoption. Kozak (2002) found that secondary industries with higher priced custom products (e.g. engineered wood products, millwork, etc.) were more likely than firms selling lower priced commodity products (e.g. pallets, boxes, shingles, etc.) to adopt information technology and have a web presence.

The majority of the literature reviewed here is an assessment of the low IT adoption rate in forest products industries. Only a few studies have begun to investigate why the adoption rate may be so low. Information processing requirements, corporate orientation, human capital, and value-added factors have begun to receive attention, but further research could be done to give more insight on why adoption is so low. Additionally, more research on the pulp and paper industry could reveal why and how that industry has adopted IT much more rapidly than others in the sector.

Comprehensive data on IT expenditure currently exist for the main industry sectors (i.e. manufacturing, services, finance, etc.). More detailed data on IT investment amounts for industry subsectors (NAICS 321 (Wood Product Manufacturing), 322 (Paper Manufacturing), and 337 (Furniture and Related Product Manufacturing) would enable a more rigorous comparison of forest products industries against other manufacturing industries. More detailed investment data would also allow for better IT benchmarking within the forest products sector.

Information technology is characterized by rapid change and innovation (Brynjolfsson \& Saunders 2009). Consequently, research in this domain becomes outdated relatively quickly. Most of the research on IT in forest products industries has taken place in the first half of the 2000s. Likewise, much of it could already be outdated. For example, as the costs of information technology continue to decrease, the previously observed positive correlation between firm size and adoption rates may have changed due to lower capital requirements. The recent development of the software-as-a-service (SaaS) business model is making enterprise-level software applications available to small and medium-sized businesses at much lower costs. Therefore, more research could be done to investigate how IT adoption in the wood products industry has changed during the past five years due to the evolution of IT.

There are four main methods for IT investment evaluation: the financial approach, multicriteria approach, ratio approach, and portfolio approach (Renkema \& Berghout 1997). The 
financial approach utilizes traditional discounted cash flow methods such as internal rate of return (IRR) and net present value (NPV). Multi-criteria methods use many different tangible and intangible evaluation criteria such as cost reduction and strategic match in to consideration. The ratio approach uses different ratios, both financial and non-financial, to gauge the attractiveness of an investment. The portfolio approach tries to optimize or balance a portfolio of IT projects to yield the largest overall benefit.

Ultimately, this research utilizes the multi-criteria method for several reasons. First, since intangible costs and benefits often play a large role in IT investments, financial approaches may not be the most appropriate (Brynjolfsson and Hitt 1998). Second, it has been suggested by previous researchers that IT adoption by wood products manufacturers needs to be understood with regards to a technology's overall economic impact, not just a single benefit or improvement (Rosenburg et al. 1990). Thus, there are several factors (or criteria) that need to be taken into consideration when trying to determine which types of IT are most important for the cabinet industry's competitiveness. Finally, there have been numerous previous studies using AHP and ANP for analysis of strategic information technologies (Roper-Lowe \& Sharp 1990; Presley \& Meade 1999; Raisinghani et al. 2007). These methods appear to be relatively common in the IT investment evaluation, likely due to their ability to handle tangible and intangible benefits and costs. 


\section{Chapter 3 - Methods}

\subsection{Synopsis}

Chapter 3 discusses the methods used in this research: cluster analysis, association rule learning, and analytic network process (ANP). There is a section devoted to each of the methods. Each section begins with a brief overview of the method in question. Next, the source of the data used with that method is described. Finally, each section concludes with details concerning the researcher's particular implementation of each method. Justification is given for each variation on the methods.

The chapter begins with cluster analysis. Cluster analysis is used to group similar software products together by their functionalities. A binary dataset generated from online research is used for this analysis. Partitional clustering, using the partition-around-mediods algorithm, and the Dice distance metric is implemented for analysis of the binary dataset.

Association rule learning, a common data mining technique, is also introduced. The definition of an association rule is given. Also, three measures of validity for association rules (support, confidence, and lift) are defined. The dataset used for analysis is identical to the one used for cluster analysis. The apriori algorithm is used to search for association rules.

ANP is introduced in the final section of this chapter. This section begins with its relation to the more commonly known analytic hierarchy process (AHP). Next, mathematical details of ANP are provided. The data for ANP is gathered from surveys of two different groups of experts: IT experts and cabinet industry experts. This section concludes with a detailed description and justification of the variations on traditional ANP used by the researcher. These variations include the network structure, scale values, scale increments, preference elicitation method, pairwise comparison reduction method, and response aggregation method.

\subsection{Cluster Analysis}

\subsubsection{Overview}

Cluster analysis is a common technique for assigning observations to different clusters so that each cluster contains similar observations. Cluster analysis has previously been used on 
binary data sets for market segmentation, which closely resembles the data structure of this research (Dolnicar \& Leisch 2004). In this study, cluster analysis will show how products are grouped together by similar functionalities and highlight functionalities that are poorly represented in the industry.

There are at least three considerations with regards to the specific methods employed in cluster analysis. First, one must choose between the two main types of clustering: hierarchical and partitional clustering. In hierarchical clustering, observations are treated as individuals and are incrementally grouped together until one large cluster is formed containing all observations. Oftentimes, a visual tool called a dendrogram is then used to determine the appropriate number of clusters. In partitional clustering, all observations are initially clustered into one group and then partitioned into a predetermined number of clusters $(k)$. For the second consideration, a method must be chosen to either link observations together (in hierarchical clustering) or divide them out (in partitional clustering). Third, a distance measure must be decided upon to calculate the distances between data points (Kaufman et al. 1990).

Even after the specific variant of cluster analysis has been decided upon, there is the task of choosing the "correct" number of clusters. Performance indexes can help in answering this question by plotting a performance value against the number of clusters $(k)$ and choosing the value that minimizes or maximizes the performance index. There are at least 76 different performance indexes available that are appropriate for binary data, the data type used in this analysis (Choi et al. 2010). Additionally, a validation method can be used to verify the clustering results. In this study, a visual method called silhouette widths is used (Rousseeuw 1987).

\subsubsection{Data}

To assess the current state of cabinet industry software, data collection began by examining the exhibitor lists of the most popular North American wood industry trade shows: the 2009 Association of Woodworking \& Furnishing Suppliers (AWFS 2009) show, the 2010 International Woodworking Fair (IWF 2010), and the 2009 Woodworking Machinery \& Supply Expo (WMS 2009). Trade shows have a significant influence on purchasing decisions in the cabinet industry. Attendees of a major 1996 secondary wood products show rated trade shows as 
the most important factor in making machinery purchase decisions (Smith \& Smith 1999). Several other studies have also noted the strong influence of trade shows on purchasing decisions in the wood industry (Smith \& Smith 2000) (Michael 1999). The AWFS 2011 exhibitor prospectus states that $83 \%$ of 2009 visitors attended the show with the intent of purchasing or researching a purchase (AWFS 2011).

Given the importance of trade shows on purchasing decisions, it is reasonable to assume that an exhaustive list of exhibiting software vendors will closely represent the types of software products currently used (or available to be used) in the industry. First, a list of software vendors for AWFS 2009, IWF 2010, and WMS 2009 was obtained performing an online search. Additional vendor research was done using online search engines. Next, each vendor's website and marketing material was reviewed by the researcher to discern the products each sold and their functionalities in order to populate the research dataset. When a product contained a functionality, a "1" was placed in the appropriate cell in an MS Excel spreadsheet, otherwise a “0” was placed in that cell. Each vendor's website was reviewed multiple times to ensure that all available information was collected. The final list contained 149 products sold by 61 vendors.

The software products were evaluated according to their functionality. This study adopted the functionalities described in the International Data Corporation (IDC) Software Taxonomy due its thoroughness, application to commercial-off-the-shelf COTS products, and IDC's high prominence in IT sector research (Heiman 2010). The IDC Software Taxonomy separates COTS products into eight different categories based on their functionality: (1) Consumer applications, (2) Collaborative applications, (3) Content applications, (4) Enterprise resource management (ERM) applications, (5) Supply chain management (SCM) applications, (6) Operations \& manufacturing applications, (7) Engineering applications, and (8) Customer relationship management (CRM) applications. Consumer applications are not included in this study as it focuses solely on business applications. Thus, the final taxonomy, for the purpose of this study, includes seven major groups of functionalities. Within the major groups, there are 32 more specific second-level functionalities, which are the ones being investigated in this study. The research taxonomy and descriptions of each application type can be found in Appendix 2 .

Based on the search results, a database was developed in which the rows were software products and the columns were software functionalities. Each product was evaluated based on 
the presence or absence of each of the functionalities. After reviewing the product information available online, if the functionality was present a " 1 " was assigned in the dataset, otherwise a “ 0 ”. Thus, the final dataset is a 149 × 32 binary matrix (Figure 8 ).

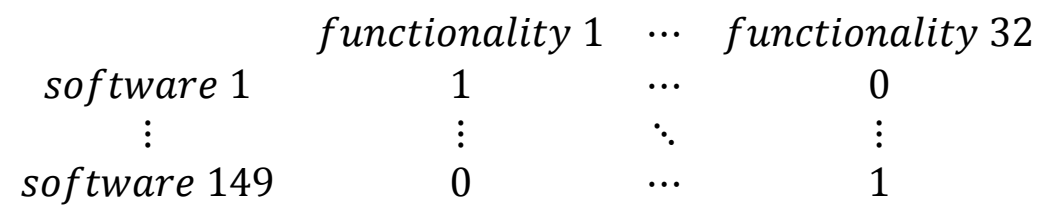

Figure 6: Example of a binary matrix such as the one used in this analysis

\subsubsection{Analysis}

In this study, partitional clustering is used since hierarchical clustering may produce larger errors than partitional methods when used with binary data (Ordonez 2003). Furthermore, the open-source $\mathrm{R}$ software package used in this research (pamk) provides useful performance indexes for validation of the partitional clustering results (Hennig et al. 2010). Since the traditional partitional clustering algorithm, $k$-means, has received some criticism when used with binary data (IBM 2007), a more robust algorithm called partitioning around mediods (PAM) is used in this research (Kaufman et al. 1987).

Since the dataset is binary, a distance measure that is appropriate for binary variables is required. As such, Euclidean distance (the most popular measure) is not used in this study since it is intended for continuous variables and is not appropriate for binary variables (Dillon \& Goldstein 1984). There are distance metrics specific to binary variables, with a recent survey identifying 76 of such measures (Choi et al. 2010). These can be divided into two main categories, symmetric and asymmetric binary. To demonstrate the difference, suppose there are two observations ( $i$ and $j$ ) of a binary variable. There are then four possible outcomes: both $i$ and $j$ have the presence of the variable $(a)$, both $i$ and $j$ have the absence of the variable $(d), i$ has the variable present and $j$ does not $(b)$, and $j$ has the variable present and $i$ does not $(c)$. Figure 9 summarizes these outcomes. 


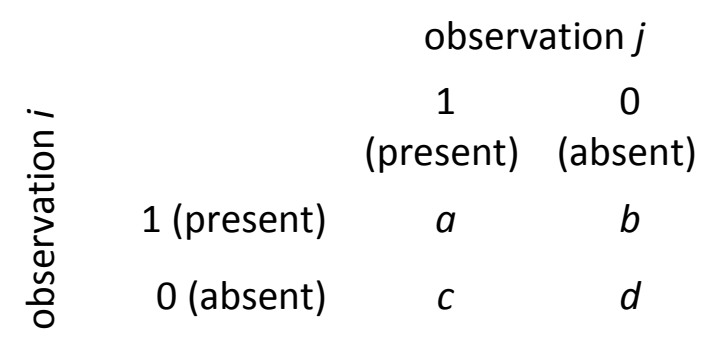

Figure 7: Possible outcomes of a binary variable with two observations

In symmetric binary measures, the positive match $a$ and negative match $d$ are both included in the distance measure. In asymmetric binary measures, $d$ is excluded, meaning the absence of the variable in both observations has no information value. For the data in this research, asymmetric binary measures are more appropriate. This is because the software products have many more functionalities not in common than they have in common. Thus, the functionalities they have in common are their distinguishing features. For example, if two products both do not have instant messaging functionality, that does not make them related because most products also do not have that functionality. The Jaccard and Dice asymmetric measures (Equations 1 and 2) were chosen for comparison since they are suitable for binary variables and are available in the $\mathrm{R}$ software package pamk (Jaccard 1901) (Dice 1945). The difference between these two measures is that Dice gives the positive match $a$ double the weight of $b$ and $c$.

$$
\begin{gathered}
\text { Dice distance }=\frac{2 a}{2 a+b+c} \\
\text { Jaccard distance }=\frac{a}{a+b+c}
\end{gathered}
$$

Milligan \& Cooper (1985) conducted a Monte Carlo simulation of 30 performance indexes and determined that the Calinski-Harabasz index (Equation 3) performed best overall. Dimitriadou et al. (2002) investigated whether similar results would be achieved on only binary data. They found that the Ratkowsky-Lance index performed best overall on binary data. However, they deemed the Calinski-Harabasz index good enough to be put in the 'reliable index' group. Therefore, the Calinski-Harabasz index was chosen because of its acceptable 
performance with binary variables and its availability in the $\mathrm{R}$ software package pamk. The Calinski-Harabasz index is computed as follows:

$$
\text { Calinski }- \text { Harabasz index }=\frac{S S B /(k-1)}{S S W /(n-k)}
$$

Where SSB is the sum of squared distances between every pair of cluster centroids and $S S W$ is the sum of squared distances between a point and the centroid of the cluster it is in, $n$ is the number of data points, and $k$ is the number of clusters. Since this index measures the ratio of $S S B$ to $S S W$, the number of clusters will be determined by the $k$ value that maximizes this index (Calinski \& J. Harabasz 1974).

In order to validate the clustering of observations, a method called silhouette widths can be used (Rousseeuw 1987). This method provides a graphical representation of how well observations are clustered. It indicates whether an observation fits well within its assigned cluster or not by comparing its average dissimilarity with all other observations in the same cluster to its average dissimilarity with observations in any other clusters. For an observation ( $i$ ) assigned to a cluster, a "neighbouring cluster" is a cluster with the next lowest average dissimilarity with $i$. Distance measures are usually used as a measure of dissimilarity. If $i$ is an observation that has been assigned to cluster $A$ and $B$ is the next nearest neighboring cluster for $i$, then we define the silhouette width $s(i)$ as:

$a(i)=$ average dissimilarity of $i$ to all other observations in $A$

$b(i)=$ average dissimilarity of $i$ to all observations in $B$

$$
s(i)=\frac{b(i)-a(i)}{\max \{a(i), b(i)\}}
$$

Silhouette width values range between -1 and 1 . Values close to 1 indicate that the average dissimilarity of the observation to its neighbouring cluster is larger than the average dissimilarity of the observation to its own cluster, so the assignment of the observation is appropriate. Values close to -1 indicate that the observation is misclassified. A value of 0 
essentially means that the observation could be assigned to either cluster indiscriminately (i.e. an intermediate point). Table 1 summarizes the clustering methodology used in this research.

Table 1: Summary of clustering methodology

Clustering type

Partitioning algorithm

Performance index to determine No. of clusters

Distance measure

Cluster validation
Partitioning

Partitioning Around Medoids

Calinski-Harabasz

Dice

Silhouette widths

\subsection{Association Rule Learning}

\subsubsection{Overview}

Association rule learning (ARL) is a popular data mining method for detecting patterns in binary datasets (Kotsiantis \& Kanellopoulos 2006). It was employed in this study to find patterns of association between the functionalities represented in cabinet industry software products. Frequently occurring associations between functionalities give an indication of how software is used to complete complex, integrated business processes.

An association rule consists of a left-hand side (LHS) and a right-hand side (RHS), whereby the combination of items on the LHS are frequently found together with the combination of items on the RHS. The rule is written in the form $\{$ LHS $\} \rightarrow\{$ RHS $\}$. For example, in manufacturing software, a common association could be computer-aided drawing $(\mathrm{CAD})\} \rightarrow\{$ computer-aided machining $(\mathrm{CAM})\}$ because these two functionalities are often sold together in the same package.

If we consider an association rule $\{\mathrm{X}\} \rightarrow\{\mathrm{Y}\}$, three metrics called support, confidence, and lift are commonly used to measure the validity of that rule. Support is simply the proportion of all observations that contain the association rule (Equation 5). Confidence is the ratio of all observations that contain $X$ and $Y$ to the number of observations containing only $X$ (Equation 6). Lift is the ratio of observed support to expected support if $X$ and $Y$ were independent (Equation 7). It measures the association rule against random association. 


$$
\begin{gathered}
\operatorname{support}(x \rightarrow y)=P(X \cup Y)=\frac{\text { support count }}{n} \\
\operatorname{confidence}(x \rightarrow y)=P(X \mid Y)=\frac{P(X \cup Y)}{P(X)} \\
\operatorname{lift}(x \rightarrow y)=\frac{P(X \cup Y)}{P(X) P(Y)}
\end{gathered}
$$

where $n$ is the total number of observations in the dataset and support count is the total number of instances of the association rule $\{X\} \rightarrow\{Y\}$ in the dataset (Agrawal et al. 1993).

\subsubsection{Data}

The dataset used for association rule learning is identical to that used for cluster analysis (see Section 3.2.2).

\subsubsection{Analysis}

There are several search algorithms used with association rule learning to discover association rules. The apriori algorithm was used in this research because of its popularity in data mining and its availability in the arules R software package used (Hahsler et al. 2007).

There are three main steps to the apriori algorithm (Agrawal et al. 1993). First, frequent (or large) itemsets of size $k\left(L_{k}\right)$ are generated from all possible candidate itemsets of size $k\left(C_{k}\right)$ by performing the operation $C_{k}=L_{k-1}$ Join $L_{k-1}$, where "Join" is the set of all possible unique combinations of a sequence of numbers. This is called the join step. Next, the apriori property says that a frequent itemset can only achieve the minimum support count if all of its subsets also achieve the minimum support $\left(S_{\text {min }}\right)$ (Equation 5). Thus, we do not consider any itemsets $c \in C_{k}$ if the $(k-1)$ subset is not present in $L_{k-1}$. This is called the prune step because of the "pruning" of possible candidates. This step is critical for the algorithm's performance because in large databases the number of unique combinations of $C_{k}$ gets exponentially large. These first two steps are repeated for each $k+1$ itemset size until a $k^{\text {th }}$ size is reached where none of the $k-1$ subsets can achieve the minimum support count (i.e. support count $\left(L_{k-1}\right)<\mathrm{S}$ ). Once the loop is broken, the last step is the generation of association rules from the frequent itemsets. In this step, only the association rules that are equal to or greater than the minimum confidence $\left(\mathrm{Q}_{\min }\right)$ (Equation 6) are kept. 
Pseudo code of the apriori algorithm has been adapted from Agrawal et al. 1993 and is given below. Additionally, a flowchart visualization of the algorithm is provided in Figure 8.

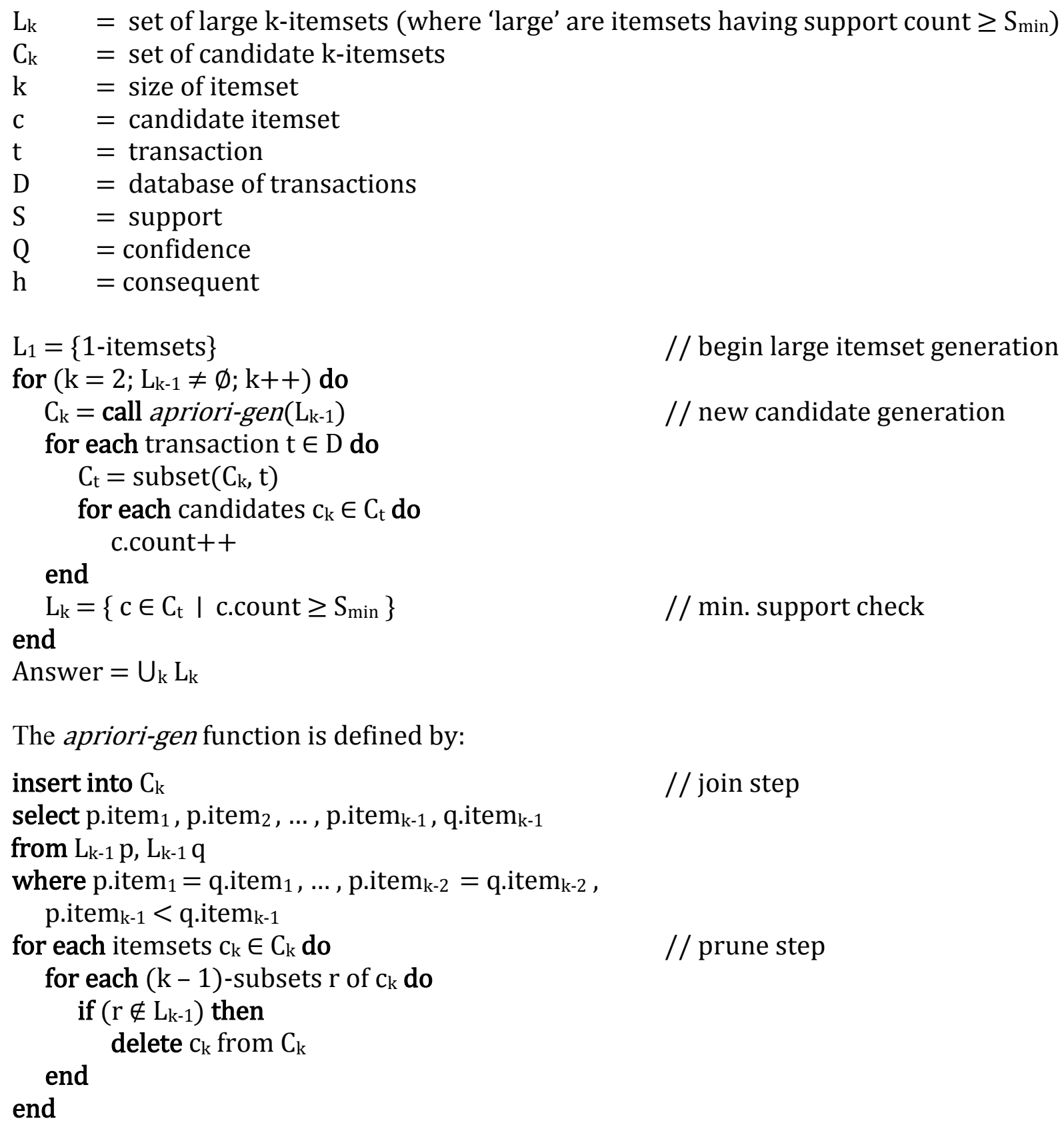

for each $\mathrm{l}_{\mathrm{k}} \in \mathrm{L}_{\mathrm{k}}, \mathrm{k} \geq 2$ do

// begin rule generation

$\mathrm{H}_{1}=\{$ consequents of rules from 1 with one item in the consequent $\}$

call ap-genrules $\left(\mathrm{l}_{\mathrm{k}}, \mathrm{H}_{1}\right)$ end 
Where the ap-genrules function is defined by:

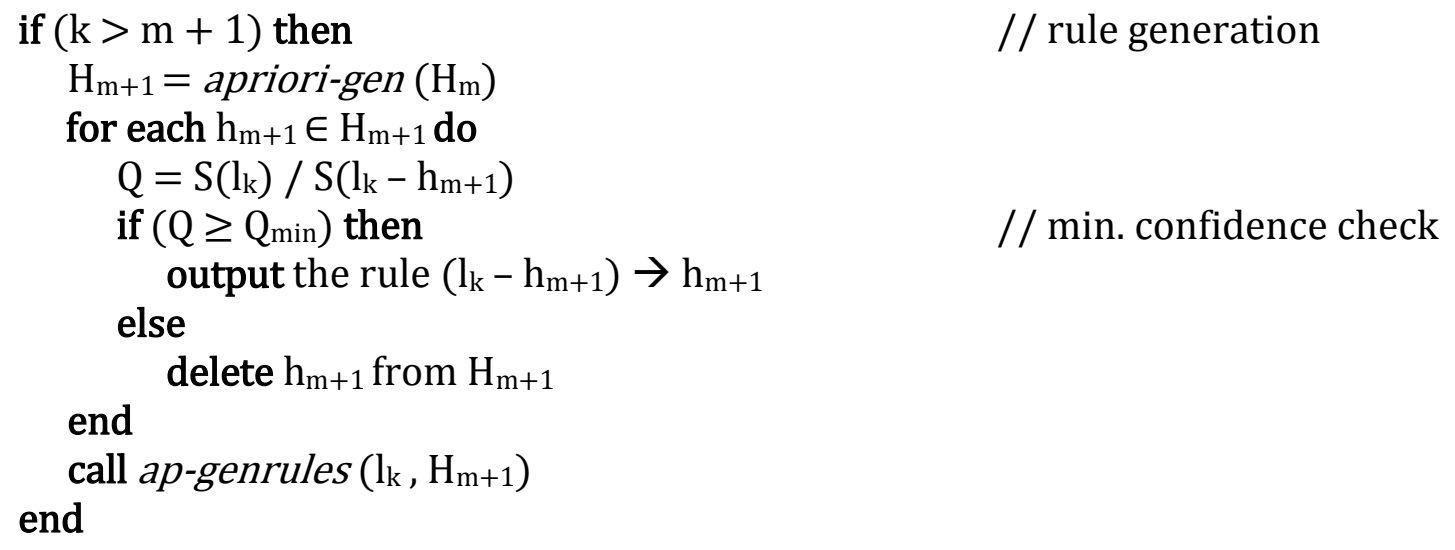




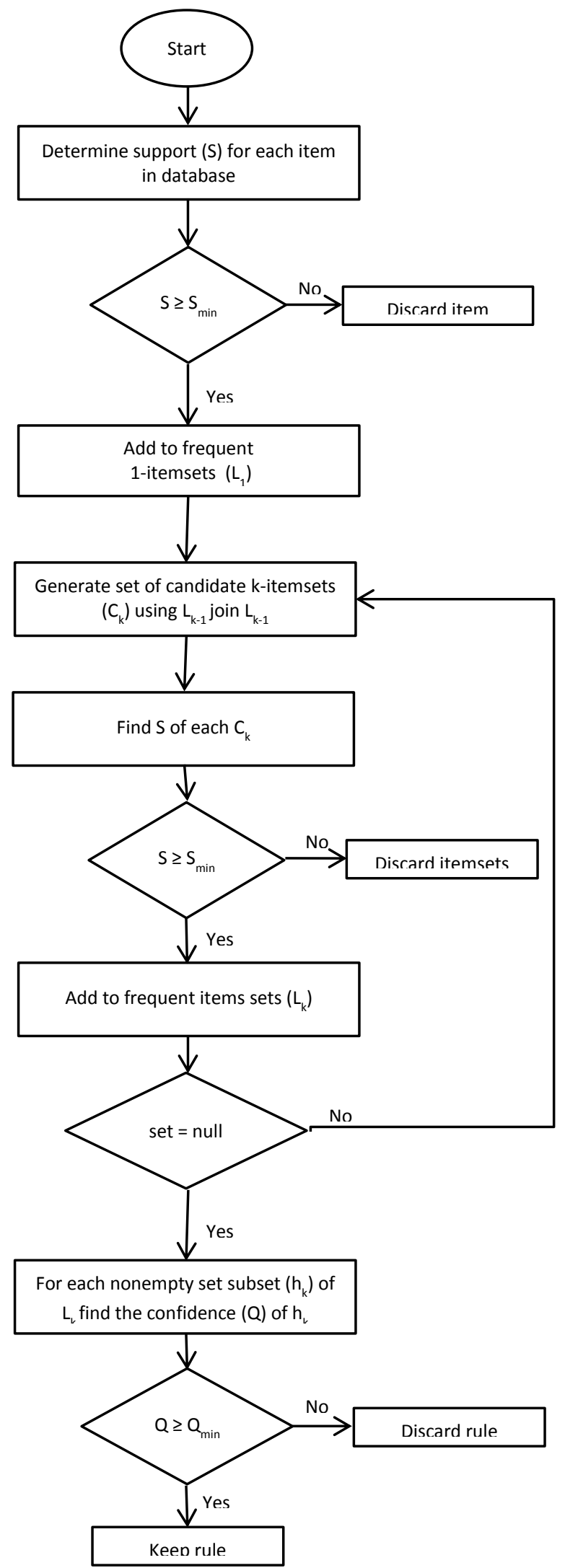

Figure 8: Flowchart briefly explaining the steps of the apriori algortihm 


\subsection{Analytic Hierarchy / Network Process}

\subsubsection{Overview}

The Analytical Hierarchy Process (AHP) and Analytical Network Process (ANP) were developed by Dr. Thomas L. Saaty (Saaty 1980; Saaty 1996). AHP and ANP are methods of decomposing a multi-criteria decision problem into its objective, criteria, and alternatives components and then structuring the components into either a hierarchy (Figure 9) or network structure (Figure 10). The primary difference between AHP and ANP is that AHP assumes that different alternatives and different criteria are independent of each other. In ANP, the influence of alternatives and criteria on one another is considered. The ultimate goal of both methods is to determine the best alternative for a decision.

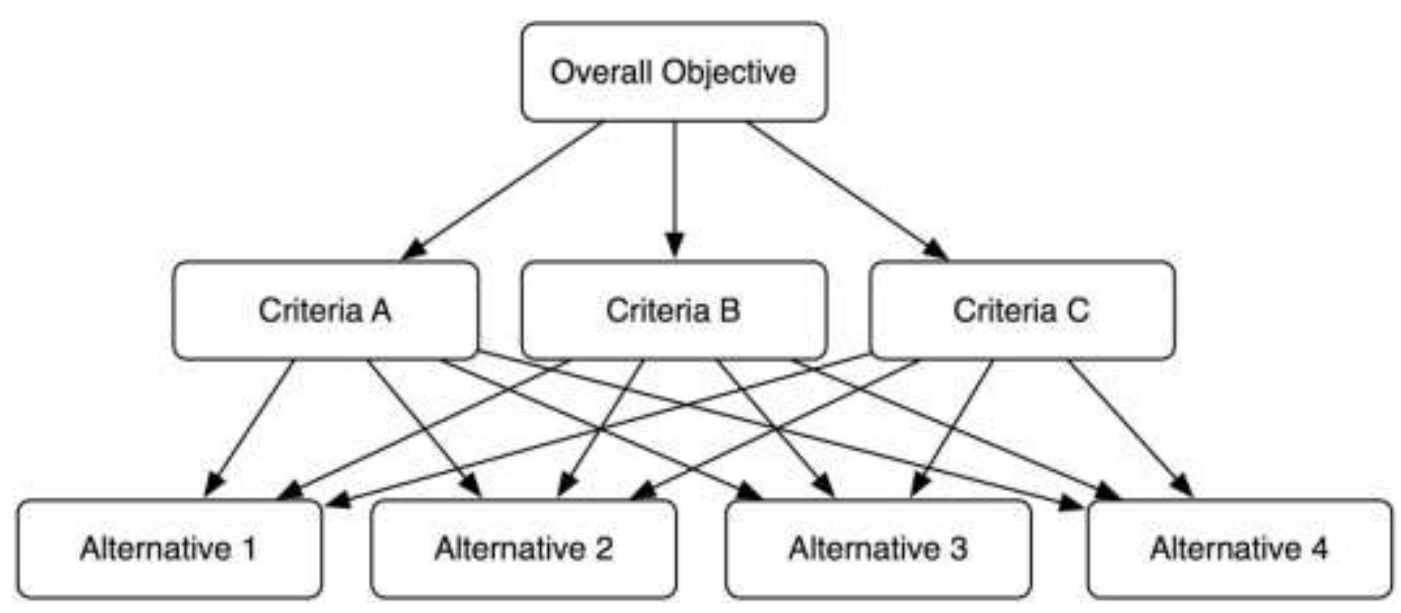

Figure 9: A basic hierarchy structure for use with AHP. 


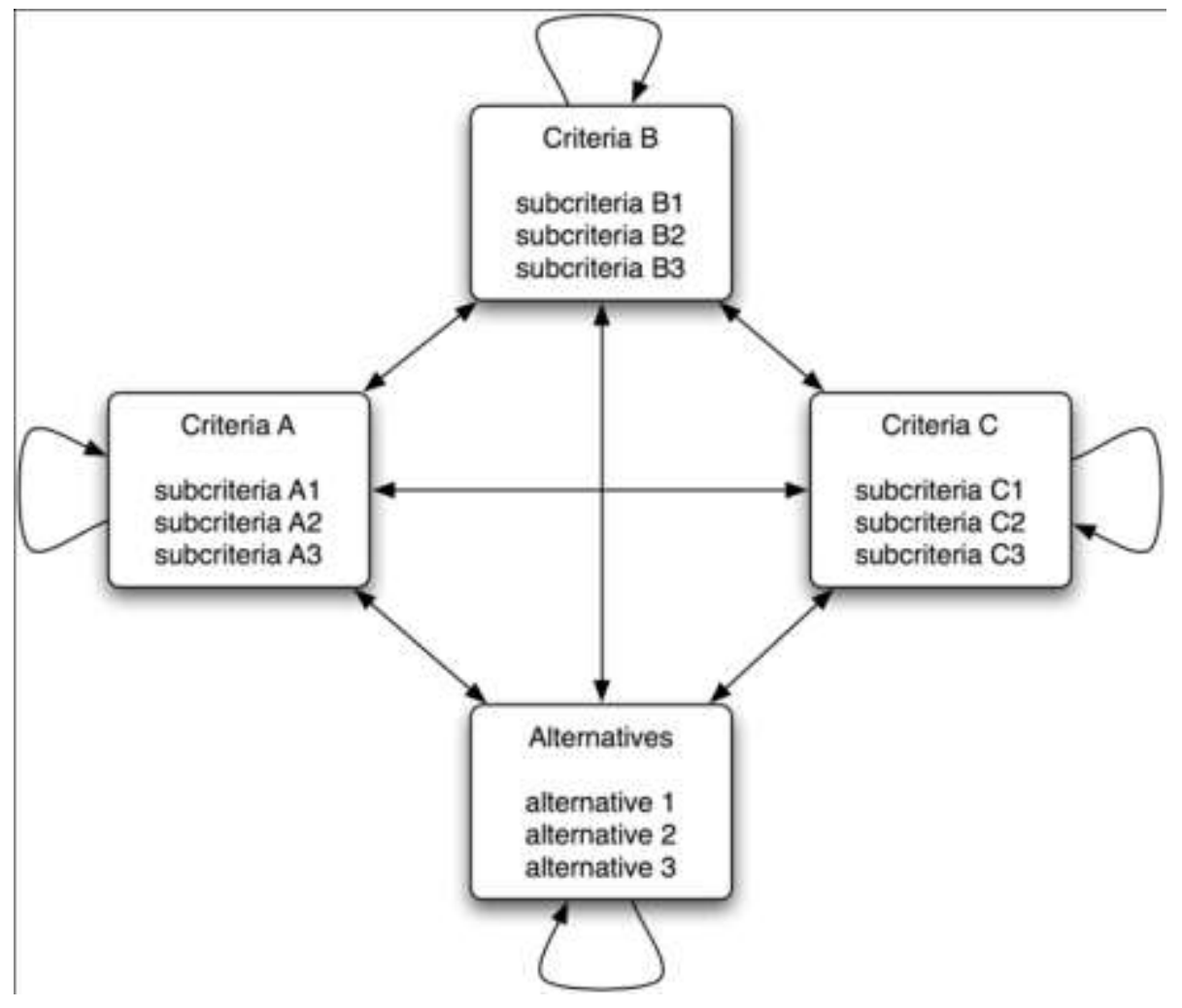

Figure 10: A basic network structure for use with ANP

For the model input, a decision maker is asked a series of pairwise comparison questions. The pairwise comparisons represent a ratio of preference (or importance) for one alternative (or criteria) over another with respect to a higher-level criterion, using a predetermined scale. These comparisons are placed into a pairwise comparison matrix (PCM) (Equation 8).

$$
A=\left[\begin{array}{ccc}
\frac{w_{1}}{w_{1}} & \cdots & \frac{w_{1}}{w_{n}} \\
\vdots & \ddots & \vdots \\
\frac{w_{n}}{w_{1}} & \cdots & \frac{w_{n}}{w_{n}}
\end{array}\right]
$$

where $\mathrm{A}$ is the pairwise comparison matrix, $w_{1}$ is the weight of preference for alternative (or criterion) 1 and $n$ is the number of alternatives (or criteria) being compared in the PCM. The ratio of the weight of alternatives $i$ and $j$ is represented by a single number in the PCM $\left(a_{i j}=w_{i}\right)$ $w_{j}$ ) (Saaty 1990).

In a PCM, the inverse judgment is assumed to be the reciprocal of the original judgment $\left(a_{j i}=1 / a_{i j}\right)$. Also, an alternative compared to itself is equally important to itself and thus has a 
value of $1\left(a_{i i}=1\right)$. Consequently, a standard PCM is always a reciprocal matrix with the sum of the trace equal to $n$ (Saaty 1990).

If a pairwise comparison matrix $A$ is multiplied by the vector of alternative weights $w$, we get the equation $A w=c w$ (Equation 9). If $c$ is an eigenvalue of $A$, then $w$ is the eigenvector corresponding to $c$. It has been shown that the eigenvector representing the weights of the alternatives is the one associated with the largest eigenvalue. Therefore, the priority vector $w$ is the principle right eigenvector of $A$. This priority vector is then normalized so that it sums to unity (Saaty 1990).

$$
A w=\left[\begin{array}{cccc}
1 & a_{12} & \cdots & a_{1 n} \\
\frac{1}{a_{12}} & 1 & \cdots & a_{2 n} \\
\vdots & \vdots & \ddots & \vdots \\
\frac{1}{a_{1 n}} & \frac{1}{a_{2 n}} & \cdots & 1
\end{array}\right]\left[\begin{array}{c}
w_{1} \\
\vdots \\
\vdots \\
\vdots \\
\vdots \\
w_{n}
\end{array}\right]=c w
$$

In AHP and ANP there will be multiple PCMs, depending on the structure of the model. For example, in a simple three level hierarchy as shown in Figure 9, there will be a PCM comparing the criteria with respect to the overall objective and PCMs comparing the alternatives with respect to each criterion (one for each criterion). To determine the final priorities of alternatives, each pairwise comparison matrix $A_{i j}$ is placed into the supermatrix (Equation 10). Each PCMs placement in the supermatrix is determined by how it spreads influence, as indicated by connecting arrows in the structure. Once the supermatrix is obtained, its Cesaro Sum is calculated until the supermatrix converges on a unique limit (Equation 11). When a stable limit is achieved, the final priorities of the alternatives can be found within the supermatrix. This lengthy process has been automated in the SuperDecisions software package used in this research (Adams and Saaty 2003).

$$
W=\left[\begin{array}{cccc}
A_{11} & A_{12} & \cdots & A_{1 n} \\
A_{21} & A_{22} & \cdots & A_{21} \\
\vdots & \vdots & \ddots & \vdots \\
A_{n 1} & A_{n 2} & \cdots & A_{n n}
\end{array}\right]
$$




$$
\lim _{k \rightarrow \infty} \frac{1}{N} \sum_{k=1}^{N} W^{k}
$$

AHP and ANP have a measure for logical inconsistency as defined by the transitivity principle $\left(a_{i j}{ }^{*} a_{j k}=a_{i k}\right)$. That is, if alternative $i$ is $a_{i j}$ times more preferred than $j$ and $j$ is $a_{j k}$ times more preferred than $k$, then $i$ should be $a_{i j}{ }^{*} a_{j k}$ times more preferred than $k$. In a perfectly consistent PCM, all elements of the matrix adhere to the transitivity principle. In the special case where PCM is perfectly consistent, $\lambda_{\max }=n$, where $\lambda_{\max }$ is the maximum (or principal) eigenvalue of the PCM.

However, due to the inconsistency of human thinking, it is rare that a PCM is perfectly consistent. Thus, we measure the logical consistency of a PCM using a consistency ratio (CR), given by the following equation:

$$
C R=\frac{C I}{R I}
$$

where CI is the Consistency Index and RI is the Random Index. The RI values are the average principal eigenvalues of a large set of randomly generated PCMs and is given by the table below.

Table 2: The random index for computing the consistency ratio

\begin{tabular}{|rcccccccc|}
\hline matrix size & 3 & 4 & 5 & 6 & 7 & 8 & 9 & 10 \\
\hline RI & 0.52 & 0.89 & 1.11 & 1.25 & 1.35 & 1.40 & 1.45 & 1.49 \\
\hline
\end{tabular}

The CI is given by the following equation:

$$
C I=\frac{\left(\lambda_{\max }-n\right)}{n-1}
$$

Thus, the CR is the percentage of inconsistency in the decision maker's PCM compared to a randomly generated PCM. It is very unlikely that a human will be perfectly consistent in their judgments, but we would like them to be within an acceptable range of inconsistency. It is generally accepted that the CR should not exceed 0.10 (Saaty 2005). 
In a group decision making problem such as the one used in this research, it is also helpful to determine the level of agreement or consensus between the individual decision makers. Since, priorities are given as vectors, this can be considered a distance or angle between two vectors problem. There are a number of ways to compute such a distance or angle. Euclidean distance and the sine of the angle between vectors have been suggested for use with AHP/ANP consensus (Herrera-Viedma et al. 2005) (Bryson 1996). The sine of the vector-angle method was chosen for this study for two reasons. First, it is independent of the magnitude of the vector, unlike Euclidean distances. Second, the values range from $0-1$ with increasing values meaning increasing consensus. This is convenient because it is consistent with many of the other measures in this study being on a $0-1$ scale. The consensus measure is adopted from Bryson (1996) and is defined as:

$$
s\left(w^{t}, w^{G M}\right)=1-\sin \left(w^{t}, w^{G M}\right)
$$

where $w^{t}$ is the priority vector of decision maker $t$ and $w^{G M}$ is the priority vector resulting from the geometric mean of all decision makers' vectors. Thus, $s\left(w^{t}, w^{G M}\right)$ is a measure of the level of agreement between an individual and the group consensus as determined by the geometric mean. If $s\left(w^{t}, w^{G M}\right)$ is less than a threshold value $(\alpha)$, then we say the individual disagrees with the group consensus. The most appropriate value for $\alpha$ is not known clearly. Likewise, we adopt the value arbitrarily established by Bryson (1996) at 0.826 . This means that two vectors should not have an angle greater than $10^{\circ}$ between them to be considered in agreement.

\subsubsection{Data}

Data for the ANP model was obtained through expert response to surveys. To recruit experts, first a list of potential qualified experts was compiled using the personal recommendations of academics and professionals in the wood industry. Additionally, a list of Management Information Systems experts was gathered through perusing the citation lists of the relevant literature. Since, the first round of recruitment did gather enough willing participants for the strategy group, a 'call for experts' was posted on the Internet's largest woodworking forum (www.woodweb.com). To be considered an "expert" a candidate needed at least five years of relevant experience and be able to demonstrate knowledge of the subject area. In total, nine experts completed surveys (Table 3 ). 
Because the experts were located across North America, the survey was deployed using SurveyGizmo $^{\circledR}$, a web-based surveying software (SurveyGizmo Inc. 2011). Once the surveys were completed, responses corresponding to complete PCMs were transferred directly into the SuperDecisions ${ }^{\circledR}$ software. Responses corresponding to incomplete PCMs (see Section 3.4.3.5) could not be directly transferred into SuperDecisions ${ }^{\circledR}$ because the software only supports the calculation of complete PCMs. To overcome this, the principal right eigenvector of the incomplete PCMs was calculated using an MS Excel plugin called PopTools ${ }^{\circledR}$ (Hood 2009). These eigenvectors could then be transferred into SuperDecisions ${ }^{\circledR}$.

Table 1: Composition of expert groups

\begin{tabular}{|c|c|c|c|c|}
\hline & $\begin{array}{c}\text { Decision } \\
\text { Maker (DM) }\end{array}$ & $\begin{array}{c}\text { Years of } \\
\text { Experience }\end{array}$ & $\begin{array}{c}\text { State / } \\
\text { Province }\end{array}$ & Occupation \\
\hline \multirow{5}{*}{ 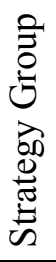 } & $\mathrm{DM}_{1}$ & 38 & $\mathrm{ON}$ & Industry consultant \\
\hline & $\mathrm{DM}_{2}$ & 27 & $\mathrm{BC}$ & Industry consultant \\
\hline & $\mathrm{DM}_{3}$ & 17 & $\mathrm{BC}$ & Production manager \\
\hline & $\mathrm{DM}_{4}$ & 15 & $\mathrm{BC}$ & Production manager \\
\hline & $\mathrm{DM}_{5}$ & 7 & $\mathrm{ON}$ & Production manager \\
\hline \multirow{4}{*}{ 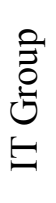 } & $\mathrm{DM}_{6}$ & 21 & $\mathrm{BC}$ & Professor of Management Information Systems \\
\hline & $\mathrm{DM}_{7}$ & 12 & $\mathrm{BC}$ & Professor of Management Information Systems \\
\hline & $\mathrm{DM}_{8}$ & 12 & $\mathrm{ON}$ & Software company president** \\
\hline & $\mathrm{DM}_{9}$ & 11 & FL* & Technical manager, owner/operator \\
\hline
\end{tabular}

*It is acceptable for an expert in the IT group to be outside Canada, since these questions are country independent **Since $\mathrm{DM}_{8}$ represents a software vendor, any potential bias was tested. The final rankings of software applications did not change with $\mathrm{DM}_{8}$ 's responses included, so they were retained for the analysis.

Two surveys were administered because there were two expert groups involved: the technology group and the strategy group. The technology group determined how each software application type contributes to each competitive capability. The strategy group determined the priorities of competitive strategies and the strength of relationships between different competitive capabilities.

The survey design was driven by the ANP model. There were two general types of question: ranking questions and pairwise comparison questions. Below are examples of ranking type questions, depending on the expert group. 
Strategy group:

"Rank the list of competitive capabilities (product flexibility, process flexibility, skilled labour, conformance quality, delivery speed) from having the most to least influence on delivery dependability."

Technology group:

"Rank the list of software applications (Supply Chain Management, Enterprise Resource Management, Content, Collaboration, Operations \& Engineering, Customer Relationship Management) from providing the most to the least contribution towards conformance quality."

The pairwise comparison questions followed the general format below, where $\mathrm{X} \mathrm{Z}$ is always a competitive capability, and $\mathrm{X}$ and $\mathrm{Y}$ are both either a software application type (technology group) or another pair of competitive capabilities (strategy group) different from Z.

"With regards to $Z$, is $X$ or $Y$ more important and how much more important"

The responses available for the pairwise comparison questions were: equally, moderately, strongly, very strongly, and extremely. These verbal responses correspond to the standard verbal scales used with AHP/ANP (see Section 3.4.1).

Several measures were taken to improve the respondents' experience. First, the number of questions was reduced dramatically using a method for reducing the number of pairwise comparisons required for calculating an eigenvector (see Section 3.4.3.5). Second, surveys were administered using web-based software that allowed the user to partially complete the survey, save the results, and continue at a later time. Third, each survey page included a hyperlinked glossary of terms used in the survey. This was important to ensure that all experts had the same definition to work from. In addition, the survey software had a graphical progress bar and grouped multiple related questions on the same page. These two techniques have been shown to improve respondent motivation to finish the survey (Couper et al. 2001).

Non-response bias is a common issue that is normally addressed in research involving surveys (Fowler 2009). However, this specific bias is considered inconsequential here because this study only samples experts, not from the population. Since this research utilizes expert 
responses and does not intend to make inferences on a population, the standard survey sampling concerns are less applicable but still relevant. Ideally, the industry experts should be distributed across Canada to take into account geographical differences in competitive strategies. Also, since firm size and export intensity can heavily influence competitive strategy, it would be ideal to separate industry experts by firm size and export intensity. At a practical level, though, the researcher found it difficult to recruit enough qualified experts to meet these ideal sampling conditions. Additionally, it would be difficult to categorize an industry consultant as belonging to a certain category if that person consults with firms of all types. For IT experts, concerns regarding geographic location, firm size, and export intensity are less applicable because it is assumed that a software application's contribution to a particular competitive capability is largely independent of these variables.

\subsubsection{Analysis}

\subsubsection{Model Structure}

One of the major assumptions of AHP is that the criteria and alternatives are independent of each other. However, this is oftentimes a poor assumption in real-world decision scenarios. ANP was developed by Saaty to overcome the independence assumption of AHP. In AHP, the structure is linear, with influence and dependence flowing top-down. Elements are compared with respect to the element above it in the structure. In ANP, the structure flows out in all directions creating a network of interactions between all criteria and alternatives, thus allowing for feedback between criteria and alternatives. This more complex view of a decision problem as a system of feedback loops is oftentimes a better reflection of reality (T. Saaty 2006).

This research is concerned with how software applications can contribute to different competitive capabilities. When modeling competitive capabilities, it is important to consider their interdependencies. Capabilities do not function in isolation. Rather, they operate in a dynamic system, constantly changing and influencing each other (Dangayach \& Deshmukh 2001). Likewise, these capabilities should be modeled in a network to reflect this dynamic systems view of capabilities.

An informal meta-analysis of 32 papers on manufacturing competitive capabilities was conducted to determine the capabilities relevant to the cabinet industry and the relationships 
between those capabilities. Definitions of competitive capabilities can be found in Appendix 3 . When more than one paper demonstrated the significance of a capability and/or showed evidence of a relationship between capabilities, it was included in the model (Table 4). In the SuperDecisions $^{\circledR}$ software, this network of relationships between competitive capabilities is represented by an arrow looping back into itself (Figure 11). The final model had five criteria, 11 subcriteria, and six alternatives.

Table 2: Relationships between competitive capabilities.

\begin{tabular}{|c|c|c|c|}
\hline $\begin{array}{l}\text { Capability } \\
\text { receiving influence }\end{array}$ & $\begin{array}{l}\text { Capabilities } \\
\text { contributing influence }\end{array}$ & $\begin{array}{l}\text { Capability } \\
\text { receiving influence }\end{array}$ & $\begin{array}{l}\text { Capabilities } \\
\text { contributing influence }\end{array}$ \\
\hline \multirow[t]{2}{*}{ Low operating cost } & $\begin{array}{l}\text { Conformance quality } \\
\text { Skilled labour } \\
\text { Delivery speed }\end{array}$ & Delivery speed & $\begin{array}{l}\text { Conformance quality } \\
\text { Product flexibility } \\
\text { Process flexibility }\end{array}$ \\
\hline & Delivery quality & \multirow{3}{*}{ Delivery dependability } & Conformance quality \\
\hline Performance quality & $\begin{array}{l}\text { Product flexibility } \\
\text { Skilled labour } \\
\text { Customer service }\end{array}$ & & $\begin{array}{l}\text { Product flexibility } \\
\text { Skilled labour } \\
\text { Process flexibility }\end{array}$ \\
\hline \multirow{2}{*}{ Conformance quality } & \multirow{2}{*}{$\begin{array}{l}\text { Product flexibility } \\
\text { Skilled labour }\end{array}$} & & Delivery speed \\
\hline & & \multirow{3}{*}{ Advertising } & Performance quality \\
\hline Product flexibility & $\begin{array}{l}\text { Skilled labour } \\
\text { Process flexibility } \\
\text { Market research }\end{array}$ & & $\begin{array}{l}\text { Product flexibility } \\
\text { Delivery speed } \\
\text { Delivery dependability }\end{array}$ \\
\hline \multirow[t]{2}{*}{ Skilled labour } & $\begin{array}{l}\text { Performance quality } \\
\text { Product flexibility }\end{array}$ & & $\begin{array}{l}\text { Customer service } \\
\text { Market research }\end{array}$ \\
\hline & Advertising & \multirow{3}{*}{ Customer service } & Skilled labour \\
\hline Process flexibility & $\begin{array}{l}\text { Conformance quality } \\
\text { Delivery speed }\end{array}$ & & $\begin{array}{l}\text { Delivery speed } \\
\text { Delivery dependability }\end{array}$ \\
\hline Market research & Skilled labour & & Market research \\
\hline
\end{tabular}




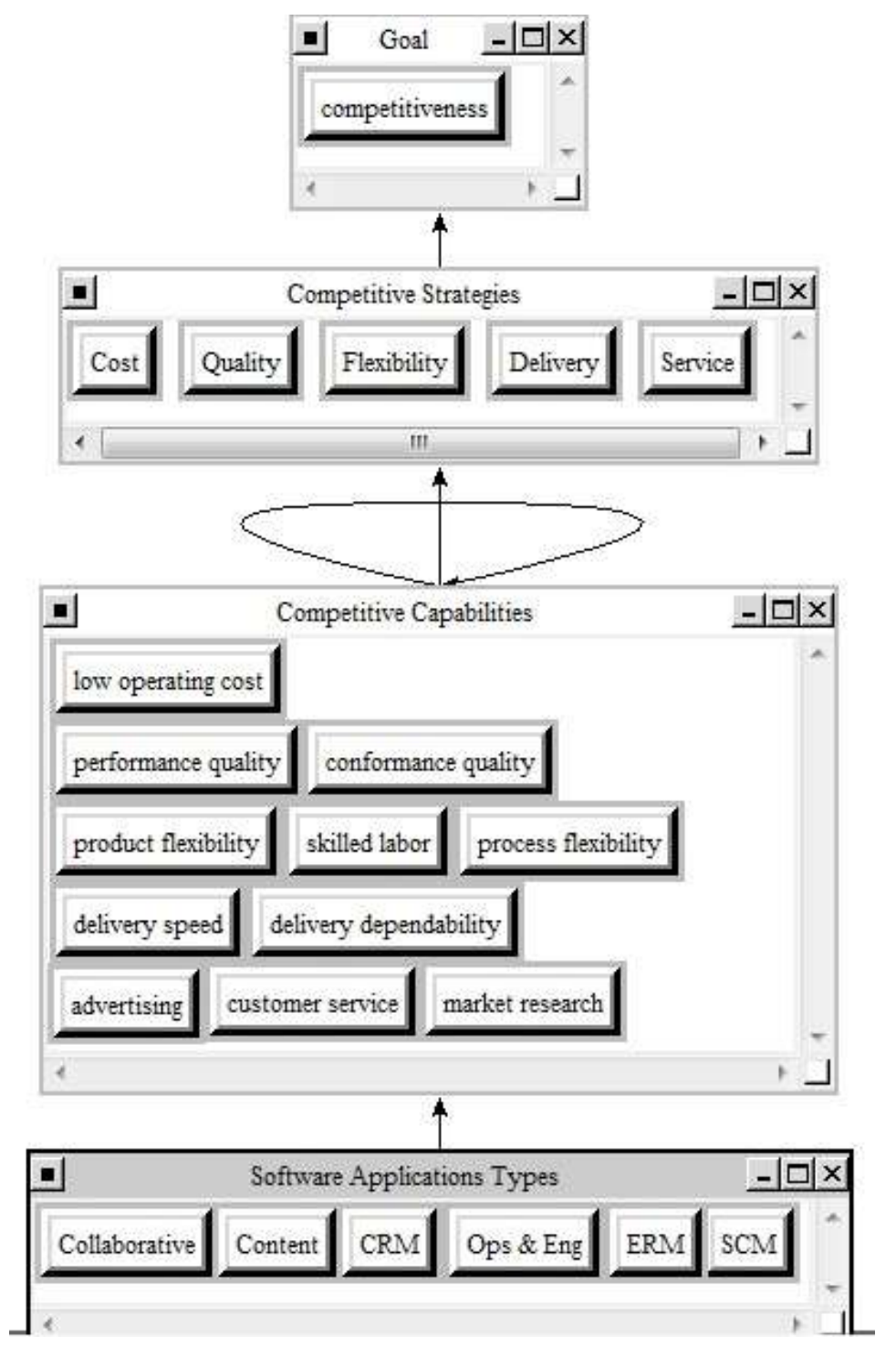

Figure 11: The ANP model used in the study as seen in the SuperDecisions ${ }^{\circledR}$ software

\subsubsection{Scale Values}

Traditionally, the scale used for pairwise comparisons are the integers from 1 to 9 as shown in Equation 15. This is generally referred to as the Saaty scale or the integer scale. The value 1 represents two alternatives being equally important and 9 represents one alternative being extremely more important over the other one. Between the major levels of importance (or preference), there are four intermediate levels (Table 5). This scale has been the subject of intense academic debate. Some of the more popularly suggested alternative scales are the exponential scale (Lootsma 1989) and the balanced scale (Salo \& Hämäläinen 1997). The recently proposed power scale will also be considered for comparison (Elliott 2010). 
Table 3: Four possible AHP scales with values shown up to 9 increments. Even increments are intermediate values between odd increments.

\begin{tabular}{|cccccc|}
\hline & & $\begin{array}{c}\text { Saaty } \\
\text { scale }\end{array}$ & $\begin{array}{c}\text { Exponential } \\
\text { scale } \\
(\mathbf{1}+\boldsymbol{\varepsilon}=\mathbf{2})\end{array}$ & $\begin{array}{c}\text { Balanced } \\
\text { scale } \\
(\boldsymbol{s}=\mathbf{1} / \mathbf{2 0})\end{array}$ & $\begin{array}{c}\text { Power } \\
\text { scale }\end{array}$ \\
\hline equally & $\left(s_{1}\right)$ & 1 & 1 & 1 & $\sqrt[8]{9}^{0}$ \\
intermediate & $\left(s_{2}\right)$ & 2 & 2 & $11 / 9$ & $\sqrt[8]{9}^{1}$ \\
moderately & $\left(s_{3}\right)$ & 3 & 4 & $3 / 2$ & $\sqrt[8]{9}^{2}$ \\
intermediate & $\left(s_{4}\right)$ & 4 & 8 & $13 / 7$ & $\sqrt[8]{9}^{3}$ \\
strongly & $\left(s_{5}\right)$ & 5 & 16 & $7 / 3$ & $\sqrt[8]{9}^{4}$ \\
intermediate & $\left(s_{6}\right)$ & 6 & 32 & 3 & $\sqrt[8]{9}^{5}$ \\
very strongly & $\left(s_{7}\right)$ & 7 & 64 & 4 & $\sqrt[8]{9}^{6}$ \\
intermediate & $\left(s_{8}\right)$ & 8 & 128 & $17 / 3$ & $\sqrt[8]{9}^{7}$ \\
extremely & $\left(s_{9}\right)$ & 9 & 256 & 9 & $\sqrt[8]{9}^{8}$ \\
\hline
\end{tabular}

Saaty has provided several justifications for developing the 1 - 9 scale. First, the WeberFechner law of stimulus response states that humans can perceive a change in stimulus (e.g. weight of an object) only if the amount of change is a constant percentage of the stimulus itself. This theory states that the magnitude of stimuli follows a geometric progression and the perception of the stimuli follows an arithmetic progression (Saaty 1980). Second, the psychologist George Miller (1956), has famously observed that most people cannot simultaneously process more than $7 \pm 2$ pieces of information at one time. Finally, the principal eigenvector used to determine the priorities is unstable to large scale values. Thus, Saaty established an upper-bound of 9 on the scale. This line of reasoning led Saaty to incorporate the homogeneity axiom into AHP, which states that any alternatives being compared must be within one order of magnitude of each other. If they are not, then an intermediate comparison step should be used (Saaty \& Ozdemir 2003).

$$
s_{i}=i
$$

where $s_{i}$ is the $i^{\text {th }}$ stimulus

The exponential, or geometric scale (Equation 16) was first introduced by Lootsma in 1989 (Lootsma 1989). The origins of this scale are rooted in Roberts' (1979) work in the psychology of stimulus perception. It has been observed that a difference in stimulus $s_{i+1}-s_{i}$ is 
only perceived if that difference is greater than or equal to the smallest perceptible difference, which is proportional to the initial stimulus $s_{i}$ (Roberts 1979). This exponential progression of perception has been observed in the loudness of sounds and the brightness of light (Triantaphyllou 2000).

$$
s_{i}=e^{\gamma(i-1)}
$$

where $\gamma=\ln (1+\varepsilon)$ is the scale parameter, $(1+\varepsilon)$ is the progression factor, and $s_{i}$ is the $i^{\text {th }}$ stimulus. The question of determining the best progression factor has received criticism from Saaty because it has such a significant effect on the scale values (Saaty 1991).

Salo \& Hamalainen (1997) introduced an alternative scale that is referred to as the balanced scale (Equation 17). They argued that the Saaty scale is not balanced because, for example, increasing a judgment from 1 to 2 will result in weighting 15 times greater than increasing from 8 to 9 . The Saaty scale will tend to produce a high difference between two alternatives' weights because more weights are possible on the extreme ends of the $0-1$ range. Alternatively, the balanced scale produces possible weights that are evenly distributed on the $0-$ 1 range for a scenario with two alternatives. The logic is that the scale being used should not have a preference for one set of weights over another.

$$
s_{i}=\frac{0.5+(i-1) s}{0.5-(i-1) s}
$$

where $s=\frac{1}{20}$ and $s_{i}$ is the $i^{\text {th }}$ stimulus

The balanced scale produces a uniform priority distribution for PCMs involving two alternatives or criteria. In PCMs with three or more alternatives, some clustering of priority weights becomes evident (indicated by blue circles). It is very unlikely that a real-world decision would involve only two alternatives or criteria. This limitation of the balanced scale was the inspiration for Elliot's (2010) power scale as defined by Equation 18. The power scale produces uniform priority distributions for PCMs with more than two alternatives or criteria (Elliott 2010).

$$
s_{i}=\sqrt[n-1]{9}{ }^{i}
$$

where $n=\#$ of echelons or increments of the scale and $s_{i}$ is the $i^{\text {th }}$ stimulus 
Simulations have been done by researchers to determine if one scale outperforms the others. (Dong et al. 2008) ran a simulation on the Saaty scale, exponential scale, and balanced scale using two performance metrics. The first performance metric measured the difference between the initial, discrete PCM given by the decision maker and the continuous PCM of the derived priority vector. The second performance metric is the root-mean-square deviation between the true and derived priority vector. The results of the simulation showed that the exponential and balanced scales consistently outperformed the Saaty scale on both performance metrics. Furthermore, the exponential scale with $(1+\varepsilon)=2$ performed the best (Dong et al. 2008). Numerous other researchers, through separate simulations, have also concluded that the best progression factor is between $\sqrt{2}$ and 2 (Ze 2000) (Satoh 1999); (Ji \& Jiang 2003) (Finan \& Hurley 1999) (Lootsma 1993). Ultimately, though, the exponential scale was not included in this study because it violates the homogeneity axiom for all the commonly proposed progression factors.

Beynon (2002) ran a simulation to determine the probability distributions of acceptable priority values resulting from different AHP scales. "Acceptable", in this context, means any priority vector resulting from a PCM that has a $C R \leq 10 \%$. The Saaty scale was found to have narrower distributions for each weight, with lower means for the lowest ranked alternative and higher means for the highest ranked alternatives than the other scales considered in the study. This may lead to an artificially low weight for the lowest ranked alternative and artificially high weight for the highest ranked alternative (Beynon 2002). These findings are in accordance with other researchers who have found the Saaty scale to overestimate the differences in preferences between alternatives (Huizingh \& Vrolijk 1997) (Pöyhönen et al. 1997).

Due to the intensity of the continuing debate, it is difficult to determine whether there is a clearly "best" scale. Ultimately, though, the power scale was used in this research because of its improvement on the balanced scale for more than two alternatives and the theoretical argument that priority distributions should have no prior bias resulting from scale choice. Additionally, since the power scale has lower scale values between "equally important" and "extremely important", the resulting priority vector will have smaller differences between high ranked and low ranked alternatives than the Saaty scale; thus avoiding the problems observed by Huizingh and Vrolijk (1997) and Pöyhönen et al. (1997). 


\subsubsection{Scale Increments}

Traditionally, AHP has been used with scales having nine increments (or points) between and including "equally important" and "extremely important". In this study, the concern was whether such a granular scale would confuse or strain respondents. An Australian study (Moisiadis 1999) investigating respondents' feelings towards different scales reported that $62 \%$ found the 9-point scale too difficult to work with. Additionally, 50\% preferred a 5-point scale as opposed to $33 \%$ and $17 \%$ for a 3-point and 9-point scale, respectively. Similar results were obtained by Elliott (2010), where 53.1\% of respondents deemed the 5-point scale "just right", compared to just $15.6 \%$ for the 9-point scale. A 2009 study (Saiko 2009) concluded that a 3point scale was much more expedient and sufficiently accurate when compared to the 9-point scale. In the end, a 5-point scale was chosen for this study due to its balance between simplicity and granularity as well as its overall acceptance by respondents in previous studies.

\subsubsection{Preference Elicitation}

There are three main techniques for eliciting a decision maker's preferences in AHP/ANP: graphical, numerical, and verbal. Graphical techniques utilize pie charts or bars, where the area of the pie chart or length of the bar represents the relative dominance of one element over another. The numerical technique asks the decision maker to directly quantify preferences using the established scale (usually $1-9$ ). The verbal technique assigns a word to each number on the scale and asks the decision maker to choose the word that most accurately describes his or her preference (Millet 1997). For this study, graphical techniques were not an option because the survey software did not allow for it.

The verbal technique was observed to be the most accurate in a small-scale study of MBA students (Millet 1997). Additionally, the students found this technique to be easier to use than the numerical technique. A 1997 study (Huizingh \& Vrolijk 1997) found the numerical technique to give only slightly (but not significantly) better results than the verbal technique. The authors concluded that since most people have a natural inclination towards verbal scales, where accuracy is not of extreme importance, a verbal scale should be used. An earlier study (Webber et al. 1997) also observed no strong evidence for a difference between results from a numerical and verbal scale. Thus, the verbal technique was chosen for preference elicitation due 
to its support from previous research and its ability to be easily implemented using the available software.

\subsubsection{Reduction in Pairwise Comparisons}

One of the practical issues with AHP/ANP concerns the large number of pairwise comparisons required from the decision maker. Each full PCM is a reciprocal matrix with the sum of its trace values equal to $n$. Hence, the number of comparisons $(m)$ required for each PCM in the model is given by the following equation:

$$
m=\frac{n(n-1)}{2}
$$

Since there is a PCM at each node in the hierarchy or network, for a three level hierarchy with eight alternatives and six criteria, there would be 183 comparisons. During implementation of AHP/ANP, each comparison is really a question on a survey. Since this research involves questioning experts and professionals with a limited amount of time, effort was made to reduce the number of questions.

Perhaps the simplest way to reduce the number of pairwise comparisons is to divide the model into separate parts for different groups of decision makers (Weiss \& Rao 1987). In our research model the strategy-related questions were answered by cabinet industry professionals, hereafter referred to as the strategy group. The strategy group answered questions that establish the strength of relationships between competitive capabilities as well as weighting the relative importance of general strategies in the Canadian cabinet industry. A separate panel of IT professionals and researchers answered questions evaluating each type of software application against each of the competitive capabilities. They are hereafter referred to as the technology group. By splitting up the survey into logical parts, the strategy group answers $39 \%$ of the questions and the technology group answers the remaining 61\%. Another benefit of this approach is that it makes expert recruitment easier for the researchers because the respondent only needs to be an expert in one area instead of both areas, which is much more difficult to find.

There are a number of other, more sophisticated, mathematical methods to reduce the number of pairwise comparisons. These include the balanced incomplete block design (BIBD) (Weiss \& Rao 1987), incomplete pairwise comparison (IPC) method (Harker 1987), globally 
effective questioning (Millet \& Harker 1990), attribute subsets (Shen et al. 1992), iterative AHP (Lim \& Swenseth 1993), duality approach (Triantaphyllou 1999), and chained pairwise comparisons (Ra 1999). Ultimately, Harker's IPC method was chosen for this research because of its simplicity and support from other researchers (Carmone et al. 1997) (Setiawan 2002). The other methods were either much more complex, were not supported by other researchers, or involved specialized software requiring real-time interaction with respondents.

The simplified IPC method involves following three simple rules for obtaining the incomplete matrix approximation of the full matrix. First, keep all comparison values given by the decision maker. Second, enter a " 0 " for every missing entry of the PCM. Third, replace the trace with a value equal to the number of zeros in that row plus one. The right principal eigenvector of this new matrix is the decision maker's approximate priority vector (Harker 1987). Using this method, the minimum number of pairwise comparisons required to derive a priority vector is only $n-1$.

Carmone et al. (1997) conducted a Monte Carlo simulation to determine the effectiveness of this method using 11 performance measures. They concluded that up to $90 \%$ of comparisons can be deleted from the PCM using the IPC method and still yield a priority vector that approximates the true priority vector with sufficient accuracy (Carmone et al. 1997). A separate simulation study (Setiawan 2002) concluded that for a 10 x 10 matrix, nine comparisons will yield an accuracy of $97.6-98.9 \%$.

Once one decides to use the IPC method, there is still the problem of choosing which comparisons to eliminate. That is, what is the best rule to determine which $n-1$ comparisons should be selected out of all $n(n-1) / 2$ comparisons to achieve the best results? This question was first addressed by Wedley et al. (1993), who observed that first ranking the $n$ alternatives and then using the lowest ranked alternative as the common referent yielded the lowest errors (Wedley et al. 1993). Almost a decade later, an exhaustive simulation study (Setiawan 2002) concluded that for the case of $n-1$ comparisons, making those comparisons with respect to one common alternative yielded the lowest errors. This finding corroborates Wedley et al. (1993), with the former study going further in suggesting not only a common alternative, but the lowest ranked alternative yields best results. Intuitively this makes sense because a decision maker 
would first choose the smallest (or lowest ranked) object and then compare each successive object as a multiple of the first.

By using the pre-ranked IPC method, the number of questions asked from experts was largely reduced. This was an important goal for the research design to help increase the response rate and reduce respondent fatigue. A complete set of full PCMs would have required 165 pairwise comparisons for the technology group. With the IPC method, this was reduced by $67 \%$ to 55 pairwise comparisons. For the strategy group, the reduction was less impressive because using the IPC method is unnecessary for PCMs that have less than four alternatives. Thus, the original 61 comparisons were reduced by $41 \%$ to 36 comparisons.

\subsubsection{Aggregation of Individual Responses}

It is rarely the case in a real-world decision problem where there is only one decision maker involved. Typically there are multiple decision makers, stakeholders, or experts involved in a decision. Fortunately, ANP can handle scenarios with multiple decision makers. In such a case, the individual responses need to be aggregated to form a final decision.

There are three general approaches for group decision making with ANP. First, the group comes to a consensus for every entry in the PCMs. Second, each decision maker can make their own judgments independently, thus forming their own PCMs. Then the final priority vectors of each decision maker are calculated and are then mathematically aggregated to form a group decision. Third, each individual's judgments are made independently but are then aggregated into each PCM of the network. The group's final priorities are derived from the network's PCMs, each representing the aggregated judgments of every decision maker (Van Den Honert \& Lootsma 1997). The first procedure is not relevant to this research as each respondent is surveyed independently, so there is no opportunity to reach a consensus for every entry in the PCM. The second procedure has been referred to as aggregation of individual priorities (AIP) and the third as aggregation of individual judgments (AIJ) (Forman \& Peniwati 1998).

Since this research utilizes the IPC method, some entries in each PCM will be zero. Furthermore, since the IPC method utilizes pre-ranking of the criteria or alternatives, the individual entries in each decision maker's PCM will likely represent different comparisons. Consequently, if AIJ is used with a pre-ranked IPC matrix, the resulting matrix could have 
insufficient non-zero values to calculate the right principal eigenvector. This is obvious because taking the geometric mean of any sequence with at least one zero will equal zero. Because of this limitation imposed by using the pre-ranked IPC method, AIP is the most appropriate aggregation procedure for this research.

In addition to the general procedures of aggregation, there are also two calculation methods for aggregating individual priorities: the arithmetic mean and the geometric mean (Forman \& Peniwati 1998).

The weighted arithmetic mean of aggregated individual priorities:

$$
P_{g}\left(A_{j}\right)=\sum_{i=1}^{n} w_{i} P_{i}\left(A_{j}\right)
$$

The weighted geometric mean of aggregated individual priorities:

$$
P_{g}\left(A_{j}\right)=\prod_{i=1}^{n} P_{i}\left(A_{j}\right)^{w_{i}}
$$

where for both Equation 20 and 21, $P_{g}\left(A_{j}\right)$ is the group's priority of alternative $j, P_{i}\left(A_{j}\right)$ is the individual's priority of alternative $j, w_{i}$ is the weight of importance for individual $i$ 's input, and $n$ is the number of decision makers. In this research, each expert is given equal preference such that $w_{1}=w_{2} \ldots=w_{n}$ and $\sum_{i=1}^{n} w_{i}=1$.

The geometric mean is the most commonly accepted method because of the multiplicative nature of the ratio scales used in AHP/ANP. It is also the method championed by Saaty due its ability to satisfy the various axioms of AHP/ANP (Aczél \& Saaty 1983). Forman \& Peniwati (1998) and Van Den Honert \& Lootsma (1995) have also concluded that the geometric mean is the best aggregation method. 


\section{Chapter 4 - Results}

\subsection{Synopsis}

This chapter begins with the findings of which types of applications and functionalities are currently available on the market. Operations \& Engineering applications are the most common application type, occurring in $65.7 \%$ of the 149 products investigated. CRM, Collaborative, and Content applications are rare, being found in less than $10 \%$ of the products. Other back office was the most common functionality, occurring $52.3 \%$ of the time. Clustering analysis yielded seven clusters, which is also the same number of groups in the IDC Software Taxonomy used in this research. Association rule analysis showed that while oftentimes design is automated in these software products, production is not.

Using ANP for the strategic analysis, a Quality strategy (0.332 priority vector value) was determined to be most important for future competitiveness, while a Delivery strategy $(0.111$ priority vector value) was least important. Operations \& Engineering and ERM applications were the most important software types for future competitiveness, with respective priority vector values of 0.227 and 0.222 . Content applications were the least important. The final priority vector was most sensitive to the weighting of the Customer Service strategy. A higher emphasis on this strategy will result in CRM and Collaboration applications being the most important software types.

\subsection{Results}

\subsubsection{Current State of Software}

\subsubsection{Representation of Applications and Functionalities}

The percentages shown in Table 6 represent the sum of all the individual functionalities falling under each application type according to the taxonomy given in Appendix 2. For example, looking at Table 6 we can see that $6.3 \%$ of all functionalities observed in the software products fell under the CRM application type.

Overall, functionalities related to Operations \& Engineering applications were the most common in the cabinet industry software market, representing $65.7 \%$ of all observed 
functionalities (Table 6). ERM and SCM applications have similar presence in the market, representing $12.3 \%$ and $11.4 \%$ of all functionalities, respectively. The functionalities found in CRM, Content, and Collaborative applications are rare in the industry.

Table 4: Representation of software application types in the cabinet industry software market.

\begin{tabular}{|lc|}
\hline Software Application Type & $\begin{array}{c}\text { Proportion of } \\
\text { Functionalities Observed }\end{array}$ \\
\hline Operations \& Engineering & $65.7 \%$ \\
ERM & $12.3 \%$ \\
SCM & $11.4 \%$ \\
CRM & $6.3 \%$ \\
Collaborative & $2.2 \%$ \\
Content & $2.2 \%$ \\
\hline
\end{tabular}

The proportion of products containing individual functionalities was also calculated (Table 7). With regards to specific functionalities, other back office was the most common functionality, occurring in just over half of all products. This functionality includes project cost estimation and panel optimization. CAM, other engineering, and manufacturing functionalities were also well represented. Other engineering includes parametric design products and manufacturing includes functionalities such as Bill-of-Materials (BOM) generation. In this study, "parametric design" refers to software specifically designed for the cabinet industry, where the designer creates drawings along pre-defined parameters that are common to the industry. This is separated from dedicated $C A D$ products, which are generally industry independent and do not have as many design restrictions.

Six functionalities were not present in any products: integrated collaborative environments, conferencing applications, enterprise portals, services operations management, computer-assisted engineering ( $C A E)$, and contact center. Functionalities related to marketing and sales were not represented very well, occurring in less than $10 \%$ of all products. 
Table 5: Proportion of products having specified functionality ${ }^{1}$.

\begin{tabular}{|lc|}
\hline Software Functionality & $\begin{array}{c}\text { Proportion of Products } \\
\text { Having Functionality }\end{array}$ \\
\hline Other Back Office & $52.3 \%$ \\
CAM & $34.2 \%$ \\
Other Engineering & $31.5 \%$ \\
Manufacturing & $28.9 \%$ \\
Inventory Management & $18.1 \%$ \\
CAD & $11.4 \%$ \\
\hline
\end{tabular}

\subsubsection{Clustering Results}

For validation, the Calinski-Harabasz index was plotted for $k=2$ to 10 clusters using both the Jaccard and Dice distances. Both measures obtained a local maximum at $k=7$, indicating the solution is robust. The Dice metric obtained the highest Calinski-Harabasz value and also had a more pronounced maximum than the Jaccard metric (Figure 12). Based on these results, the Dice metric was chosen to compute distances and the number of clusters was determined to be seven. It is interesting that the optimal number of clusters in our analysis is the same as the number of main groups of functionalities (minus the consumer applications group which is not applicable) in the IDC Software Taxonomy. Since the number of clusters found in our sample of business software equals that of the IDC Software Taxonomy, it gives the researchers more confidence that the adopted taxonomy was appropriate for the study.

\footnotetext{
${ }^{1}$ Percentages do not add up to $100 \%$ because software products can have more than one functionality.
} 


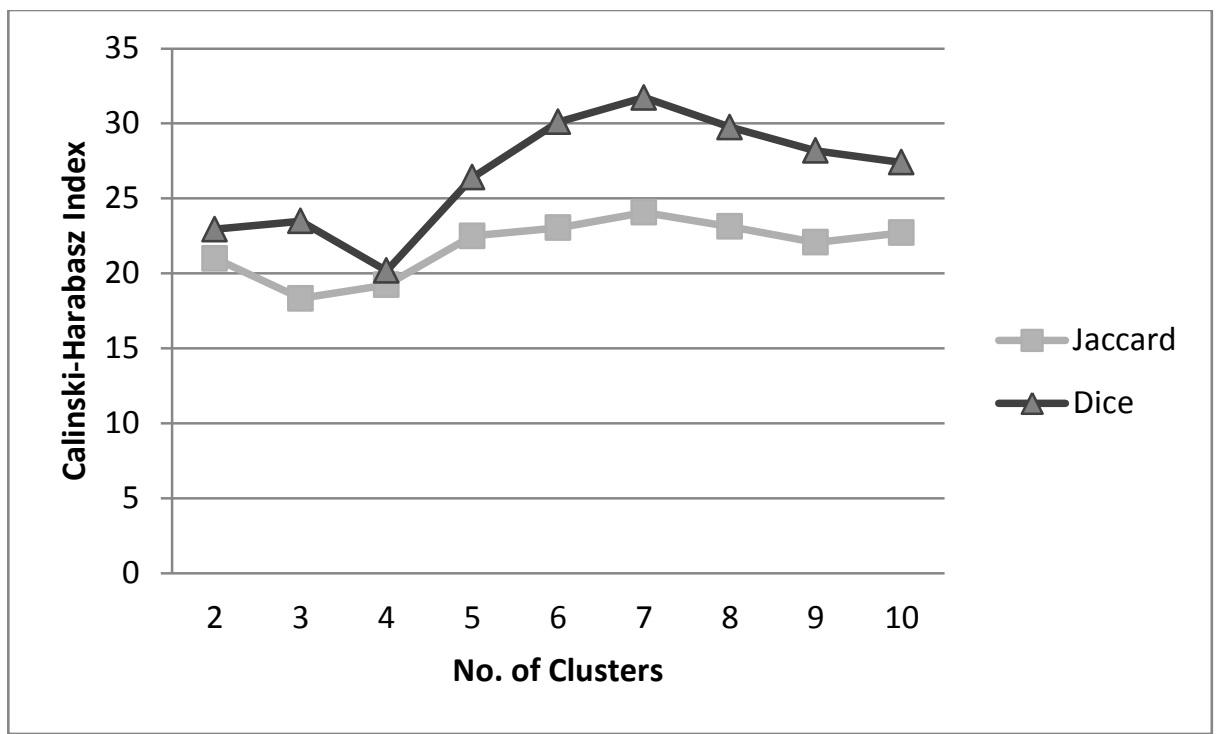

Figure 12: Calinski-Harabasz vs. Number of Clusters for select asymmetric binary measures

The silhouette widths of each observation within a cluster are plotted in decreasing order in Figure 13. Clusters showing strong validity will have most values above 0.5 and should not drop off steeply after the first few values. Cluster 5 has perfect support because its members' width are all 1; clusters 6 and 7 have strong support; clusters 3 and 4 have moderate support; and clusters 1 and 2 have weak support for their members being correctly assigned. Fortunately, no negative silhouette values were obtained, meaning there is little evidence to suggest that data points were assigned to incorrect clusters.

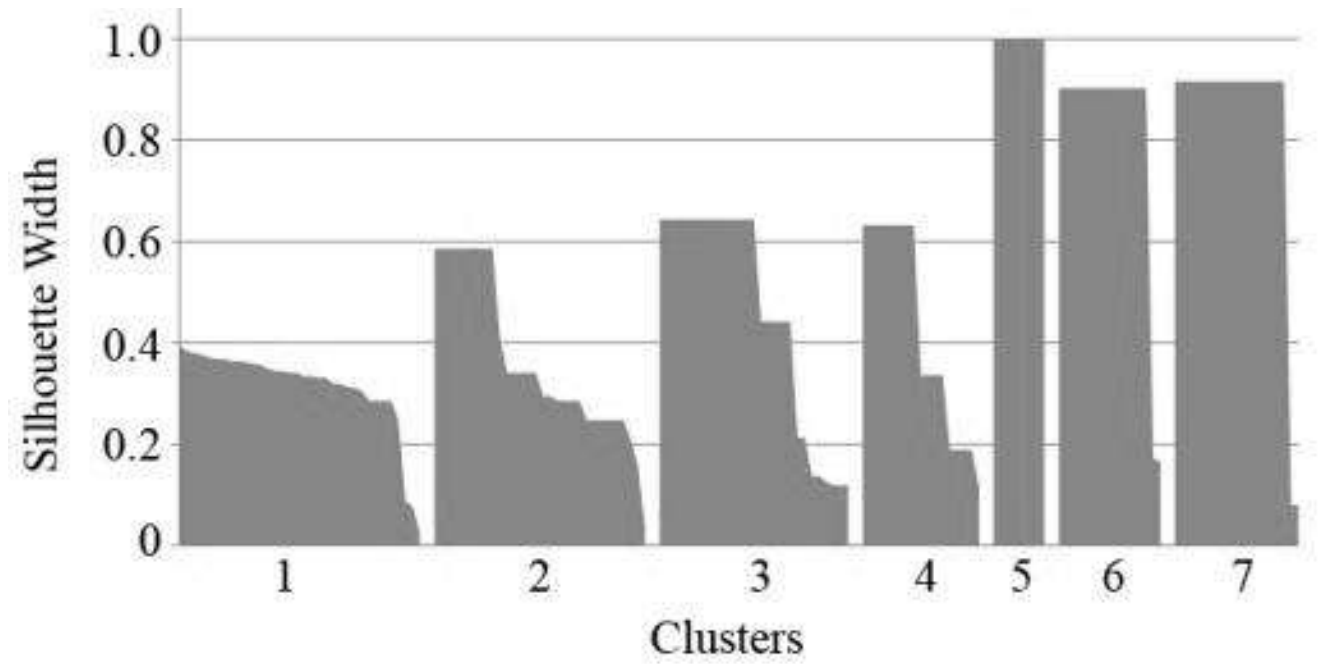

Figure 13: Silhouette widths for clustering results 
Table 8 gives summary statistics of the clustering results for $k=7$ clusters. Cluster 1 had the highest proportion of all software products, but it was also the least cohesive, having the most dissimilarity within the cluster and the smallest silhouette width. This means that nearly a quarter $(22.8 \%)$ of the products had a scattering of functionalities. Cluster 5 had the fewest products in it, but also had no dissimilarity and a silhouette width of 1 because all of its products had exactly the same functionality (inventory).

Table 6: Summary statistics of cluster analysis

\begin{tabular}{|ccccc|}
\hline Cluster & $\begin{array}{c}\text { No. of } \\
\text { members }\end{array}$ & $\begin{array}{c}\text { Proportion } \\
\text { of total }\end{array}$ & $\begin{array}{c}\text { Average } \\
\text { dissimilarity }\end{array}$ & $\begin{array}{c}\text { Average } \\
\text { silhouette } \\
\text { width }\end{array}$ \\
\hline 1 & 34 & $22.8 \%$ & 1.79 & 0.31 \\
2 & 30 & $20.1 \%$ & 1.55 & 0.37 \\
3 & 27 & $18.1 \%$ & 1.18 & 0.46 \\
4 & 17 & $11.4 \%$ & 1.31 & 0.43 \\
5 & 8 & $5.4 \%$ & 0.00 & 1 \\
6 & 15 & $10.1 \%$ & 0.31 & 0.81 \\
7 & 18 & $12.1 \%$ & 0.35 & 0.82 \\
\hline
\end{tabular}

The relative lack of cohesion in cluster 1 is evident in Table 9 where functionalities are widely distributed. Several of the products in this cluster are ERM type applications that market themselves as being a one-stop solution for a wide range of business needs. One such product on the market is Ufactory ${ }^{\mathrm{TM}}$ (Safertek Software), which handles a variety of processes including financial accounting, customer relationship management, and inventory control. Another example is J-MOS System ${ }^{\mathrm{TM}}$ (Jefferson Industrial Software).

Products in cluster 2 generally perform three main functions together. They allow the user to parametrically design cabinets (other engineering), produce a BOM from that design (manufacturing), and produce an accurate project estimate (other back office). A minority of those products will also produce $\mathrm{CNC}$ machine code $(C A M)$ to manufacture the design. Examples of products in this cluster include 20-20 Design ${ }^{\mathrm{TM}}$ (20-20 Technologies) and CabnetWare ${ }^{\mathrm{TM}}$ (Planit).

Cluster 3 is dominated by panel optimization software that nests parts on a panel to achieve maximum material utilization (other back office) and then produces the necessary CNC 
machine code $(C A M)$. Some of these products also print out part labels for identification and tracking (inventory). Examples of products in this cluster include NestMaker ${ }^{\mathrm{TM}}$ (CADCode Systems) and Pro Series ${ }^{\mathrm{TM}}$ (Ardis Information Systems).

Cluster 4 is well represented by CAD/CAM products. This software allows an engineer to draw a part $(C A D)$ and then automatically generate the $\mathrm{CNC}$ machine code $(C A M)$. Examples of products in this cluster include Mastercam Router ${ }^{\mathrm{TM}}$ (CNC Software) and EnRoute Wood $\operatorname{Pro}^{\mathrm{TM}}$ (SA International).

Cluster 5 is comprised exclusively of products that track inventory and make part labels for identification and tracking. Some labels are simply alphanumeric, some print a barcode, and one vendor supplies radio-frequency tracking. ALIS $^{\mathrm{TM}}$ (Microvellum) and ShopWare Quikrak ${ }^{\mathrm{TM}}$ (20-20 Technologies) are representative of this cluster.

Clusters 6 and 7 are dominated by products that have a single function: estimation (other back office) and parametric design (other engineering) respectively. Prime $6400^{\mathrm{TM}}$ (Prime Estimating \& Software Services) is an example of a product in cluster 6. Cabinet Designer ${ }^{\mathrm{TM}}$ (KCD Software) is an example of a product in cluster 7. 
Table 7: Representation of functionalities in each cluster $^{2}$

\begin{tabular}{|lccccc|}
\hline Cluster 1 & $\begin{array}{c}\text { Manufacturing } \\
(10.9 \%)\end{array}$ & $\begin{array}{c}\text { Production } \\
\text { Planning } \\
(8.8 \%)\end{array}$ & $\begin{array}{c}\text { Financial \& } \\
\text { Strategy } \\
(7.3 \%)\end{array}$ & $\begin{array}{c}\text { Inventory } \\
(7.3 \%)\end{array}$ & $\begin{array}{c}\text { Sales } \\
(6.6 \%)\end{array}$ \\
\hline Cluster 2 & $\begin{array}{c}\text { Other Back } \\
\text { Office } \\
(31.5 \%)\end{array}$ & $\begin{array}{c}\text { Manufacturing } \\
(29.2 \%)\end{array}$ & $\begin{array}{c}\text { Other } \\
\text { Enineering } \\
(25.8 \%)\end{array}$ & $\begin{array}{c}\text { CAM } \\
(9.0 \%)\end{array}$ & $\begin{array}{c}\text { Marketing } \\
(2.2 \%)\end{array}$ \\
\hline Cluster 3 & $\begin{array}{c}\text { Other Back } \\
\text { Office } \\
(38.6 \%)\end{array}$ & $\begin{array}{c}\text { CAM } \\
(38.6 \%)\end{array}$ & $\begin{array}{c}\text { Inventory } \\
(11.4 \%)\end{array}$ & $\begin{array}{c}\text { Engineering } \\
(5.7 \%)\end{array}$ & $\begin{array}{c}\text { Manufacturing } \\
(2.9 \%)\end{array}$ \\
\hline Cluster 4 & $\begin{array}{c}\text { CAM } \\
(50.0 \%)\end{array}$ & $\begin{array}{c}\text { CAD } \\
(46.2 \%)\end{array}$ & $\begin{array}{c}\text { Order Mgmt } \\
(3.8 \%)\end{array}$ & & \\
\hline Cluster 5 & $\begin{array}{c}\text { Inventory } \\
(100.0 \%)\end{array}$ & & & & \\
\hline Cluster 6 & $\begin{array}{c}\text { Other Back } \\
\text { Office } \\
(88.2 \%)\end{array}$ & $\begin{array}{c}\text { Financial \& } \\
\text { Strategy } \\
(5.9 \%)\end{array}$ & $\begin{array}{c}\text { Sales } \\
(5.9 \%)\end{array}$ & & \\
\hline Cluster 7 & $\begin{array}{c}\text { Other } \\
\text { Engineering } \\
(90.0 \%)\end{array}$ & $\begin{array}{c}\text { CAM } \\
(10.0 \%)\end{array}$ & & & \\
\hline
\end{tabular}

\subsubsection{Association Rules}

Association rules with support greater than 0.1 and confidence greater than 0.5 are shown in Table 10. All rules have a lift greater than 1.3, meaning their probability of being together in the same product is at least $30 \%$ higher than random chance.

Twenty four percent of all products had the functionalities CAM and other back office paired together. These products optimize part layout for maximum panel utilization and produce the machine code required for $\mathrm{CNC}$ processing. It should be noted that a high support value for an association rule could be attributed to a large number of product variations from the same vendor that have similar functionalities, but were counted as separate products because they still had material differences.

\footnotetext{
${ }^{2}$ Only the top 5 functionalities in each cluster are included. The composition of functionalities in each cluster are shown in parentheses.
} 
Manufacturing and other back office were also very commonly paired, found together in $21 \%$ of products. Most of these products produce a project cost estimate along with a BOM. This is most likely because once one of these functionalities is included in the software, it is relatively easy to include the other functionality due to shared code.

Other back office was included in $86 \%$ of all products containing manufacturing and other engineering functionalities together. This means that parametric design software that produce a BOM usually also estimate the project's cost and/or do panel optimization. It is interesting to note that this rule does not include CAM functionality. Less than half (41\%) of all products containing CAD or other engineering also had CAM. So, while the design has been automated, oftentimes the production has not been automated with $\mathrm{CNC}$ routers.

Table 8: Association rules with minimum support of 0.1 and minimum confidence of 0.6

\begin{tabular}{|lccc|}
\hline Association Rule & Support & Confidence & Lift \\
\hline$\{\mathrm{CAM}\} \rightarrow$ \{Other Back Office & 0.23 & 0.69 & 1.3 \\
$\{$ Manufacturing $\rightarrow$ \{Other Back Office\} & 0.21 & 0.72 & 1.4 \\
$\{$ Manufacturing, Other Engineering $\rightarrow \rightarrow$ \{Other Back Office\} & 0.12 & 0.86 & 1.6 \\
\hline
\end{tabular}

\subsubsection{Future State of Software}

\subsubsection{Consistency and Consensus Measures}

Consistency ratios are not available for all PCMs for a couple of reasons. First, all technology group PCMs were evaluated using the IPC method. A CR cannot be calculated for PCMs using the IPC method because there are no redundant pairwise comparisons. This is also the reason why a CR cannot be obtained for the overall competitiveness, delivery dependability, and advertising PCMs belonging to the strategy group. Secondly, the PCMs associated with conformance quality and process flexibility only have two alternatives being compared, resulting in a perfectly consistent matrix regardless of the decision maker's comparison value.

Traditionally, any PCM with a CR greater than 0.10 is deemed too inconsistent and is discarded (Saaty 1980). In this study, 10 out of 30 CRs were between the range 0.10 and 0.15 (Table 11). The researchers thought it was important to keep these responses so as to not make 
any node in the network too sensitive to any individual decision maker. Thus, the CR threshold was relaxed so that any PCMs with CRs greater than 0.15 were discarded.

The average consistency ratio was highest for the low costs (0.16) and delivery speed (0.19) nodes (Table 11). In general, though, the strategy group experts were fairly consistent, with only four out of $30 \mathrm{PCMs}$ being discarded (i.e. CR > 0.15). It is interesting to note that decision maker $3\left(\mathrm{DM}_{3}\right)$ was perfectly consistent in all responses and also spent the most time completing the survey.

Consensus measures were obtained for the priority vectors of PCMs with a CR less than 0.15. The strategy group had a high level of agreement on the contribution of competitive capabilities connected to conformance quality (0.934), process flexibility (0.914), and customer service (0.823) (Table 12). In the technology group, there was low consensus on how different types of software applications contributed to each of the competitive capabilities (Table 13). In fact none of the technology comparisons exceeded the 0.826 threshold recommended by Bryson (1996). 
Table 9: Consistency ratio for strategy group

\begin{tabular}{|c|c|c|c|c|c|c|c|c|c|c|c|c|}
\hline & & $\begin{array}{c}\text { Overall } \\
\text { competiti } \\
\text { veness }\end{array}$ & $\begin{array}{l}\text { Low } \\
\text { costs }\end{array}$ & $\begin{array}{c}\text { Performance } \\
\text { quality }\end{array}$ & $\begin{array}{c}\text { Conformance } \\
\text { quality }\end{array}$ & $\begin{array}{l}\text { Product } \\
\text { flexibility }\end{array}$ & $\begin{array}{l}\text { Skilled } \\
\text { labour }\end{array}$ & $\begin{array}{c}\text { Process } \\
\text { flexibility }\end{array}$ & $\begin{array}{c}\text { Delivery } \\
\text { speed }\end{array}$ & $\begin{array}{c}\text { Delivery } \\
\text { dependability }\end{array}$ & Advertising & $\begin{array}{c}\text { Customer } \\
\text { service }\end{array}$ \\
\hline \multirow{6}{*}{ 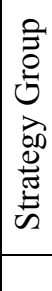 } & $\mathrm{DM}_{1}$ & -- & 0.07 & 0.13 & -- & 0.13 & 0.03 & -- & 0.54 & -- & -- & 0.01 \\
\hline & $\mathrm{DM}_{2}$ & -- & 0.50 & 0.00 & -- & 0.00 & 0.13 & -- & 0.30 & -- & -- & 0.06 \\
\hline & $\mathrm{DM}_{3}$ & -- & 0.00 & 0.00 & -- & 0.00 & 0.00 & -- & 0.00 & -- & -- & 0.00 \\
\hline & $\mathrm{DM}_{4}$ & -- & 0.12 & 0.30 & -- & 0.13 & 0.03 & -- & 0.13 & -- & -- & 0.07 \\
\hline & $\mathrm{DM}_{5}$ & -- & 0.12 & 0.00 & -- & 0.13 & 0.13 & -- & 0.00 & -- & -- & 0.13 \\
\hline & mean & -- & 0.16 & 0.09 & -- & 0.08 & 0.07 & -- & 0.19 & -- & -- & 0.06 \\
\hline
\end{tabular}

Table 10: Consensus measures for strategy group

\begin{tabular}{|c|c|c|c|c|c|c|c|c|c|c|c|c|}
\hline & & $\begin{array}{c}\text { Overall } \\
\text { competiti } \\
\text { veness }\end{array}$ & $\begin{array}{l}\text { Low } \\
\text { costs }\end{array}$ & $\begin{array}{c}\text { Performance } \\
\text { quality }\end{array}$ & $\begin{array}{c}\text { Conformance } \\
\text { quality }\end{array}$ & $\begin{array}{c}\text { Product } \\
\text { flexibility }\end{array}$ & $\begin{array}{l}\text { Skilled } \\
\text { labour }\end{array}$ & $\begin{array}{l}\text { Process } \\
\text { flexibility }\end{array}$ & $\begin{array}{c}\text { Delivery } \\
\text { speed }\end{array}$ & $\begin{array}{c}\text { Delivery } \\
\text { dependability }\end{array}$ & Advertising & $\begin{array}{c}\text { Customer } \\
\text { service }\end{array}$ \\
\hline \multirow{6}{*}{ 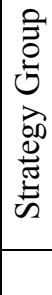 } & $\mathrm{DM}_{1}$ & 0.637 & 0.540 & 0.314 & 1.000 & 0.878 & 0.634 & 0.955 & -- & 0.550 & 0.643 & 0.760 \\
\hline & $\mathrm{DM}_{2}$ & 0.484 & -- & 0.568 & 1.000 & 0.377 & 0.474 & 0.876 & -- & 0.642 & 0.536 & 0.843 \\
\hline & $\mathrm{DM}_{3}$ & 0.722 & 0.594 & 0.688 & 0.799 & 0.306 & 0.588 & 0.914 & 0.570 & 0.694 & 0.485 & 0.867 \\
\hline & $\mathrm{DM}_{4}$ & 0.785 & 0.617 & -- & 1.000 & 0.967 & 0.634 & 0.914 & 0.589 & 0.678 & 0.511 & -- \\
\hline & $\mathrm{DM}_{5}$ & 0.357 & 0.685 & 0.586 & 0.869 & 0.878 & 0.461 & 0.914 & 0.778 & 0.780 & 0.727 & -- \\
\hline & mean & 0.597 & 0.609 & 0.539 & 0.934 & 0.681 & 0.558 & 0.914 & 0.646 & 0.669 & 0.581 & 0.823 \\
\hline
\end{tabular}

Table 11: Consensus measures for technology group

\begin{tabular}{|c|c|c|c|c|c|c|c|c|c|c|c|c|}
\hline & & $\begin{array}{l}\text { Low } \\
\text { costs }\end{array}$ & $\begin{array}{c}\text { Performance } \\
\text { quality }\end{array}$ & $\begin{array}{c}\text { Conformance } \\
\text { quality }\end{array}$ & $\begin{array}{c}\text { Product } \\
\text { flexibility }\end{array}$ & $\begin{array}{l}\text { Skilled } \\
\text { labour }\end{array}$ & $\begin{array}{c}\text { Process } \\
\text { flexibility }\end{array}$ & $\begin{array}{c}\text { Delivery } \\
\text { speed }\end{array}$ & $\begin{array}{c}\text { Delivery } \\
\text { dependability }\end{array}$ & Advertising & $\begin{array}{c}\text { Customer } \\
\text { service }\end{array}$ & $\begin{array}{l}\text { Market } \\
\text { research }\end{array}$ \\
\hline \multirow{5}{*}{$\begin{array}{l}O \\
0 \\
0 \\
\tilde{0} \\
\tilde{U} \\
\oplus\end{array}$} & $\mathrm{DM}_{6}$ & 0.740 & 0.639 & 0.640 & 0.577 & 0.595 & 0.698 & 0.646 & 0.709 & 0.647 & 0.785 & 0.620 \\
\hline & $\mathrm{DM}_{7}$ & 0.623 & 0.442 & 0.685 & 0.802 & 0.577 & 0.477 & 0.683 & 0.507 & 0.423 & 0.651 & 0.205 \\
\hline & $\mathrm{DM}_{8}$ & 0.619 & 0.649 & 0.777 & 0.611 & 0.479 & 0.514 & 0.594 & 0.755 & 0.630 & 0.665 & 0.665 \\
\hline & $\mathrm{DM}_{9}$ & 0.747 & 0.625 & 0.668 & 0.652 & 0.652 & 0.690 & 0.731 & 0.643 & 0.748 & 0.845 & 0.599 \\
\hline & mean & 0.682 & 0.589 & 0.692 & 0.661 & 0.575 & 0.595 & 0.664 & 0.654 & 0.612 & 0.736 & 0.522 \\
\hline
\end{tabular}




\subsubsection{Intermediate Priorities}

Intermediate priorities, like final priorities, can be obtained from the supermatrix once it has converged on a stable solution (see Section 3.4.1). A Quality strategy was determined to be the most important $(0.332)$ for the future competitiveness of the Canadian cabinet industry, followed by a Cost strategy (0.214) (Figure 14). Customer Service and Flexibility strategies had equivalent priorities $(0.172)$, while a Delivery strategy had the lowest overall priority $(0.111)$ for future competitiveness.

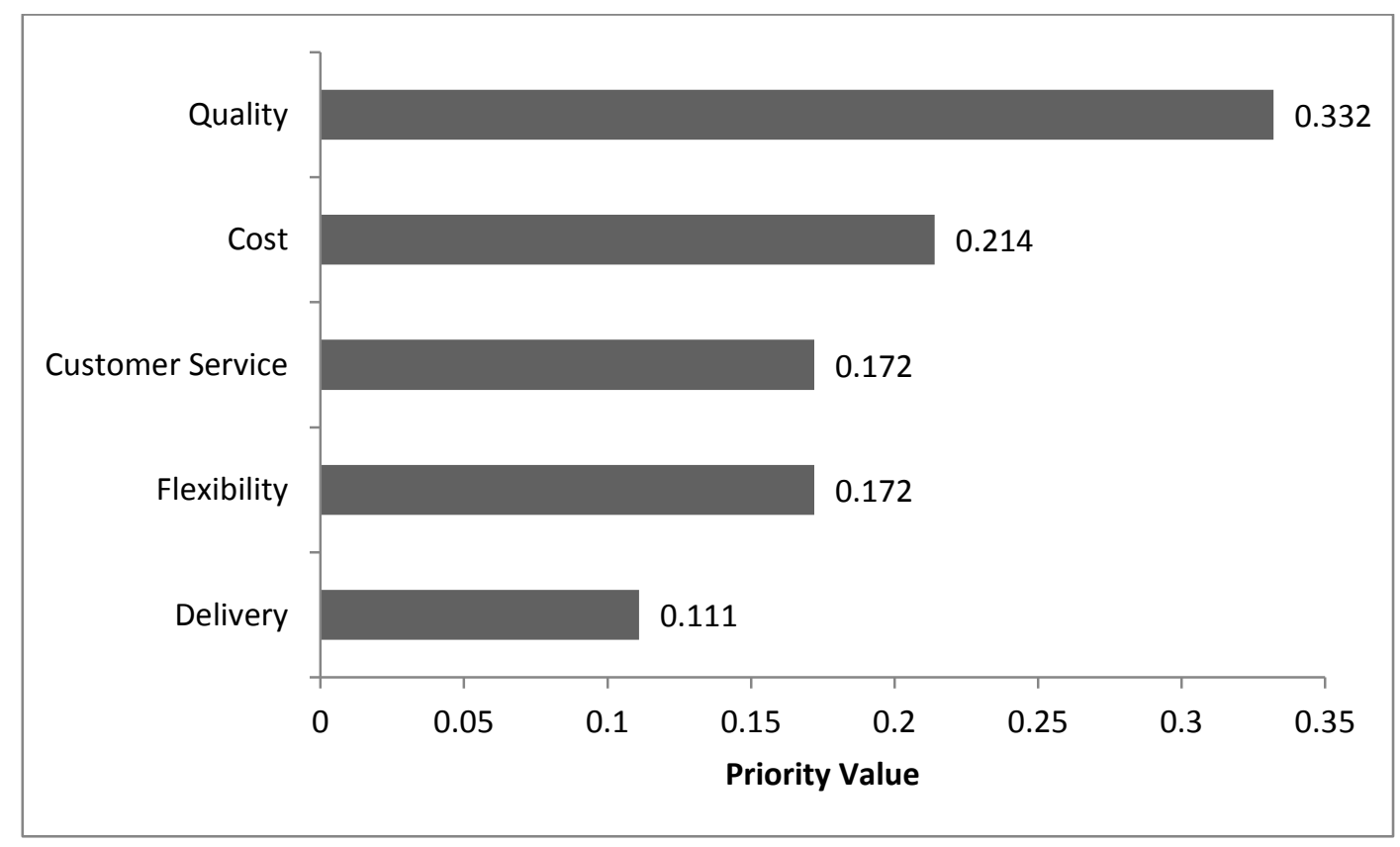

Figure 14: Intermediate priorities for general competitive strategies

Since a Quality strategy is determined to be of such a high priority, the priorities of software applications contributing to performance quality and conformance quality (the competitive capabilities linked to the Quality strategy) will greatly influence the final priority vector of software applications. Operations \& Engineering applications have the highest contribution towards conformance quality (0.307) and ERM applications have the highest contribution towards performance quality (0.230) (Figure 15). 


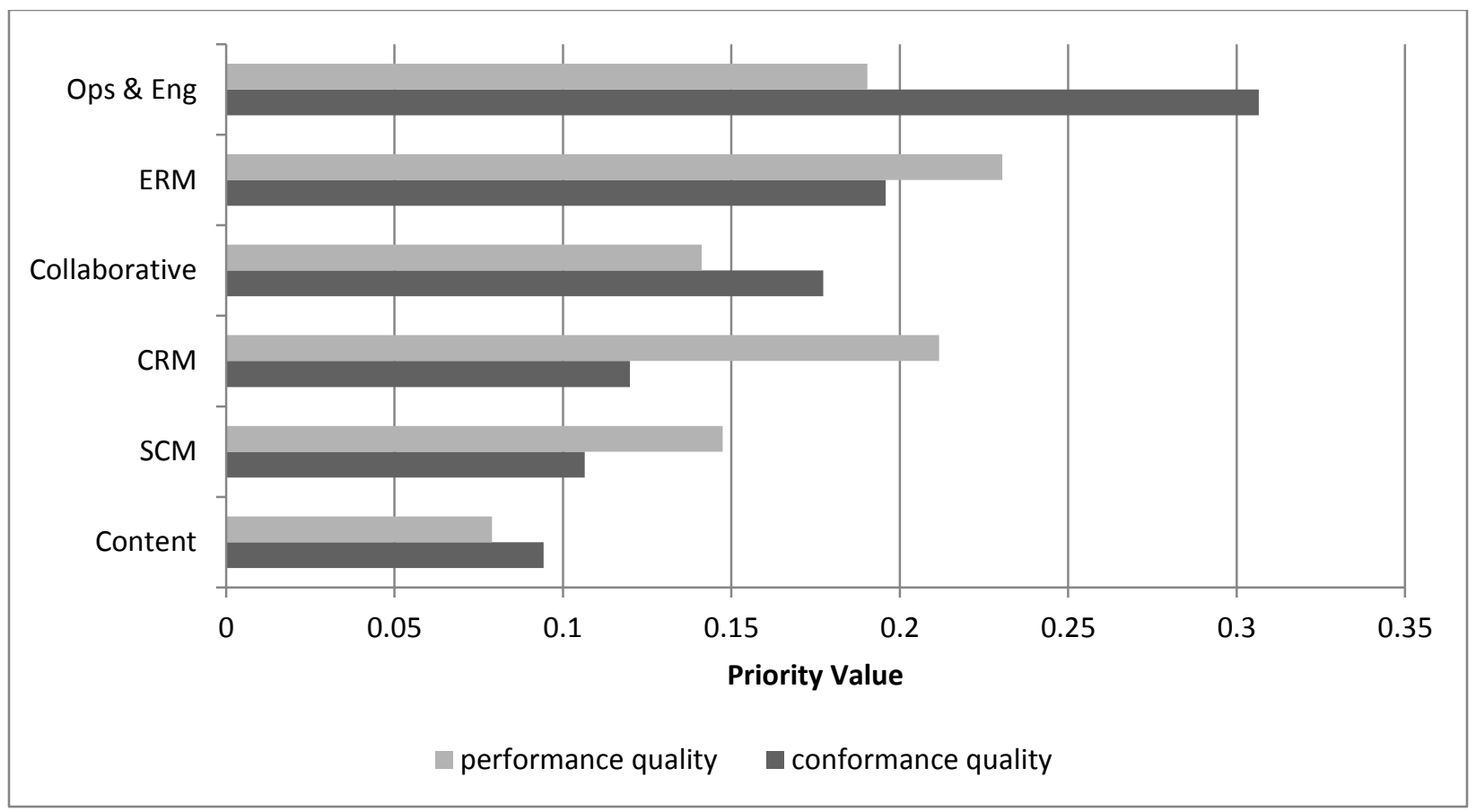

Figure 15: Intermediate priorities of software applications contributions towards performance quality and conformance quality

\subsubsection{Final Priorities}

Operations \& Engineering and ERM applications are the two highest priority software application types, scoring 0.227 and 0.222 respectively (Figure 16). Collaborative and CRM applications are tied for the third highest priority with a value of 0.164. SCM and Content applications have the lowest priorities at 0.136 and 0.087 , respectively. 


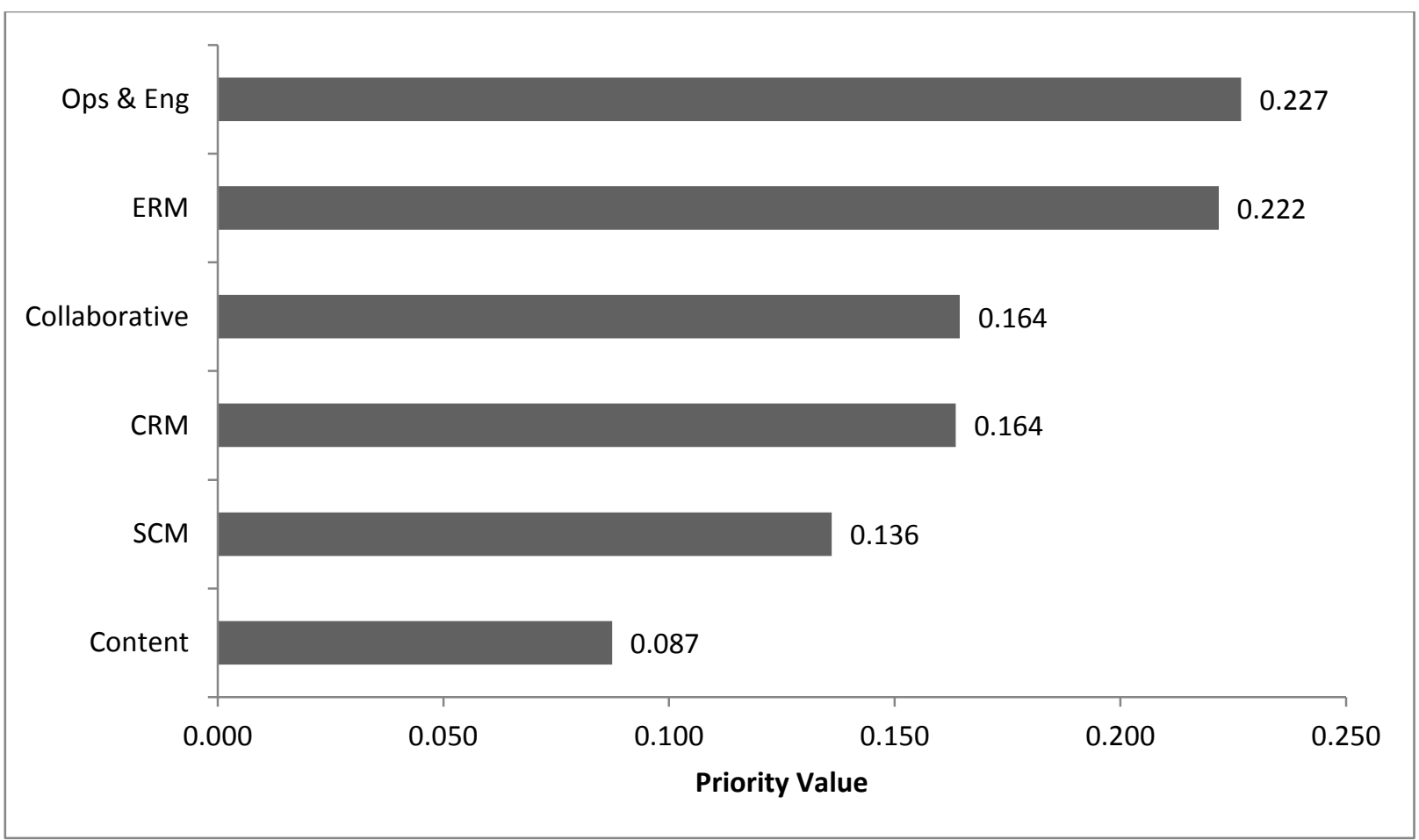

Figure 16: Final priorities for software applications

\subsubsection{Sensitivity Analysis}

When using ANP, it is important to do sensitivity analysis to address expert uncertainty. Also, since this research is done with respect to the industry as a whole, the results may not be relevant to an individual firm employing a unique strategy. Using sensitivity analysis, we can see how varying the weights of different competitive strategies will affect the final priorities of software application types. This is commonly referred to as a "what if" analysis, where effect of different scenarios can be explored.

In the sensitivity analysis, only one competitive strategy is adjusted at a time, while the others are kept constant. For example, in Figure 17, the weight of the Cost strategy (x-axis) is allowed to vary and the resulting final priorities of the software applications (y-axis) are given as a linear function of Cost In the sensitivity plot, a steeper slope means that the application's final priority value is more sensitive to the weight of that particular strategy.

For the Cost, Quality, Flexibility, and Delivery strategies; ERM and operations \& engineering applications are either the first or second highest priorities for all feasible weightings of those strategies (Figures 17 - 20). SCM, CRM, and collaborative applications alternate 
between third, fourth, and fifth highest priorities. Content applications consistently have the lowest priority.

Interestingly, this pattern does not hold for varying weights of the Customer Service strategy. An increasing emphasis on this strategy yields highest priorities for CRM and Collaborative applications (Figure 21). In the sensitivity plot clearly shows that the final rankings of applications changes frequently and the slopes of the lines are steeper than in the other plots. Thus, the final priority vector is most sensitive to the Customer Service strategy.

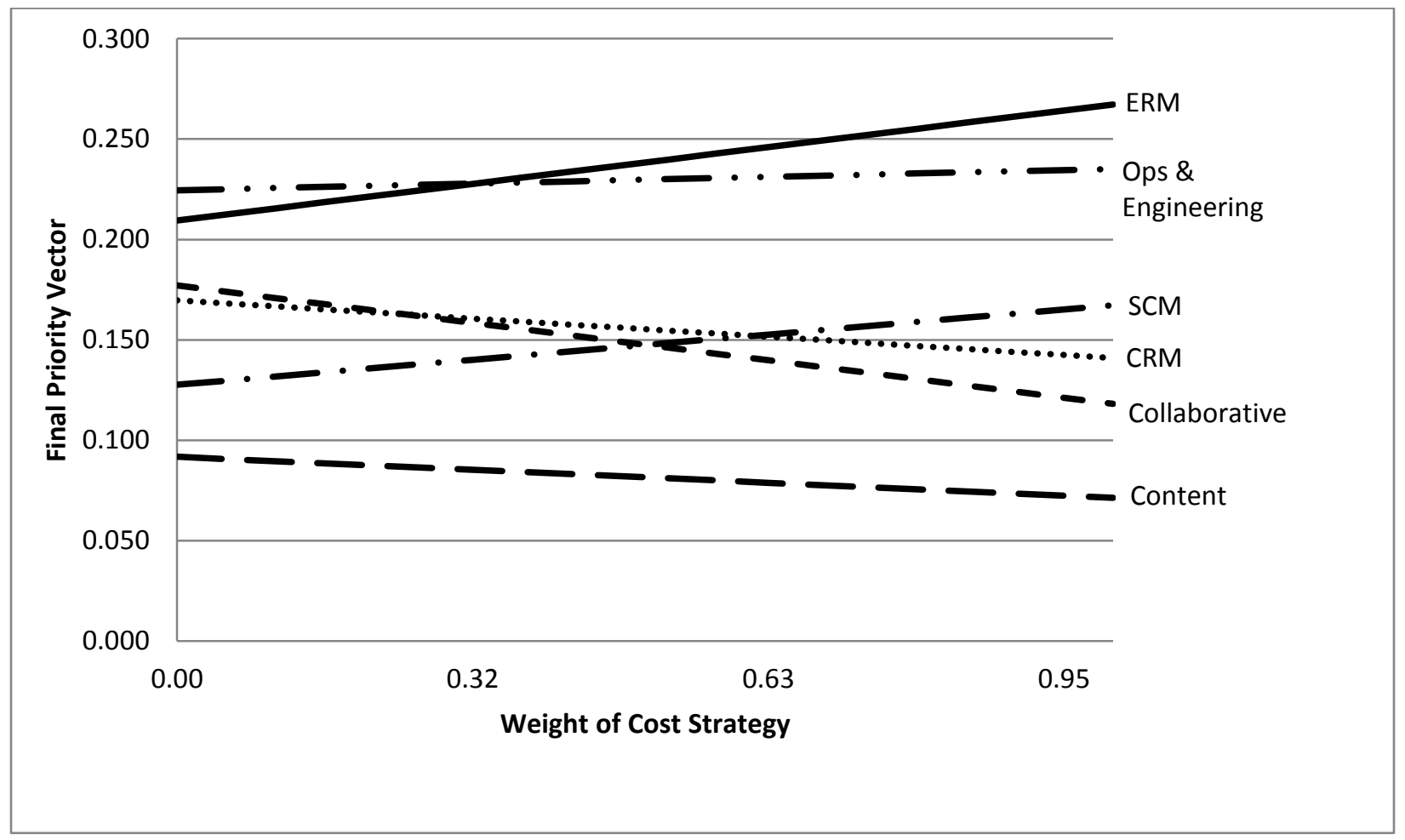

Figure 17: Sensitivity of final priority vector to Cost strategy 


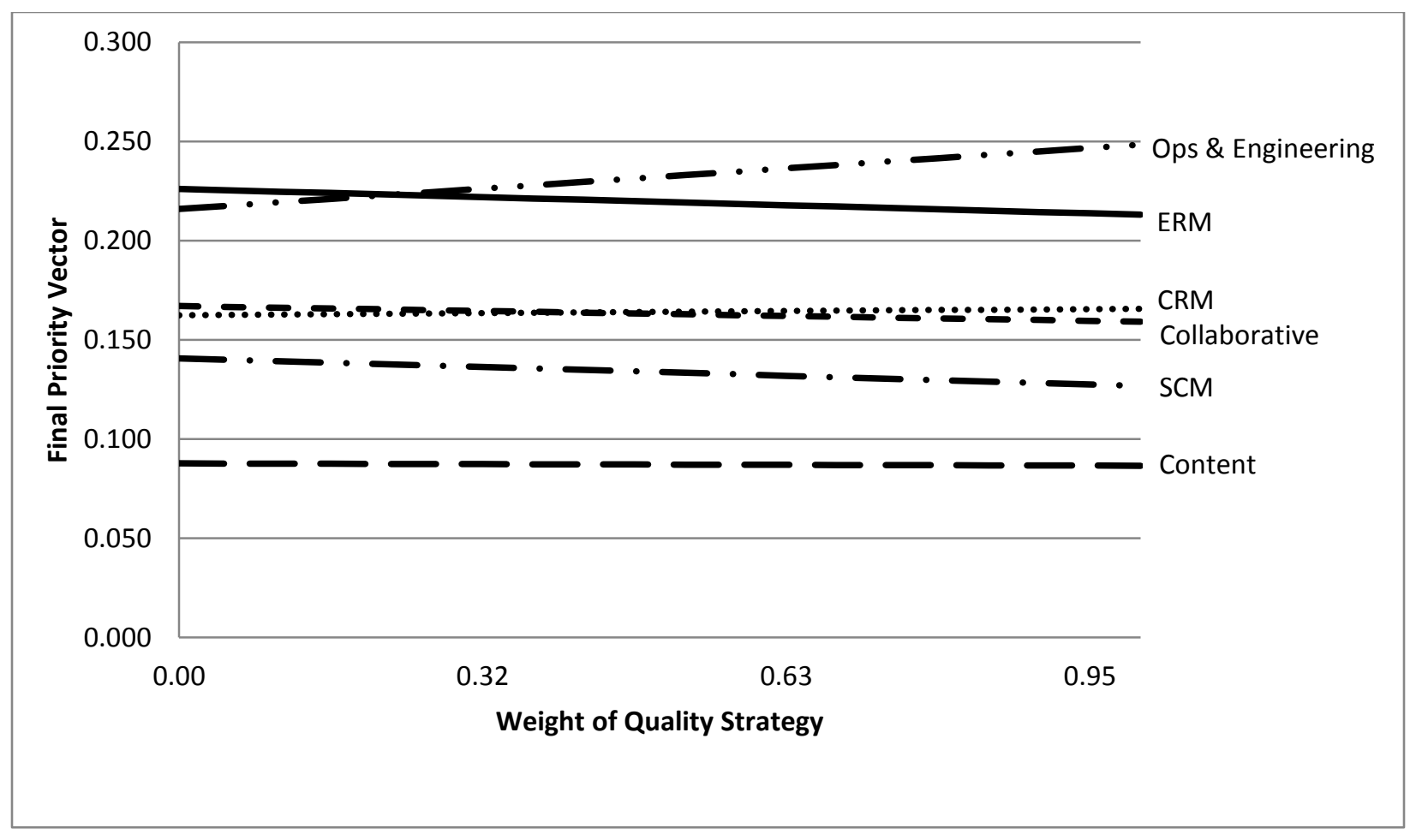

Figure 18: Sensitivity of final priority vector to Quality strategy

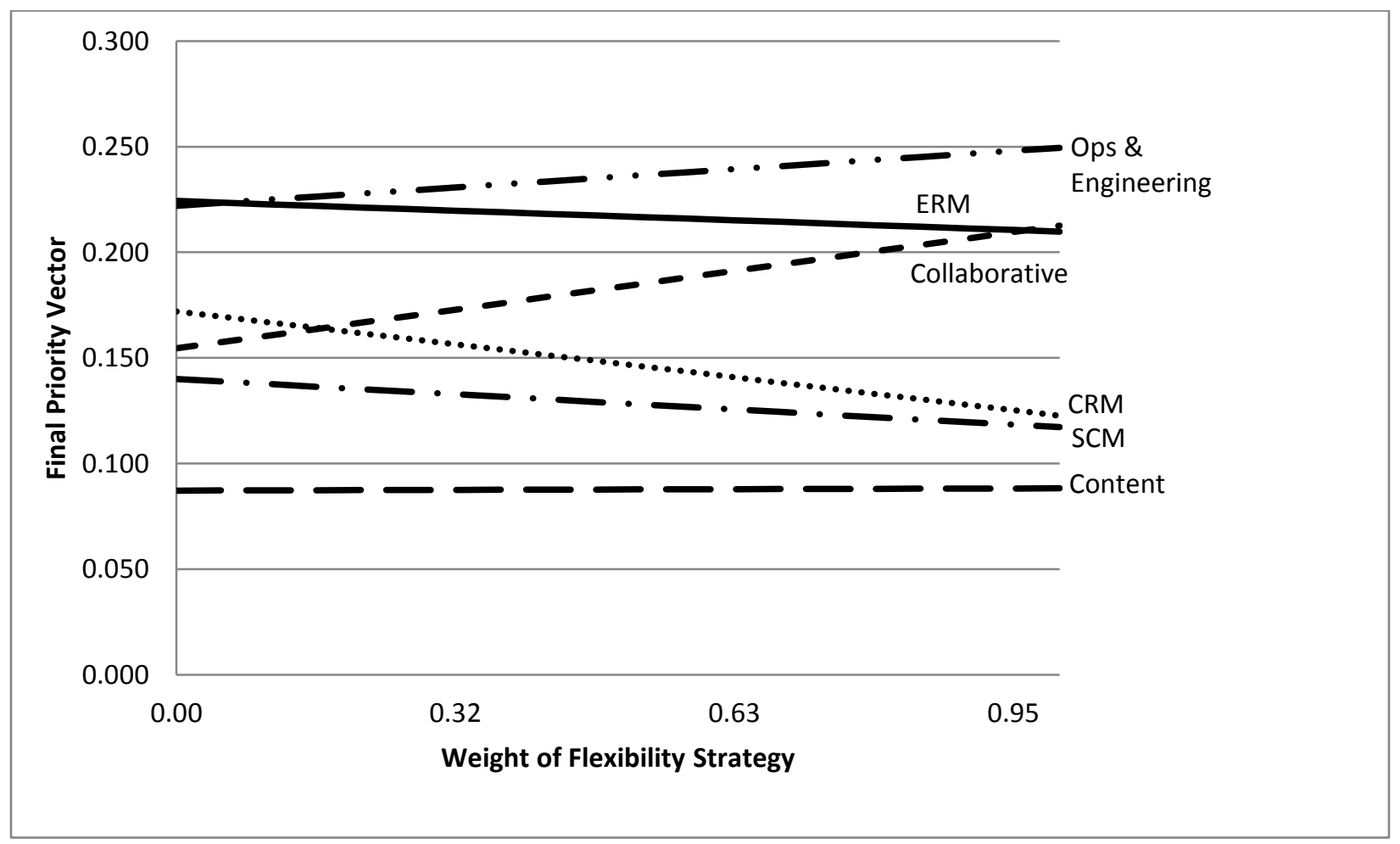

Figure 19: Sensitivity of final priority vector to Flexibility strategy 


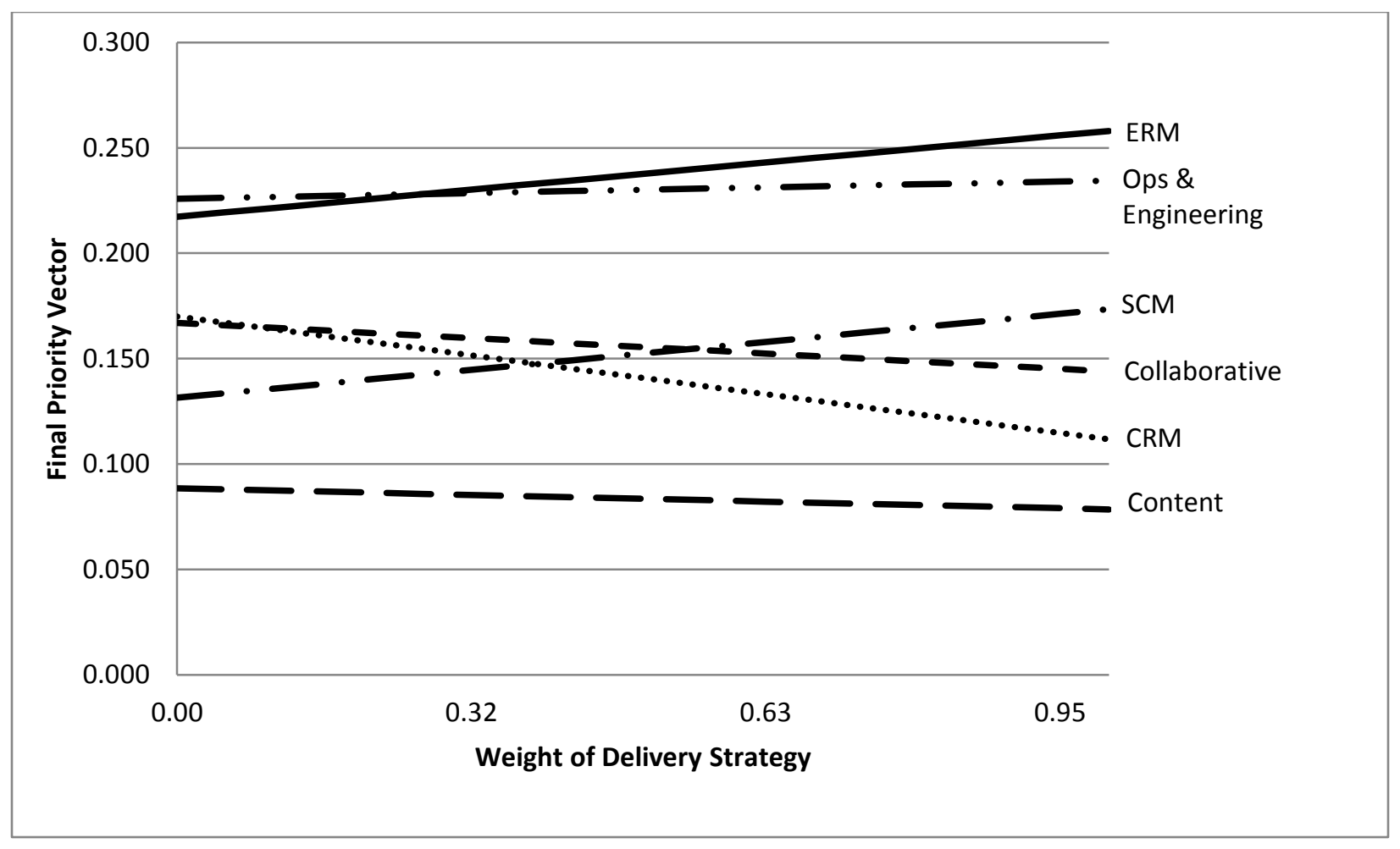

Figure 20: Sensitivity of final priority vector to Delivery strategy

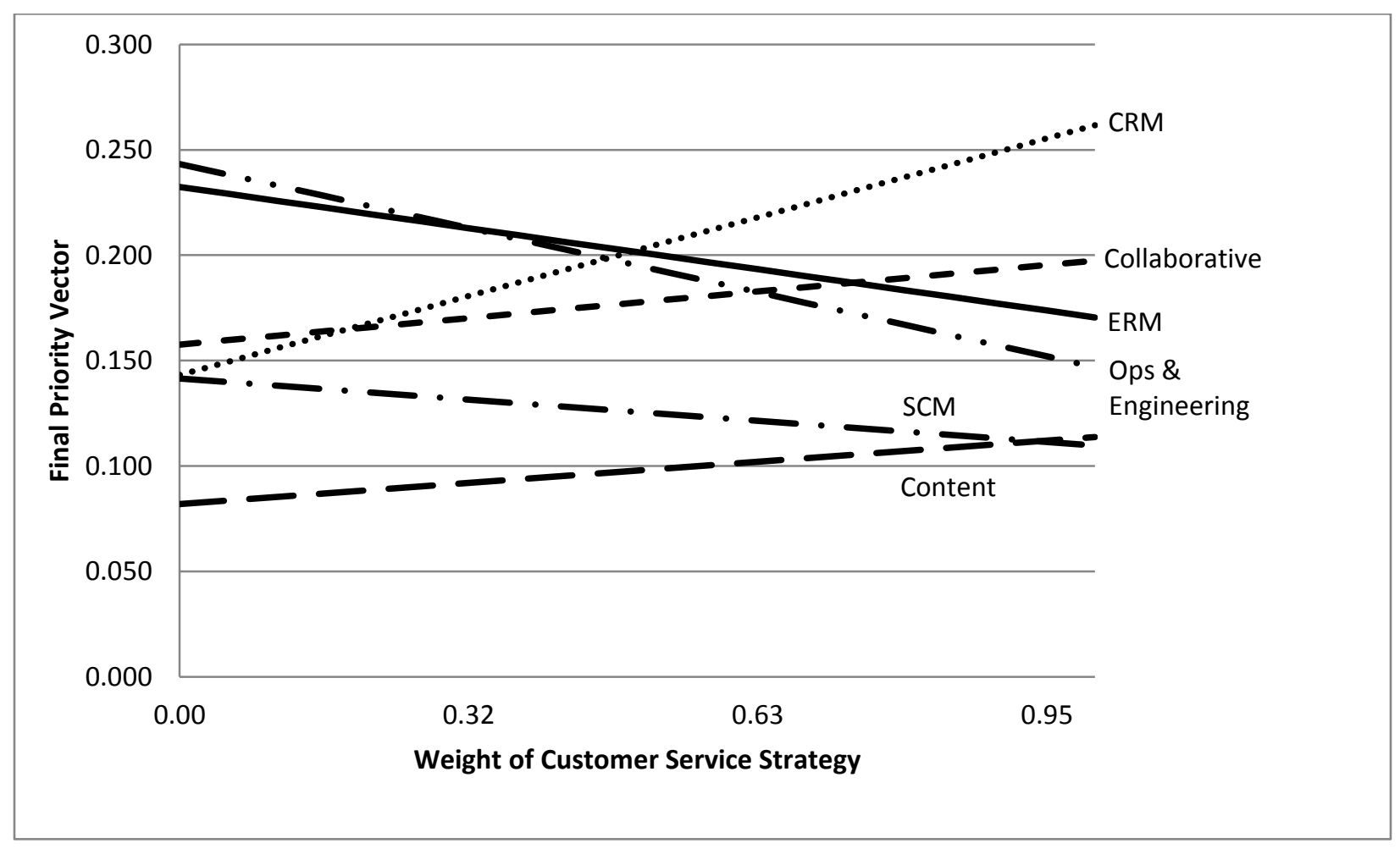

Figure 21: Sensitivity of final priority vector to Customer Service strategy 


\section{Chapter 5 - Discussion}

\subsection{Synopsis}

This chapter is broken up into two major sections. In the first section, the research results are discussed and related back to previous research in this area. The simple proportions of functionalities indicate that production-oriented functionalities are very well represented, but marketing and sales functionalities are not. This could be an issue because past research in wood products competitiveness indicates that marketing will become increasingly important to the sector in the future. The association rules show that design is commonly automated in $C A D$ and parametric design (other engineering) products, but production is not necessarily automated as well (as indicated by $C A M$ functionality). This has negative implications for the industry's productivity, but previous research has shown that wood products firms perceive lowering costs as the least important benefit of IT investments.

The ANP results are discussed later on in the first section of this chapter. A Quality strategy was rated as the most important, followed by a Cost strategy. The Delivery strategy was rated the least important. This agrees with the previous literature to some extent. Past studies have discussed the importance of high quality for North American manufacturers. But, the experts did not rank the Customer Service strategy as high as previous research indicates. The low value for the Delivery strategy is largely in accordance with earlier studies. Operations \& Engineering and ERM applications had the highest final priorities, while Content applications had the lowest. The gap identification indicates that Operations \& Engineering are highly overrepresented in the market, while CRM and Collaborative applications are underrepresented. The final priorities of software applications are most sensitive to the Customer Service strategy. This result is interesting because there appears to be some disagreement on the priority level of this strategy between the experts used in this study and previous research.

The second section of this chapter elaborates on the contribution of this research. Firstly, this research contributes by updating the current knowledge base in this area. It also differs from previous work in that it focuses exclusively on software products. Additionally, much of the past research has served as an account of the current status of IT adoption in the sector. This research evaluates the current state of software, but also goes further in trying to determine what is 
important for future competitiveness, thus making the work strategic in nature. Finally, this research contributes by providing a structured method (ANP) to work with expert groups. Experts have been used before in this sector for technology roadmapping, but the methodology appears to be somewhat unstructured and susceptible to groupthink.

\subsection{Discussion of Research Results}

The overall representation of functionalities gives insight into what types of business activities are commonly addressed with software in the cabinet industry. It is evident that most software packages are design and/or production orientated. Product innovation is an important source of competitiveness in secondary wood products firms (Vickery et al. 1997), so it is encouraging that design software is well represented. Although, it should be noted that most of these products were parametric design software. These products greatly speed up the design process, but could also limit the designer to predefined design parameters. Truly unique and innovative product designs may require a full-fledged, dedicated CAD package which allows for freeform design. However, these products were much less represented.

While production-oriented functionalities were well represented, marketing and sales functionalities were poorly represented and could signify a gap for the future competitiveness of the industry. These activities are important for any business, but previous research has suggested that marketing is especially crucial for small and medium-sized secondary wood manufacturers (Hoff et al. 1997). Also, previous research on competitive factors in the Canadian secondary wood products sector suggests that there is room for improvement in customer service and marketing (DeLong et al. 2007). CRM software can help improve customer service and marketing, but this software group was only seen in $6.3 \%$ of all observed functionalities. Generally speaking, wood products industries have been slowly shifting away from a strictly

production orientation towards a marketing orientation as we move further into the $21^{\text {st }}$ century (Cohen \& Kozak 2002).Unsurprisingly, the clustering results show that some software products are very focused, while others try to meet a wider range of business needs. Clusters 1, 2, and 3 have the widest distribution of functionalities. Many products in cluster 1 are ERM type applications, which try to integrate numerous functions into a single platform. This can overcome the problem of non-compatibility between different products, but it oftentimes comes 
at a higher price. Products in clusters 4, 5, 6, and 7 have a narrower range of functionalities and are much more focused on a single business function.

The association rules indicate that many products automate design, but not necessarily production (via $\mathrm{CNC}$ technology). Parametric design functionality (other engineering) and $C A D$ were not associated with $C A M$ in any of the acceptable association rules. If the software market is an accurate reflection of how industry uses software, then many cabinet firms are automating design but not production. This has negative implications for the industry's productivity and production costs because $C A M$ software is used in conjunction with $\mathrm{CNC}$ machinery which automates production.

This result seems to corroborate with six previous studies which found that lowering costs is the lowest perceived benefit of IT in the industry (Appendix 1). It could also be that these products are marketed to smaller shops who do not have access to capital for such a relatively large investment in $\mathrm{CNC}$ machinery. Also, since it has been observed that product innovation is more important for smaller wood products companies while process innovation is more important for larger wood products companies, these products may be more appropriate for smaller firms where high productivity and low variable costs are less of a concern (Wagner \& Hansen 2005).

High raw material costs and supply uncertainty have been cited as top concerns in numerous surveys of secondary wood manufacturers (Hoff et al. 1997). The high support (0.23) and confidence (0.69) for the association rule $\{\mathrm{CAM}\} \rightarrow$ OOther Back Office $\}$ is encouraging because these products increase raw material utilization through panel optimization. They do this by optimally laying out components on a panel to minimize waste and then automatically generating the machine code required for $\mathrm{CNC}$ machining. This is commonly referred to as nested-based manufacturing because the components are nested into each other. The results indicate that these functionalities have been paired together by software vendors to meet this industry challenge.

An emphasis on a Quality strategy over a Cost strategy is largely in accordance with a study of leading North American and European value-added wood products firms (Korhonen \& Niemelä 2004). The study concluded that while low cost is necessary to compete in the industry, 
it is not enough for sustainable competitive advantage. A Delivery strategy scored the lowest or second lowest for all but one strategy group expert. This level of agreement is encouraging because a 2006 study of Canadian value-added wood manufacturers found that an emphasis on quick delivery has significant negative effects on firm's profitability (DeLong et al. 2007).

It is not surprising that Operations \& Engineering applications had the highest overall priority $(0.227)$ because these applications address design and production which are everyday activities in the cabinet industry. The most common uses for software in this application category were parametric design, CAD, CAM, panel optimization/nesting, and BOM generation.

ERM functionalities were given a high final priority (0.222) perhaps because these software applications address activities that are common to most businesses (e.g. accounting, payroll). Another functionality in the ERM category, order management, could be especially useful in the cabinet industry. One of the experts surveyed, an experienced industry consultant who had worked with numerous cabinet firms across Canada, spoke at length about many clients having difficulties of product and order configuration. These issues arise because cabinetry often has many customizable options such as box material, door material, door style, veneer species, finish colour, and cabinet construction. This can create thousands of possible product variations. Applications having order management functionality address these business problems. The potential of software to solve these order processing problems has also been previously highlighted in a recent industry technology roadmap (WMC 2008).

Content applications had the lowest priority (0.087) because their contribution was lowest or second lowest for all competitive capabilities except advertising. Given that this industry is very product-oriented, it is expected that content applications will have low influence on the industry's competitiveness.

The sensitivity analysis results revealed that regardless of an individual experts' weighting of Cost, Quality, Flexibility, and Delivery strategies; Operations \& Engineering and ERM applications will always be the first and second highest priority applications and content applications will be inconsequential to the industry's competitiveness. However, the priorities of SCM, CRM, and Collaboration applications will vary between third and fifth highest priority depending on the weighting of strategies. Thus, for every strategy except Customer Service, 
there are three groups of applications with decreasing levels of strategic importance: (High) Operations \& Engineering, ERM; (Medium) SCM, CRM, and Collaboration; (Low) Content.

The sensitivity analysis also showed that the final priority vector is the most sensitive to the weighting of the Customer Service strategy. Thus, a company who places a high emphasis on customer service as part of their strategy will likely have very different final priorities for software applications. In this case, CRM and Collaborative applications become much more important and Operations \& Engineering and ERM applications become much less important. This result is interesting because there seems to be some disagreement between the experts' and previous researchers' weighting of the importance of customer service and marketing. The experts rated the Customer Service strategy as only moderately important, with the third highest priority value of 0.172 . This conflicts with several wood products business studies stating that customer service and marketing will be more important for North American wood products manufacturers to remain competitive in the future (Hoff et al. 1997; Cohen \& Kozak 2002). Thus, due to the apparent sensitivity to the Customer Service strategy, it is critical to continue research on its effect on competitiveness as this will greatly affect the types of information technologies that are most important to the industry.

The consensus measures yielded mixed results with regards to the level of agreement between experts. The strategy group experts largely agreed on the strength of relationships for conformance quality, process flexibility, and customer service. This indicates that there is a common understanding in the industry as to how these competitive capabilities are influenced by other capabilities. On the other hand, there was a surprisingly low level of consensus in the technology group with respect to how different software applications contribute to each competitive capability. This could be due to a number of reasons. First, each expert's professional background could greatly influence how IT can work for businesses and/or bias them towards particular types of software. Additionally, it is possible each expert had a slightly different personal definition of each application type. Explicit definitions of the applications were included with the survey and it was strongly recommended to them to use the definitions as they took the survey. However, it is possible that the experts did not carefully examine these definitions responding to the survey. 
This research seeks to compare what is currently represented with what is important for future competitiveness and identify any gaps (Table 6) that could be areas of concern (but also opportunities for software vendors). It should be noted at this point, that these two vectors cannot be directly compared because they were obtained using different methods and consequently do not have commensurable units. However, the results of both methods are both measured in a normalize scale that sums to unity. So, they can be qualitatively compared and any large, obvious differences between these two vectors could represent an area where the software industry is not closely aligned to support strategic priorities. A positive difference between current representation and future priorities would indicate that an application type is overrepresented in the market. A negative difference would indicate an underrepresentation and, thus, cabinet firms would have a low selection of products from which to choose from in that area.

SCM applications are closely aligned with future strategic priorities (Table 14), with a total difference of -0.022 . It is encouraging that this market segment is not overly represented, considering that previous research has found that a Delivery strategy can have a negative effect on profitability in the Canadian cabinet industry (DeLong et al. 2007).

ERM, CRM, and Collaborative applications appear to be somewhat underrepresented in the industry. As mentioned previously, ERM products could be especially helpful in the cabinet industry to deal with problems of order management. CRM's underrepresentation is concerning because the final priorities of software applications is the most sensitive to the weight of the Customer Service strategy. In Figure 21, it is obvious that CRM applications have the steepest positive slope and are therefore the most sensitive to increasing weights of the Customer Service strategy. Thus, for individual firms having a high priority for this strategy, the cabinet software market will appear even more underrepresented.

Operations \& Engineering applications are very abundant in the industry with numerous products offering $C A D$, other back office, and other engineering functionalities. This segment is saturated with similar products, creating robust competition in the market. Software vendors may consider shifting some focus away from Operations \& Engineering and towards ERM, CRM, and (especially) Collaborative applications and their functionalities. 
Table 12: Difference between current market representation and future priorities of software applications.

\begin{tabular}{|lccc|}
\hline & $\begin{array}{c}\text { Current } \\
\text { Market } \\
\text { Representation }\end{array}$ & $\begin{array}{c}\text { Future } \\
\text { Priorities }\end{array}$ & difference \\
\hline Operations \& Engineering & 0.657 & 0.227 & 0.430 \\
ERM & 0.123 & 0.222 & -0.099 \\
SCM & 0.114 & 0.136 & -0.022 \\
CRM & 0.063 & 0.164 & -0.101 \\
Collaborative & 0.022 & 0.164 & -0.142 \\
Content & 0.022 & 0.087 & -0.065 \\
\hline
\end{tabular}

\subsection{Discussion of Research Contribution}

Most of the previous research on IT in wood products industries has focused on Internet and e-commerce technologies (e.g. email, websites, EDI) (Hewitt et al. 2011). This study is the first to take a comprehensive look at the software products currently being used in a specific wood products industry. Since IT investment dollars have begun shifting away from hardware and towards software, it is important that research reflect this trend (CSLS 2011). Additionally, since information technology changes so rapidly, it is important to constantly update the knowledge base in this area. The majority of IT research in wood products industries has occurred in the ten year period 1996 - 2006, with very few studies afterwards. Five years later, the landscape has changed enough to justify further work.

Previous research in this area has also been largely focused on providing an assessment of the current state of IT adoption in the sector. This study achieves that objective by looking at the software products currently available in the market, but then goes further in asking which types of software are most important for the future competitiveness of the industry. This makes the research strategic in nature. Previous work has been done on technology strategy in the forest products sector, but these reports typically focus on physical technologies such as materials and processing technologies and not exclusively on information technologies (Agenda 2006; WMC 2008).

In 2008, the WMC conducted a technology roadmap for Canadian secondary wood products industries that included some information technologies. The WMC roadmap was similar to this study in that it used industry professionals, consultants, and academics as experts 
in forecasting future technology trends. Little information was provided on the methodology, but it appears that the process consisted mostly of in-person meetings and some email and telephone correspondence. The ANP method used in this research could improve upon the WMC's method in a couple ways. First, AHP and ANP provide logical structure to a seemingly complex issue. This structure serves as a common model for the experts to reference. Second, ANP (as applied in this study) collects information from experts individually, not in a group meeting setting. This can avoid problems of "groupthink", where experts tend to conform to a dominant idea (Janis 1982). 


\section{Chapter 6 - Conclusions and Future Research}

\subsection{Conclusion}

The cabinet industry is a significant player in the Canadian economy, contributing $\$ 1.3$ billion dollars in value-added and directly employing approximately 20,000 people. The domestic market for cabinet products has been strong over the past decade, increasing $87.9 \%$ in total value (Industry Canada 2011). It is, however, beginning to see increased competition as exports to the US decline and imports from foreign competitors slowly increase.

One way for the Canadian cabinet industry to achieve sustainable competitive advantage is through greater IT adoption. The presence of IT has been found to be positively correlated with productivity and market share in Canadian manufacturing industries (Baldwin \& Sabourin 2001). However, North American value-added wood industries have low IT adoption and when they do adopt it is usually with relatively low sophistication. Furthermore, IT becomes more important for firms exporting wood products (Hewitt et al. 2011) and seeking new markets (Hetemäki \& Nilsson 2005). Since the cabinet industry's exports are declining rapidly, more effective IT use may be necessary to recover lost ground in the US and/or explore new markets elsewhere.

Previous studies on IT in the forest products sector have generally been an account of current adoption. This study takes a more strategic, forward-looking approach. If IT (software specifically) is important for the future competitiveness of the industry, then which types of software are the most important ones? Additionally, we should ask which types of software are currently represented in the industry. Any mismatch between current representation and future priorities indicates an area that could be exploited more effectively to increase competitiveness.

Currently, most software products in the cabinet industry are related to design and production activities. This is unsurprising because the industry is mostly production-oriented. Additionally, marketing and sales functionalities are poorly represented. This is an area of concern, because North American wood products firms may need to become more marketingoriented in the future (Cohen \& Kozak 2002). Also, parametric design products are much more common than fully-dedicated CAD products. While this greatly speeds up the design process, 
true product innovation is more likely to require fully-dedicated CAD software that does not restrict design along pre-defined parameters. Finally, association rule learning showed that design activities are commonly automated, but not necessarily fabrication through CNC machinery. This has serious negative implications for productivity in the industry.

The future priorities of software show that, in most cases, Operations \& Engineering and ERM are the first and second most important applications to the industry. Content applications are inconsequential for the competitiveness of the industry. SCM, CRM, and Collaboration applications are alternatively the third, fourth, and fifth most important. This is true for all reasonable weights of Cost, Quality, Flexibility, and delivery strategies. However, the weights of software priorities are most sensitive to the weighting of the Customer Service strategy, which includes marketing and sales. In this case, CRM and Collaborative applications become much higher priority.

The future priorities of SCM and CRM applications are aligned relatively well with their current representation in the market. ERM, CRM, and Collaborative applications may be somewhat underrepresented. It is clear, though, that the market is saturated with operations \& engineering products. It may be beneficial for software vendors if they shift some focus away from those applications towards ERM, CRM, and Collaborative functionality. This would give cabinet firms more choices in these areas, where options are currently limited. This would have the dual benefit of providing the software vendor with growth and enable the cabinet firm to be more competitive.

Historically low IT investment in the cabinet industry could be due to their relative riskiness, high capital investment amounts, and a low-skilled workforce (Hetemäki \& Nilsson 2005). A new IT business model known as software-as-a-service (SaaS), addresses and lowers many of these barriers to adoption. In the SaaS business model, software is sold as a service, not a product. Application hosting is the responsibility of the service provider and is accessed by the customer via an Internet connection. This shifts the investment cost structure from fixed costs towards variable costs, often on a monthly or annual subscription basis. Since initial investment amounts are lowered, risk is reduced as well. SaaS also provides value by lowering the technological skill level required to setup and use these information systems (Campbell-Kelly 2009). This benefit may be especially relevant to the cabinet industry. A 2006 survey indicated 
that a lack of skilled employees was rated the number one limiting factor for B.C. secondary wood manufacturers (DeLong \& Cohen 2006). This was also found in a survey of the U.S. furniture industry (Grushecky et al. 2006). Finally, Poku (2003) found that the greatest success factor in IT adoption in North American forest products sector was the level of training and familiarity with IT that a firm had. Consequently, this is an attractive proposition for the Canadian cabinet industry, where most firms are small-sized and therefore have limited capital and do not have IT savvy-personnel.

The move towards the SaaS business model has been recently embraced by large ERP vendors that have traditionally served the large enterprise market. For example, SAP® has a new line of software services called Business ByDesign ${ }^{\circledR}$. This offering is marketed to smalland-medium (SME) companies as providing ERP, CRM, and SCM functionality on a monthlysubscription with no up-front investment (SAP 2011). As another example, a small cabinet firm can have an enterprise-level CRM application with Salesforce ${ }^{\circledR}$ for a nominal monthly price and no contract (Salesforce 2011). The manufacturing sector, along with their software vendors, is increasingly adopting SaaS and cloud computing as the perceived risks decrease and it becomes more mainstream (Symonds 2011). It will be interesting to see if the cabinet industry will recognize these benefits and begin adopting IT more rapidly via the SaaS model.

\subsection{Limitations and Future Research}

There are several limitations with regards to the research design. First, the number of experts in each group was small. Increasing the number of experts involved would decrease the influence of any personal biases. Second, the vendor lists of trade shows may not be a fully representative sample of all software used in the industry. For instance, accounting software was rare in the vendors' lists, but this type of application could be normally purchased from vendors that do not exhibit at wood industry trade shows. Third, since IT use in the industry is strongly influence by a firm's size and export intensity (Hewitt et al. 2011), it may be prudent to deploy separate surveys to experts from each category of firms (e.g. large vs. small vs. domestic focus vs. export focus). Of course, this would require many more experts and greatly increase the difficulty of recruitment. 
Improvements could also be made with the three analytical methods used. First, the cluster analysis could include other types of variables in addition to the 32 binary variables representing functionalities. It may be interesting to look at variables belonging to software vendors such as gross annual sales, number of employees, or whether they're publicly traded or not. This would yield insight into whether a group of functionalities is serviced by a particular type of vendor. For example, certain functionalities could be primarily offered by only niche, private software vendors. Cost data on software products would also be valuable, but is difficult to collect because software pricing is oftentimes contingent on many factors and the options for any given product can be numerous.

The theoretical ANP decision model (Figure 11) that was developed for this study could also be improved. The current ANP model accounts for interdependencies between competitive capabilities because previous research on manufacturing competitiveness clearly shows that these capabilities are not independent of each other. By extension, the general competitive strategies that these capabilities contribute to should also be interdependent. However, for simplicity, the ANP model was developed to assume independence between strategies. Additionally, the model assumes independence between different types of software applications. In reality, these applications are often integrated and would therefore influence each other. These shortcomings of the current model represent opportunities for improvement by modeling dependencies where there is evidence for such a relationship.

One exciting possibility for further research is that in addition to vendor data, we could directly survey cabinet firms on their software use. It would be interesting to discover any correlations between firms size, profitability, productivity, geographic location, export intensity, etc. and certain types of software functionalities. Incorporating these types of variables also opens up possibilities for using other types of multivariate statistical analysis. For example, a 1989 study used principle component analysis to investigate the use of physical processing technologies in the North American plywood and lumber industries (Cohen \& Sinclair 1989).

Another major limitation could be the use of ANP as the method of data analysis for the strategic, forward-looking research objective. Numerous researchers have questioned the validity of AHP and ANP as a decision-making method (Clemen 2008). Also, even within the 
community of AHP/ANP researchers there are conflicting opinions as to which variant of AHP/ANP is "best".

One possible alternative to ANP that could be explored for achieving this research's objectives is Structural Equation Modeling (SEM). An SEM model is visually similar in structure to an ANP model, with a network or hierarchy of different factors or variables contributing to other factors or variables. One of the major differences between the two is that ANP utilizes the eigenvectors of PCMs whereas SEM is a statistical technique combining factor analysis and multiple regression (Ullman \& Bentler 1996). SEM has been used previously in determining the relationships of competitive capabilities in manufacturing (Koufterous et al. 2002) and the contribution of IT towards competitiveness (Rivard et al. 1996). 


\section{References}

Aczél, J. \& Saaty, T.L., 1983. Procedures for synthesizing ratio judgements. Journal of mathematical psychology, 27(1), pp.93-102.

Adams, W.J.L. \& Saaty, R.W., 2003. Super Decisions Software Guide.

Agenda 2020 Technology Alliance, 2006. Forest Products Industry Technology Roadmap, American Forest \& Paper Association. Available at: www.agenda2020.org/PDF/FPI_Roadmap\%20Final_Aug2006.pdf.

Agrawal, R., Imieli ski, T. \& Swami, A., 1993. Mining association rules between sets of items in large databases. In ACM SIGMOD Record. ACM, pp. 207-216.

Angehrn, A., 1997. Designing mature Internet business strategies: the ICDT model. European Management Journal, 15(4), pp.361-369.

Arano, K.G., 2008. Electronic Commerce Adoption in West Virginia's Primary and Secondary Hardwood Industries: Preliminary Results. SOFEWS, p.72.

Assadi, P. \& Sowlati, T., 2009. Design and manufacturing software selection in the wood industry using analytic hierarchy process. International Journal of Business Innovation and Research, 3(2), pp.182-198.

Assadi, P., Sowlati, T. \& Paradi, J.C., 2009. Multi-criteria evaluation of design and manufacturing software packages considering the interdependencies among criteria: the analytic network process approach. International Journal of Information and Decision Sciences, 1(4), pp.397-410.

Atrostic, B. \& Gates, J., 2001. US productivity and electronic business processes in manufacturing. Discussion Papers in Economics, pp.01-11.

AWFS, 2011. AWFS 2011 : Exhibitor Prospectus, AWFS. Available at: http://stage.wynjade.com/DocPC/ebrochure_iwf2012/ [Accessed July 10, 2011].

Baldwin, J. \& Sabourin, D., 2004. The effect of changing technology use on plant performance in the Canadian manufacturing sector. Economic Analysis (EA) Research Paper No. 020.

Baldwin, J.R. \& Sabourin, D., 2001. Impact of the adoption of advanced information and communication technologies on firm performance in the Canadian manufacturing sector, Analytical Studies Branch, Statistics Canada.

Baldwin, J.R., Macdonald, R. \& Division, S.C.E.A., 2009. The Canadian Manufacturing Sector: Adapting to Challenges, Statistics Canada.

Beynon, M., 2002. An analysis of distributions of priority values from alternative comparison scales within AHP. European Journal of Operational Research, 140(1), pp.104-117. 
Brynjolfsson, E., 1993. The productivity paradox of information technology. Communications of the ACM, 36(12), p.77.

Brynjolfsson, E. \& Hitt, L.M., 2000. Beyond computation: Information technology, organizational transformation and business performance. The Journal of Economic Perspectives, 14(4), pp.23-48.

Brynjolfsson, E. \& Hitt, L.M., 1998. Beyond the productivity paradox. Communications of the $A C M, 41(8)$, p. 55 .

Brynjolfsson, E. \& Saunders, A., 2009. Wired for innovation: how information technology is reshaping the economy, The MIT Press.

Bryson, N., 1996. Group decision-making and the analytic hierarchy process: exploring the consensus-relevant information content. Computers \& operations research, 23(1), pp.2735 .

Calinski, T. \& Harabasz, J., 1974. A dendrite method for cluster analysis. Communications in statistics, 3(1), pp.1-27.

Campbell-Kelly, M., 2009. The rise, fall, and resurrection of software as a service. Communications of the ACM, 52(5), pp.28-30.

Carmone Jr, F.J., Kara, A. \& Zanakis, S.H., 1997. A Monte Carlo investigation of incomplete pairwise comparison matrices in AHP. European Journal of Operational Research, 102(3), pp.538-553.

Choi, S., Cha, S. \& Tappert, C.C., 2010. A survey of binary similarity and distance measures. Journal of Systemics, Cybernetics and Informatics, 8(1), pp.43-48.

Clemen, R.T., 2008. Improving and measuring the effectiveness of decision analysis: Linking decision analysis and behavioral decision research. Decision Modeling and Behavior in Complex and Uncertain Environments, pp.3-31.

Cohen, D.H. \& Kozak, Robert A., 2002. Research and technology: Market-driven innovation in the twenty-first century. Forestry Chronicle, 78(1).

Cohen, D.H. \& Sinclair, S.A., 1989. An inventory of innovative technology use in North American processing of wood structural panels and softwood lumber. Canadian Journal of Forest Research, 19(12), pp.1629-1633.

Cohen, W., 1995. Empirical studies of innovative activity. Handbook of the economics of innovation and technological change, 182, p.264.

Couper, M.P., Traugott, M.W. \& Lamias, M.J., 2001. Web survey design and administration. Public opinion quarterly, 65(2), p.230. 
Dangayach, G.S. \& Deshmukh, S.G., 2001. Manufacturing strategy: literature review and some issues. International Journal of Operations \& Production Management, 21(7), pp.884932.

DeLong, D.L., Kozak, Robert A. \& Cohen, D.H., 2007. Overview of the Canadian value-added wood products sector and the competitive factors that contribute to its success. Canadian Journal of Forest Research-Revue Canadienne De Recherche Forestiere, 37(11), pp.2211-2226.

DeLong, D.L. \& Cohen, David H., 2006. What are the key success factors for the value-added sector in British Columbia?, BC Forum on Forest Economics and Policy. Available at: http://conservationeconomics.com/pdf_pubs/synth_paper/SP0502_Value_Added_Success_Factors.pdf.

Dice, L.R., 1945. Measures of the amount of ecologic association between species. Ecology, 26(3), pp.297-302.

Dillon, W.R. \& Goldstein, M., 1984. Multivariate analysis: Methods and applications, John Wiley \& Sons New York.

Dolnicar, S. \& Leisch, F., 2004. Segmenting markets by bagged clustering. Australasian Marketing Journal (AMJ), 12(1), pp.51-65.

Dong, Y. et al., 2008. A comparative study of the numerical scales and the prioritization methods in AHP. European Journal of Operational Research, 186(1), pp.229-242.

Dupuy, C.A. \& Vlosky, R.P., 2000. Status of electronic data interchange in the forest products industry. Forest Products Journal, 50(6), pp.32-38.

Elliott, M.A., 2010. Selecting numerical scales for pairwise comparisons. Reliability Engineering \& System Safety, 95(7), pp.750-763.

Finan, J.S. \& Hurley, W.J., 1999. Transitive calibration of the AHP verbal scale. European Journal of Operational Research, 112(2), pp.367-372.

Forman, E. \& Peniwati, K., 1998. Aggregating individual judgments and priorities with the analytic hierarchy process. European Journal of Operational Research, 108(1), pp.165169.

Fowler, F.J., 2009. Survey research methods, Sage Publications, Inc.

Goldman, S.L. \& Nagel, R.N., 1993. Management, technology and agility: the emergence of a new era in manufacturing. International Journal of Technology Management, 8, 1(2), pp.18-38.

Grushecky, S.T. et al., 2006. Decline in the US furniture industry: a case study of the impacts to the hardwood lumber supply chain. Wood and Fiber Science, 38(2), pp.365-376. 
Hahsler, M., Grün, B. \& Hornik, K., 2007. Introduction to arules-Mining Association Rules and Frequent Item Sets.

Harker, P.T., 1987. Incomplete pairwise comparisons in the analytic hierarchy process. Mathematical Modelling, 9(11), pp.837-848.

Heiman, R., 2010. IDC's Software Taxonomy, 2010. Available at:

http://www.idc.com/research/viewtoc.jsp?containerId=222023.

Hennig, C., Harabasz, T. \& Hennig, M.C., 2010. Package “fpc."

Herrera-Viedma, E. et al., 2005. A consensus support system model for group decision-making problems with multigranular linguistic preference relations. Fuzzy Systems, IEEE Transactions on, 13(5), pp.644-658.

Hetemäki, L. \& Nilsson, S., 2005. Information technology and the forest sector. IUFRO World Series, 18.

Hewitt, R., Sowlati, T. \& Paradi, J.C., 2011. Information technology adoption in US and Canadian forest products industries. Forest Products Journal, 61(2), pp.161-169.

Hoff, K. et al., 1997. Sources of competitiveness for secondary wood products firms: a review of literature and research issues. Forest Products Journal, 47, pp.31-37.

Hollenstein, H., 2004. Determinants of the adoption of Information and Communication Technologies (ICT):: An empirical analysis based on firm-level data for the Swiss business sector. Structural Change and Economic Dynamics, 15(3), pp.315-342.

Holmes, T.P., Vlosky, R.P. \& Carlson, J., 2004. An exploratory comparison of Internet use by small wood products manufacturers in the North Adirondack Region of New York and the State of Louisiana. Forest Products Journal, 54(12), pp.277-282.

Hood, G.M., 2009. PopTools,

Huizingh, E.K.R.E. \& Vrolijk, H.C.J., 1997. A Comparison of Verbal and Numerical Judgments in the Analytic Hierarchy Process* 1. Organizational behavior and human decision processes, 70(3), pp.237-247.

IBM, 2007. Clustering binary data with K-Means (should be avoided) - United States. Available at: https://www-304.ibm.com/support/docview.wss?uid=swg21477401 [Accessed July 9, 2011].

Industry Canada, 2011. Canadian Industry Statistics - Data Tables. Available at: http://www.ic.gc.ca/cis-sic/cis-sic.nsf/IDE/cis-sic31-33tabe.html [Accessed September 27, 2011].

Irani, Z., 2002. Information systems evaluation: navigating through the problem domain. Information \& Management, 40(1), pp.11-24. 
Jaccard, P., 1901. Etude comparative de la distribution florale dans une portion des Alpes et des Jura.[A study comparing the distribution of flora in a portion of the Jura Alps] Bulletin. Societe Vaudoise des Sciences Natirelles, 37, pp.547-579.

Janis, I.L., 1982. Groupthink, Houghton Mifflin: Boston.

Janssen, M., 2004. Survey Indicates Mills' Need to Exploit IT Systems with New Business Model. Pulp \& Paper, http://www.allbusiness.com/technology/software-servicesapplications-information/11452081-1.html(6), pp.46-51.

Ji, P. \& Jiang, R., 2003. Scale transitivity in the AHP. Journal of the Operational Research Society, 54(8), pp.896-905.

Karuranga, É., Frayret, J.M. \& D’Amours, S., 2006. E-business in the Quebec forest products industry: perceptions, current uses and intentions to adopt. Journal of Forest Products Business Research, 2, p.04.

Kaufman, L., Rousseeuw, P. \& Technische Hogeschool, D.D. of M. and I., 1987. Clustering by means of medoids, Technische Hogeschool, Delft(Netherlands). Dept. of Mathematics and Informatics.

Kaufman, L., Rousseeuw, P.J. \& Corporation, E., 1990. Finding groups in data: an introduction to cluster analysis, Wiley Online Library.

Korhonen, S. \& Niemelä, J.S., 2004. Guidelines for sustainable, external corporate growth: a case study of the leading European and North American companies in the wood industry. Journal of Forest Products Business Research, 1(2), pp.1-27.

Kotsiantis, S. \& Kanellopoulos, D., 2006. Association rules mining: A recent overview. GESTS International Transactions on Computer Science and Engineering, 32(1), pp.71-82.

Koufteros, X.A., Vonderembse, M.A. \& Doll, W.J., 2002. Examining the competitive capabilities of manufacturing firms. Structural Equation Modeling: A Multidisciplinary Journal, 9(2), pp.256-282.

Kozak, R. A., 2002. Internet readiness and e-Business adoption of Canadian value-added wood producers. Forestry Chronicle, 78(2), pp.296-305.

Lal, K., 1999. Determinants of the adoption of information technology: a case study of electrical and electronic goods manufacturing firms in India. Research Policy, 28(7), pp.667-680.

Lim, K.H. \& Swenseth, S.R., 1993. An iterative procedure for reducing problem size in large scale AHP problems. European Journal of Operational Research, 67(1), pp.64-74.

Lootsma, F., 1989. Conflict resolution via pairwise comparison of concessions. European Journal of Operational Research, 40(1), pp.109-116. 
Lootsma, F.A., 1993. Scale sensitivity in the multiplicative AHP and SMART. Journal of MultiCriteria Decision Analysis, 2(2), pp.87-110.

Melville, N. \& Ramirez, R., 2008. Information technology innovation diffusion: an information requirements paradigm. Information Systems Journal, 18(3), pp.247-273.

Michael, J.H., 1999. Information sources and purchase influences for wood products retailers: A trade show attendee perspective. Wood and Fiber Science, 31(1), pp.71-82.

Miller, G.A., 1956. The magical number seven, plus or minus two: some limits on our capacity for processing information. Psychological review, 63(2), p.81.

Millet, I., 1997. The effectiveness of alternative preference elicitation methods in the analytic hierarchy process. Journal of Multi-Criteria Decision Analysis, 6(1), pp.41-51.

Millet, I. \& Harker, P.T., 1990. Globally effective questioning in the analytic hierarchy process. European Journal of Operational Research, 48(1), pp.88-97.

Moisiadis, F., 1999. Improving the Scales Used in AHP for QFD. In 11th Symposium on Quality Function Deployment.

Mooney, J.G., Gurbaxani, V. \& Kraemer, K.L., 1996. A process oriented framework for assessing the business value of information technology. ACM SIGMIS Database, 27(2), pp.68-81.

Ordonez, C., 2003. Clustering binary data streams with K-means. In Proceedings of the 8th ACM SIGMOD workshop on Research issues in data mining and knowledge discovery. ACM, pp. 12-19.

Pitis, O. \& Vlosky, R., 2000. Web presence of U. S. primary wood products exporters. Forest Products Journal, 50(7-8), pp.55-58.

Pitis, O.T. \& Vlosky, R.P., 2000. Forest products exporting and the Internet: Current use figures and implementation issues. Forest Products Journal, 50(10), pp.23-29.

Poku, K., 2003. Impact of corporate orientation on information technology adoption in the united states forest products industry.

Pöyhönen, M.A., Hämäläinen, R.P. \& Salo, A.A., 1997. An experiment on the numerical modelling of verbal ratio statements. Journal of Multi-Criteria Decision Analysis, 6(1), pp.1-10.

Presley, A. \& Meade, L., 1999. Strategic alignment and IT investment selection using the analytic network process.

Ra, J.W., 1999. Chainwise paired comparisons. Decision Sciences, 30(2), pp.581-599. 
Raisinghani, M.S., Meade, L. \& Schkade, L.L., 2007. Strategic e-business decision analysis using the analytic network process. Engineering Management, IEEE Transactions on, 54(4), pp.673-686.

Renkema, T.J.. \& Berghout, E.W., 1997. Methodologies for information systems investment evaluation at the proposal stage: a comparative review. Information and Software Technology, 39(1), pp.1-13.

Rivard, S., Raymond, L. \& Verreault, D., 2006. Resource-based view and competitive strategy: An integrated model of the contribution of information technology to firm performance. The Journal of Strategic Information Systems, 15(1), pp.29-50.

Roberts, F.S., 1979. Measurement theory, Addison-Wesley.

Roper-Lowe, G.C. \& Sharp, J.A., 1990. The analytic hierarchy process and its application to an information technology decision. Journal of the Operational Research Society, pp.49-59.

Rosenberg, N. et al., 1990. Understanding the adoption of new technology in the forest products industry. Forest products journal, 40(10), pp.15-22.

Rousseeuw, P.J., 1987. Silhouettes: a graphical aid to the interpretation and validation of cluster analysis. Journal of computational and applied mathematics, 20, pp.53-65.

Saaty, T., 1996. Decision Making With Dependence and Feedback: The Analytic Network Process, The Organization and Prioritization of Complexity, RWS Publications, Pittsburg, USA.

Saaty, T., 2006. The analytic network process. Decision Making with the Analytic Network Process, pp.1-26.

Saaty, T.L., 1990. How to make a decision: the analytic hierarchy process. European Journal of Operational Research, 48(1), pp.9-26.

Saaty, T.L., 1991. Response to Holder's comments on the analytic hierarchy process. Journal of the Operational Research Society, 42(10), pp.909-914.

Saaty, T.L., 1980. The analytic hierarchy process: planning, priority setting, resource allocation, McGraw-Hill International Book Co.

Saaty, T.L., 2005. Theory and Applications of the Analytical Network Process: Decision Making with Benefits, Opportunities, Costs, and Risks, Pittsburg: RWS Publications.

Saaty, T.L. \& Ozdemir, M.S., 2003. Why the magic number seven plus or minus two. Mathematical and Computer Modelling, 38(3-4), pp.233-244.

Sabourin, D. \& Beckstead, D., 1999. Technology adoption in Canadian manufacturing: Survey of Advanced Technology in Canadian Manufacturing, 1998. 
Salesforce.com, 2011. CRM, the cloud, and the social enterprise - salesforce.com. Available at: http://www.salesforce.com/ [Accessed November 14, 2011].

Salo, A.A. \& Hämäläinen, R.P., 1997. On the measurement of preferences in the analytic hierarchy process. Journal of multi-criteria decision analysis, 6(6), pp.309-319.

SAP, 2011. For Your Business | Business ByDesign Overview | SaaS Solutions | SAP. Available at: http://www.sap.com/solutions/products/sap-bydesign/what-is-sap-businessbydesign/for-your-business/index.epx [Accessed November 27, 2011].

Satoh, Y., 1999. An evaluation of judgment scale in the analytic hierarchy process. Journal of the Operations Research Society of Japan, 42(1), p.77.

Setiawan, S., 2002. The effect of initial selections in estimating the missing comparisons in an incomplete AHP matrix.

Shen, Y., Hoerl, A. \& McConnell, W., 1992. An incomplete design in the analytic hierarchy process. Mathematical and Computer Modelling, 16(5), pp.121-129.

Shook, S.R., Vlosky, R.P. \& Kallioranta, S.M., 2004. Why did forest industry dot. coms fail? Forest Products Journal, 54(10), pp.35-40.

Shook, S.R. et al., 2002. Pacific Northwest secondary forest products industry. Forest Products Journal, 52(1), p.59.

Smith, T.M. \& Smith, P.M., 1999. Distributor and end-user trade show attendance objectives: an opportunity for adaptive selling. Forest Products Journal, 49(1), pp.23-29.

Smith, T.M. \& Smith, P.M., 2000. The role of trade shows in business-to-business selling strategies: A method for assessing the effectiveness of marketing communications. Wood and Fiber Science, 32(3), pp.362-374.

Statistics Canada, 2011. Gross Domestic Product by Industry, Available at: http://www.statcan.gc.ca/pub/15-001-x/15-001-x2011006-eng.pdf [Accessed September 27, 2011].

Stennes, B. et al., 2006. e-Technology adoption by value added wood processors in British Columbia. Forest Products Journal, 56(5), pp.24-28.

SurveyGizmo Inc., 2011. SurveyGizmo, Available at: http://www.surveygizmo.com.

Symonds, M., 2011. Cloud Concerns Waning in the Manufacturing Enterprise. Industry Week. Available at: http://www.industryweek.com/articles/cloud_concerns_waning_in_the_manufacturing_e nterprise_25687.aspx.

Triantaphyllou, E., 2000. Multi-criteria decision making methods: a comparative study, Springer Netherlands. 
Triantaphyllou, E., 1999. Reduction of pairwise comparisons in decision making via a duality approach. Journal of Multi-Criteria Decision Analysis, 8(6), pp.299-310.

Ullman, J.B. \& Bentler, P.M., 1996. Structural equation modeling. Handbook of psychology.

U.S. Census Bureau, 2011. New Residential Construction. Available at: http://www.census.gov/const/www/newresconstindex_excel.html [Accessed October 6, 2011].

Van Den Honert, R. \& Lootsma, F., 1997. Group preference aggregation in the multiplicative AHP The model of the group decision process and Pareto optimality. European Journal of Operational Research, 96(2), pp.363-370.

Vickery, S.K., Dröge, C. \& Markland, R.E., 1997. Dimensions of manufacturing strength in the furniture industry. Journal of Operations Management, 15(4), pp.317-330.

Vlosky, R.P., 1999. eBusiness in the forest products industry. Forest Products Journal, 49(10), pp.12-21.

Vlosky, R.P. \& Fontenot, R., 1997. The Internet and the forest products industry: Current status and projected trends. Forest Products Journal, 47(11-12), pp.33-40.

Vlosky, R.P. \& Gazo, R., 1996. The Internet and the forest products community: the role of the Forest Products Society. Forest Products Journal, 46(5), pp.19-25.

Vlosky, R.P. \& Smith, T.M., 2003. eBusiness in the US hardwood lumber industry. Forest Products Journal, 53(5), pp.21-29.

Vlosky, R.P. \& Westbrook, T., 2002. eBusiness exchange between homecenter buyers and wood products suppliers. Forest Products Journal, 52(1), pp.38-43.

Vlosky, R.P., Westbrook, T. \& Poku, K., 2002. An exploratory study of Internet adoption by primary wood products manufacturers in the western United States. Forest Products Journal, 52(6), pp.35-42.

Wagner, E.R. \& Hansen, E.N., 2005. Innovation in large versus small companies: insights from the US wood products industry. Management Decision, 43(6), pp.837-850.

Webber, S.A., Apostolou, B. \& Hassell, J.M., 1997. The sensitivity of the analytic hierarchy process to alternative scale and cue presentations. European Journal of Operational Research, 96(2), pp.351-362.

Wedley, W.C., Schoner, B. \& Tang, T.S., 1993. Starting rules for incomplete comparisons in the analytic hierarchy process. Mathematical and Computer Modelling, 17(4-5), pp.93-100.

Weill, P., 1992. The relationship between investment in information technology and firm performance: a study of the valve manufacturing sector. Information Systems Research, 3(4), p.307. 
Weiss, E.N. \& Rao, V.R., 1987. AHP design issues for large-scale systems. Decision Sciences, 18(1), pp.43-57.

WMC, 2008. Advanced Wood Processing Skills and Technology Roadmap, Wood Manufacturing Council. Available at: www.ic.gc.ca/eic/site/.../advanced-wood-produitsbois_eng.pdf.

Ze, X., 2000. A Simulation-Based Evaluation of Several Scales in the Analytic Hierarchy Process. System Engineering - Theory \& Practice, 7. 


\section{Appendix 1: Overview of Common Findings of Previous Studies on IT in Forest Products Industries}

Source: Hewitt, R., Sowlati, T. \& Paradi, J.C., 2011. Information technology adoption in US and Canadian forest products industries. Forest Products Journal, 61(2), pp.161-169.

\begin{tabular}{|c|c|c|c|c|c|c|c|c|c|c|c|c|c|c|c|}
\hline & 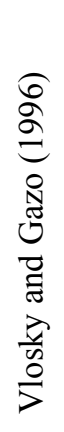 & 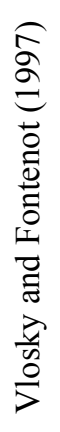 & 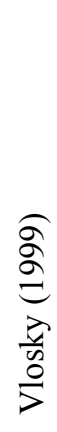 & 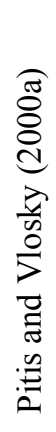 & 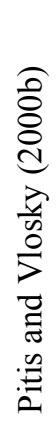 & 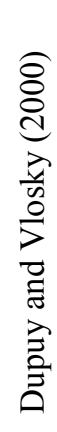 & 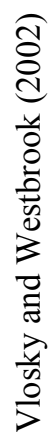 & 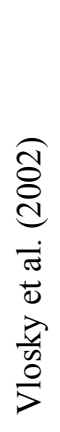 & 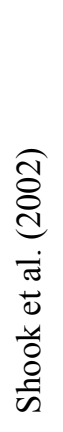 & 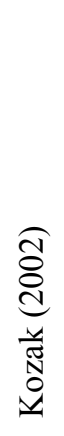 & 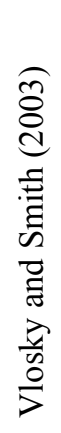 & 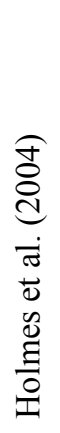 & 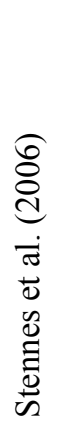 & 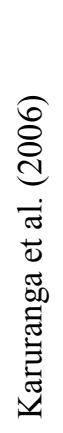 & 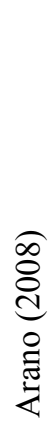 \\
\hline $\begin{array}{l}\text { Most firms used the Internet } \\
\text { for lower-order applications } \\
\text { like email, static websites, or } \\
\text { online research }\end{array}$ & & $x$ & $\mathrm{x}$ & $\mathrm{x}$ & $\mathrm{x}$ & & $\mathrm{x}$ & $\mathrm{x}$ & $x$ & $x$ & $\mathrm{x}$ & $x$ & & $\mathrm{x}$ & $\mathrm{x}$ \\
\hline $\begin{array}{l}\text { Size of firm and IT adoption } \\
\text { rates were positively } \\
\text { correlated }\end{array}$ & & & $\mathrm{x}$ & $\mathrm{x}$ & $\mathrm{x}$ & $\mathrm{x}$ & & & $\mathrm{x}$ & $\mathrm{x}$ & & & $\mathrm{x}$ & $\mathrm{x}$ & $\mathrm{x}$ \\
\hline $\begin{array}{l}\text { Most firms invested } \\
<\$ 10,000 \text { in IT }\end{array}$ & & & $\mathrm{x}$ & $\mathrm{x}$ & & $x$ & & $\mathrm{x}$ & & $\mathrm{x}$ & $\mathrm{x}$ & & & & $\mathrm{x}$ \\
\hline $\begin{array}{l}\text { Greater access to industry } \\
\text { information was one of the } \\
\text { highest perceived benefit of } \\
\text { using Internet technologies }\end{array}$ & $\mathrm{x}$ & & $\mathrm{x}$ & $\mathrm{x}$ & & & $\mathrm{x}$ & $\mathrm{x}$ & & & $\mathrm{x}$ & & & $\mathrm{x}$ & \\
\hline $\begin{array}{l}\text { Lowering costs was one of } \\
\text { the lowest perceived benefit } \\
\text { of using Internet } \\
\text { technologies }\end{array}$ & & $x$ & $\mathrm{x}$ & & & $\mathrm{x}$ & & $\mathrm{x}$ & & & $\mathrm{x}$ & & & & $x$ \\
\hline $\begin{array}{l}\text { Information security was the } \\
\text { top concern in IT adoption }\end{array}$ & & & $\mathrm{x}$ & & & & & & & & $\mathrm{x}$ & & & $\mathrm{x}$ & $x$ \\
\hline $\begin{array}{l}\text { Exporting firms were more } \\
\text { likely to use IT than non- } \\
\text { exporting firms }\end{array}$ & & & & $\mathrm{x}$ & $\mathrm{x}$ & & & & & & & & $\mathrm{x}$ & & $\mathrm{x}$ \\
\hline
\end{tabular}




\section{Appendix 2: Software Taxonomy and Definitions of Software Applications and Functionalities}

Source: Heiman, R., 2010. IDC's Software Taxonomy, 2010. Available at:

http://www.idc.com/research/viewtoc.jsp?containerId=222023.

\section{Collaborative Applications}

Collaborative applications allow groups to work better together by sharing information more effectively. Its main functions include email, instant messaging, group scheduling, online conferencing, and social networking.

Functionalities:

- Integrated Collaborative Environments

- Messaging Applications

- Standalone Email Applications

- Instant Messaging Applications

- Unified Messaging Applications

- Team Collaborative Applications

- Conferencing Applications

- Social Platforms

\section{Content Applications}

Content applications create, organize, manage, store, and publish collections of digital content (either internal or external of the organization). Some common content types include images, audio, video, text, spreadsheets, and presentations. Content applications are the foundation for knowledge management.

Functionalities:

- Content Management

- Authoring Software

- Translation Applications (for foreign languages) 


\section{Enterprise Resource Management Applications}

Enterprise resource management (ERM) applications automate the business processes related to resources needed to meet organizational objectives. Such resources include people, finances, materials, and facilities. ERM applications track, route, analyze, and report on these resources. This category does not include automation of customer-facing,engineering, or supply chain activities. This differs from Enterprise Resource Planning (ERP) products which can have these functionalities and are generally more comprehensive

Functionalities:

- Financial Applications

- Accounting

- Treasury Management

- Human Capital Management

○ eRecruiting

- Incentive Management

- HR Performance Management

- Workforce Management

- Payroll

- Procurement

- Order Management

- Business Performance Management and Financial Analytic Applications

- Project and Portfolio Management

- Asset Management and Maintenance

\section{Supply Chain Management Applications}

Supply chain management applications automate and optimize business processes related to bringing a product or service to market. These types of activities are both demand and supplyside and include such areas as transportation, wharehousing, raw material supply, and demandforecasting.

Functionalities:

- Logistics

- Production Planning 
- Inventory Management

\section{Engineering \& Operations Applications}

These applications are specific to manufacturing operations and their related engineering design activities. Manufacturing Execution Systems encompass many of these operations including shop-floor data collection and control, work-order generation, bills of materials, and quality control. Engineering applications include CAD software for design, CAM software for $\mathrm{CNC}$ machine control, and product data management for group engineering and design.

Functionalities:

- Manufacturing

- Computer-Aided Design

- Computer-Aided Manufacturing

- Computer-Aided Engineering

- Collaborative Product Data Management

\section{Customer Relationship Management Applications}

Customer relationship management (CRM) applications automate customer-related activities such as sales, marketing, customer support, and contact centres. These applications span the entire life-cycle of a customer from lead generation to sale conversion to after-sales customer service. The overall goal of CRM applications is to grow and maintain healthy customer relationships for an organization.

Functionalities:

- Sales

- Marketing

- Customer Service

- Contact Centre 


\section{Appendix 1: Glossary of Competitive Capabilities}

\section{Cost strategy}

Low production cost - the ability to minimize the total cost of production (inclusive of labor, materials, and operating costs) through efficient operations, process technology and/or scale economies.

\section{Flexibility / Innovation strategy}

Process flexibility - the ability to produce low quantities of product cost efficiently so that product mix changes are easily accommodated (i.e. mass customization)

Product flexibility - the ability to handle difficult, nonstandard orders, to meet special customer specifications and to produce products characterized by numerous features, options, sizes and/or colors. This also includes the ability to rapidly introduce completely new, innovative products.

Volume flexibility - the ability to rapidly adjust capacity so as to accelerate or decelerate production in response to changes in customer demand.

Skilled labor - the ability to employ skilled labor as well as continually updating employee skills through training.

\section{Quality strategy}

Conformance quality - the ability to manufacture a product whose operating characteristics meet established performance standards.

Performance quality - the ability to maximize the time to product failure or malfunction.

\section{Delivery strategy}

Delivery speed - the ability to reduce the time between order taking and customer delivery to as close to zero as possible.

Delivery dependability - the ability to exactly meet quoted or anticipated delivery dates and quantities. 


\section{Customer Service / Marketing strategy}

Customer service - the ability to provide after sale service.

Broad distribution - the ability to distribute the product effectively to a wide range of geographic locations.

Advertising - the ability to advertise and promote the product.

Market research - the ability to conduct marketing research to correctly identify the 4P's of marketing (product, price, place, promotion) for a given target market. 